NBER WORKING PAPER SERIES

\title{
THE DETERMINANTS OF PARTICIPATION IN A SOCIAL PROGRAM: EVIDENCE FROM A PROTOTYPICAL JOB TRAINING PROGRAM
}

\author{
James J. Heckman \\ Jeffrey A. Smith \\ Working Paper 9818 \\ http://www.nber.org/papers/w9818 \\ NATIONAL BUREAU OF ECONOMIC RESEARCH \\ 1050 Massachusetts Avenue \\ Cambridge, MA 02138 \\ July 2003
}

\begin{abstract}
James Heckman is Henry Schultz Distinguished Service Professor of Economics at the University of Chicago, and a Senior Fellow of the American Bar Foundation. Jeffrey Smith is Associate Professor of Economics at the University of Maryland. This research was supported by NSF SBR 91-11-455 and SBR 93-21-048 and by grants from the Russell Sage Foundation, the Lynde and Harry Bradley Foundation of Milwaukee, Wisconsin, the American Bar Foundation and the Social Science and Humanities Research Council of Canada. We thank Jingjing Hsee for her programming, Theresa Devine for her comments and assistance with the SIPP data, Karen Conneely and Edward Vytlacil for their excellent research assistance and Larry Katz, and seminar participants at the NBER Labor Studies Group and the University of Western Ontario for their comments. This paper was presented as an invited lecture at the SOLE meetings, San Francisco, May, 1998. The views expressed herein are those of the authors and not necessarily those of the National Bureau of Economic Research
\end{abstract}

(C)2003 by James J. Heckman and Jeffrey A. Smith. All rights reserved. Short sections of text not to exceed two paragraphs, may be quoted without explicit permission provided that full credit including (C) notice, is given to the source. 
The Determinants of Participation in a Social Program:

Evidence from a Prototypical Job Training Program

James J. Heckman and Jeffrey A. Smith

NBER Working Paper No. 9818

July 2003

JEL No. J24

\begin{abstract}
$\underline{\text { ABSTRACT }}$
This paper decomposes the participation process of a prototypical program into eligibility, awareness, application, acceptance and enrollment. With this decomposition, we determine the sources of unequal participation for different groups, and demonstrate that variables often have very different effects at different stages in the participation process. Our analysis shows that personal choices substantially affect participation and that awareness of program eligibility is a major source of variation in participation.
\end{abstract}

James J. Heckman

Department of Economics

University of Chicago

1126 East $59^{\text {th }}$ Street

Chicago, IL 60637

and NBER

jjh@uchicago.edu
Jeffrey A. Smith

Department of Economics

University of Maryland

College Park, MD 20742-7211

and NBER

smith@econ.umd.edu 


\section{Introduction}

This paper presents a framework for studying participation in social programs that decomposes the participation process into multiple stages: eligibility, awareness, application, acceptance and enrollment, allowing for distinct determinants at each stage. We apply our framework to analyze unique data gathered as part of an evaluation of a prototypical voluntary social program.

Understanding the process of participation in social programs is interesting for at least three reasons. First, it allows analysts to determine the sources of inequality in the receipt of government services. Our framework allows us to go beyond simple comparisons of the mean participation rates of different groups to learn at what stage in the process, if any, differences in participation rates occur. Overall differences in participation may have very different equity implications, and very different implications for changes in policy, depending on whether they result from differences in eligibility for the program, awareness of the program, application to the program, acceptance into the program, or enrollment in the program.

Second, patterns of program participation can reveal useful information about program operation. In programs governed by performance management systems, which now includes most major U.S. social programs, participation patterns may reveal the effects of the incentives embodied in those performance standards systems. Here the decomposition of the participation process into particular stages aids in disentangling the effects of choices made by program staff and choices made by potential participants.

Third, information regarding the participation process has important implications for program evaluation strategies. For example, the propensity score matching methods 
developed and applied in Heckman, Ichimura and Todd $(1997,1998)$ and Heckman, Ichimura, Smith and Todd (1998) build directly on estimates of the probability of participation conditional on observable characteristics. Other econometric evaluation methods, such as instrumental variables, also require an understanding of the participation process. Knowledge of how the determinants of participation vary by the stage of the participation process can inform choices about where in the process to draw a comparison group, about what variables to collect in a survey, and about what identification strategy to adopt. Heckman and Robb (1985), Heckman, LaLonde and Smith (1999), and Heckman and Navarro-Lozano (2003) describe the role of the program participation decision in econometric evaluations in detail.

We apply our framework to analyze participation in the Job Training Partnership Act (JTPA), a prototypical voluntary social program. Participation in JTPA depends on the choices of both potential participants and government bureaucrats. It is not an entitlement program. In contrast, the existing literature on program participation focuses on entitlement programs such as Aid to Families with Dependent Children (AFDC) and its successor Temporary Aid to Needy Families (TANF), Food Stamps, or Unemployment Insurance. ${ }^{1}$ Persons eligible for such programs are legally entitled to their benefits, so that participation depends primarily on the decisions of potential participants, although there is clearly room for bureaucratic discretion in interpreting eligibility rules (see, e.g., Parsons, 1991).

\footnotetext{
${ }^{1}$ On AFDC and Food Stamps see, e.g., Blank and Ruggles (1996) and Blank (2001). On Unemployment Insurance see, e.g., Anderson and Meyer (1997), McCall (1995) and Storer and Van Audenrode (1995). For discussions in other contexts see Ashenfelter (1983), Riphan (2001), Witte and Queralt (2002), and Remler, Rachlin and Glied (2001). For earlier discussions of participation in training programs see Anderson, Burkhauser and Raymond (1993), Anderson, Burkhauser, Raymond and Russell (1991), Ashenfelter and Card (1985), Card and Sullivan (1988), Sandell and Rupp (1988), Zweimüller and WinterEbmer (1996) and Jacobsen, LaLonde and Sullivan (2002).
} 
Our empirical analysis is deliberately descriptive. We seek to establish empirical regularities about the participation process for a prototypical social program using the rich information available on the JTPA program. These regularities suggest interesting behavioral relationships governing the process of program participation. As such, they demonstrate the value of our framework and suggest its applicability for the study of other programs.

We document that the JTPA eligibility rules had a substantial effect on the access of particular groups to program services. We also find wide variation in participation rates conditional on eligibility across groups defined by race, age, education, fluency in English, marital status, participation in government transfer programs, recent labor force status and family income. On the surface, this evidence supports the conclusions of a U.S. General Accounting Office (1991) report that charged the JTPA program with failing to distribute its services equitably across groups within the eligible population. Similar distributional concerns have been raised in regard to other government programs.

By decomposing the program participation process into stages, we determine the sources of unequal participation for different groups. For example, for persons with low levels of schooling, the favorable effect of the JTPA eligibility rules on the probability of participation was undone by low rates of program awareness and of application and acceptance into the program. On the other hand, for persons with a relatively high level of schooling, a low rate of eligibility was partially offset by a relatively high probability of program awareness. In addition, we find that informational barriers such as low levels of schooling and lack of fluency in English act to discourage participation conditional on eligibility, but that these barriers do not fully account for the low participation rate of 
Hispanics noted by Gonzales and Romero (1989) and Sandell and Rupp (1988). Our evidence suggests that personal choices have a major influence in determining who participates in government programs. More generally, our analysis demonstrates that program eligibility is a necessary but by no means sufficient condition for participation. Many groups of special interest to policymakers, such as high school dropouts and welfare recipients, have high rates of eligibility but low probabilities of program participation conditional on eligibility.

Caseworkers in the JTPA program faced the incentives created by the JTPA performance standards systems, which rewarded local JTPA training sites for the labor market performance of their enrollees. Anderson, Burkhauser and Raymond (1993), among others, argue that performance standards led JTPA staff to screen out hard-toserve applicants who may have difficulty obtaining work even after completing a training program. We find evidence consistent with cream skimming by JTPA staff, particularly at the stage of program enrollment. However, in some cases what appears initially to be cream skimming by JTPA staff turns out instead to reflect differences across groups in program awareness. This finding casts doubt on the value of the evidence from the literature that estimates the nature and extent of cream skimming by comparing the characteristics of program eligibles and program participants.

Finally, in regard to program evaluation, we expand on the analysis in Heckman and Smith (1999) and document the important role of labor force status dynamics, especially recent transitions to unemployment, in driving participation in JTPA among the eligible. This factor operates most strongly at the stage of application and acceptance into the program among eligible persons who are aware of JTPA. This evidence has 
important implications for the types of data that should be collected in non-experimental evaluations of employment and training programs.

This paper is organized as follows: Section 2 presents our framework. Section 3 describes the JTPA program in detail and shows that it is very similar to other public employment and training programs in the U.S. and abroad, including its successor, the Workforce Investment Act (WIA), in terms of administrative structure, population served, and types of services offered. It resembles in broad outline a large class of voluntary programs aimed at the disadvantaged. Thus lessons drawn in this paper apply more widely. Section 4 describes our data.

Sections 5, 6, 7 and 8 examine in detail four stages in the participation process: eligibility, program awareness, application and acceptance into the program and formal enrollment. In Section 9, we decompose the overall program participation process in order to examine how factors such as race, education, labor force status, participation in transfer programs and family income operate through eligibility, awareness, acceptance and enrollment to determine the overall probability of participation in JTPA. The final section summarizes our findings and draws conclusions about the usefulness of our framework for studying program participation.

\section{A Framework for Analyzing Participation in Social Programs}

For a person to participate in a voluntary social program, he or she must be eligible for it, must be aware of it, must apply for it, must be accepted into it and must be formally enrolled in it. Figure 1 depicts the process of selection into a program. Different factors govern each stage of the program participation process. Eligibility criteria are determined 
by legislators and interpreted by bureaucrats. Program awareness depends on outreach efforts by program operators, on the extent to which a person is generally informed about the availability of social programs, on the economic situation of prospective applicants who might benefit from a program, and on access to networks of friends and neighbors who have heard about or participated in a program.

The decision to apply to a program is made by the prospective participant and depends in part on the expected benefits and perceived opportunity costs of participation. Acceptance into a program depends on bureaucratic preferences over applicant types, which in many programs are determined in part by formal performance standards systems. Acceptance also depends on the willingness of the applicant to pursue the application process to its conclusion and on further changes in opportunity costs, such as sudden illnesses or the arrival of job offers, during the application process.

Formal enrollment depends on both bureaucratic and personal preferences. For example, the JTPA performance standards system counted only the employment and wages of enrollees in a specified period following termination from the program. As a result, local JTPA bureaucrats had an incentive to gain additional information about the potential employability of persons accepted into the program and to use it to guide their enrollment decisions. At the same time, the passage of time between acceptance and enrollment leads to changes in opportunity costs that may cause accepted applicants to decline enrollment even if it is offered.

To describe the participation process, consider the following conditional probabilities for a person with characteristics $x$ : (1) the probability of eligibility; (2) the probability of program awareness given eligibility; (3) the probability of application 
given eligibility and awareness; (4) the probability of acceptance given application; and (5) the probability of formal enrollment conditional on acceptance into a program. In formal terms, we have

(1a) $\operatorname{Pr}(e l=1 \mid x)$,

(1b) $\operatorname{Pr}(a w=1 \mid e l=1, x)$,

(1c) $\quad \operatorname{Pr}(a p=1 \mid a w=1, e l=1, x)$

(1c) $\operatorname{Pr}(a c=1 \mid a p=1, a w=1, e l=1, x)$,

(1d) $\operatorname{Pr}(e n=1 \mid a c=1, a p=1, a w=1, e l=1, x)$,

where $e l=1$ if a person is eligible for a program and zero otherwise, $a w=1$ if a person is aware of a program and zero otherwise, $a p=1$ if a person applies to a program and zero otherwise, $a c=1$ if a person applies to and is accepted into a program and zero otherwise, and $e n=1$ if a person is formally enrolled in a program and zero otherwise. As persons only participate in the program if they are eligible $e l=1$, are aware $a w=1$, apply $a p=1$, are accepted $a c=1$, and formally enroll $e n=1$, we can decompose the probability of participation given $X=x, \operatorname{Pr}($ par $=1 \mid x)$, into the five components on the right-hand side of the following equation:

$$
\begin{aligned}
& \operatorname{Pr}(\text { par }=1 \mid x)= \\
& \operatorname{Pr}(e n=1 \mid a c=1, a p=1, a w=1, e l=1, x) \operatorname{Pr}(a c=1 \mid a p=1, a w=1, e l=1, x)
\end{aligned}
$$




$$
\operatorname{Pr}(a p=1 \mid a w=1, e l=1, x) \operatorname{Pr}(a w=1 \mid e l=1, x) \operatorname{Pr}(e l=1 \mid x),
$$

where $p a r=1$ if a person participates in a program and zero otherwise. By estimating each of the five component probabilities, we can determine the effect of each variable in $x$ on the overall probability of participation and can determine where and how it influences program participation. A variable that has no effect on the overall probability of participation may have strong, but offsetting, effects on the component probabilities.

In the sections that follow, we apply this framework to analyze participation in the JTPA program. Data limitations force us to combine application and acceptance into a single step. We equate acceptance into the program with reaching the stage of random assignment during the experimental evaluation of JTPA. Only eligible applicants who completed the aptitude and achievement tests required at most JTPA training sites and who received a written JTPA service plan were subject to random assignment. These conditions required a substantial commitment by JTPA training centers to continued interaction with the applicant, but fall short of formal enrollment into JTPA.

Section 9 presents two sets of decompositions based on (2). The first set includes all four stages: eligibility, awareness, application and acceptance, and enrollment. In the second set, we decompose $\operatorname{Pr}(a c=1 \mid e l=1, x)$, the probability of application and acceptance conditional on eligibility, into separate stages of awareness given eligibility and acceptance given awareness. Focusing solely on these two stages allows us to examine the effects of explanatory variables not included in the full decomposition due to data limitations. 


\section{The JTPA Program}

The Job Training Partnership Act (JTPA) was the primary U.S. federal employment and training program for the disadvantaged until replaced by the programs financed under the Workforce Investment Act (WIA) of 1998. JTPA provided classroom training in occupational skills, remedial education, job search assistance, work experience and onthe-job training at private firms for approximately one million persons each year.

There were two primary avenues to eligibility for JTPA. The first and most important avenue was economic disadvantage, which occurred if one of two criteria were met: (1) low family income in the six months prior to application to the program; or (2) being in a family receiving cash public assistance such as Aid to Families with Dependent Children (AFDC) and general assistance or Food Stamps. ${ }^{2}$ According to the U.S. Department of Labor (1993a), in Program Year $1991^{3}$ around 93 percent of JTPA participants qualified because they were economically disadvantaged. A second avenue to eligibility was an "audit window" that allowed up to 10 percent of participants at each JTPA training center to be non-economically disadvantaged persons with other barriers to employment such as limited ability in English. Due to the subjective nature of these barriers, and the resulting difficulty in determining who is affected by them, we only examine persons who are eligible by virtue of being economically disadvantaged. Devine and Heckman (1996)

\footnotetext{
2 The act also specifies additional eligibility criteria for several small groups. In the Survey of Income and Program Participation (SIPP) data used in our analysis, we are not able to accurately measure foster child status, disability or homelessness on a monthly basis, and so are unable to implement the special eligibility rules applicable to these groups in selecting our sample of eligibles. However, these groups represent a very small portion of the overall eligible population, and many of those eligible under the special provisions will also be eligible under the basic family income and program participation criteria described in the text.

3 Program Year (PY) 1991 covers the period from July 1991 to June 1992.
} 
discuss the eligibility rules for JTPA and their implications for the composition of the eligible population. $^{4}$

There are three important features of the criteria that determined eligibility for JTPA through economic disadvantage. First, eligibility depended on family income rather than on individual income. Second, only family income in the past six months was relevant. Third, current receipt of welfare benefits by any family member made a person eligible for the program. The short window for income eligibility allowed highly skilled and normally highly paid workers to become eligible for JTPA after being out of work only a few months.

There are some differences between the eligibility criteria and services offered in JTPA compared to its predecessors CETA (Comprehensive Employment and Training Act) and MDTA (Manpower Development and Training Act), and its successor, the WIA program. Barnow (1993) suggests that these differences are modest in regard to CETA and MDTA. U.S. Department of Labor (1998) and O'Shea and King (2001) document the details of the WIA program. All four programs focus on displaced workers, persons with low income and transfer program participants, and all four offered roughly the same set of services, with the earlier programs focused somewhat more on substantive training, either in a classroom or on the job, and the later programs focused somewhat more on “work first” strategies such as job search assistance. MDTA and CETA also offered public service employment, which was not offered in JTPA and is not offered under

\footnotetext{
${ }^{4}$ Two other details regarding JTPA eligibility deserve note. First, the implementation of the rules varied somewhat across localities, as states and training centers had some discretion over exactly what did and did not constitute family income and what did and did not constitute a family for the purposes of the program. Devine and Heckman (1996) show that such differences are too small to affect the patterns discussed here. Second, the eligibility rules described here are those in place at the time our data were collected. Some small changes in rules took place after that time; see Devine and Heckman (1996) or U.S. Department of Labor (1993b).
} 
WIA. Overall, the broad similarity in eligibility rules and services offered suggests that our analysis applies to all of these programs and to future programs patterned after them. Moreover, the U.S. JTPA program is also quite similar in terms of target groups, administration, and services offered to programs provided to unemployed workers in Canada and to the New Deal for Young People, New Deal for 25 Plus and New Deal for Lone Parent programs in the United Kingdom. ${ }^{5}$

\section{Data}

The primary source of our data is the National JTPA Study (NJS), an experimental evaluation of the JTPA program conducted from 1987 to $1989 .{ }^{6}$ In the course of this evaluation, persons accepted into JTPA at a non-random sample of sixteen JTPA training centers were randomly assigned into either a control group excluded from JTPA (for 18 months) or a treatment group given access to JTPA services. In order to learn more about the JTPA-eligible population, and to facilitate the development of better nonexperimental evaluation methods, data were collected on JTPA-eligible non-participants (ENPs) at four of the sixteen centers. These centers are Corpus Christi, Texas, Fort Wayne, Indiana, Jersey City, New Jersey and Providence, Rhode Island.

Detailed information on demographic characteristics, labor market histories, transfer program participation and family composition and income was collected on the ENPs and on experimental control group members at the same four sites. We use this information for our analyses of awareness of JTPA and of application and acceptance

\footnotetext{
${ }^{5}$ For Canada, see the information on the Human Resources Development Canada website, www.hrdc.gc.ca. For the New Deal programs in the United Kingdom, see the New Deal website, www.newdeal.gov.uk. ${ }^{6}$ See Doolittle and Traeger (1987) for a discussion of the implementation of the NJS and Bloom et al. (1997) and Orr et al. (1996) for summaries of the impact estimates.
} 
into JTPA. For the experimental treatment group, we have only limited information collected shortly before random assignment. We use these data to study enrollment into JTPA at the four sites. Appendix A describes the National JTPA Study data in detail.

The National JTPA Study did not collect data on persons ineligible for JTPA. In order to analyze the determinants of eligibility we use a national sample drawn from the 1986 Panel of the Survey of Income and Program Participation (SIPP). The SIPP is well suited to this purpose because it contains sufficient information to precisely determine JTPA eligibility. We treat the SIPP panel as a series of repeated cross-sections, and create a data set consisting of person-months. The SIPP sample is described in detail in Appendix B.

\section{The Determinants of Eligibility for the JTPA Program}

This section examines the determinants of eligibility for JTPA. Table 1 defines the explanatory variables used in this paper. Tables $2 \mathrm{a}$ and $2 \mathrm{~b}$ present the results of logit analyses of the determinants of eligibility. Table 2a presents results for adult (age 22 and above) men and women, and Table $2 \mathrm{~b}$ presents the results for male and female out-ofschool youth (ages 16 to 21). We focus on these four demographic groups for three reasons. First, they are the groups employed in the experimental impact reports and in our other work utilizing these data. Second, because of concerns around family responsibilities and education, we would expect men and women, and youth and adults, to behave differently. Third, we have no data on in-school youth, as this group was excluded from the experimental analysis. 
The first column for each demographic group in Tables $2 a$ and $2 b$ displays estimated coefficients and associated standard errors (in parentheses) from logit models of the probability of eligibility derived from the SIPP data. The second column displays estimates of the mean derivative of the probability of eligibility with respect to each characteristic (in square brackets) along with p-values from tests of the null hypotheses that each population coefficient equals zero. ${ }^{7}$ The notes to each table document the within-sample predictive performance of each model. As discussed in Appendix C, these estimates adjust for the dependence induced by the use of person-month observations, with each respondent allowed to contribute multiple months.

A number of interesting findings emerge from this analysis. First, even after controlling for family income and productivity characteristics, race and ethnicity are very important determinants of the probability of eligibility. For example, for adult females, the average difference in the probability of eligibility for blacks and Hispanics relative to whites exceeds 0.12 , holding resource variables constant.

Being married has a large negative estimated effect on the eligibility probabilities for all groups except adult males. The eligibility status of adult males is driven primarily by their own income, while for adult females and for youth, eligibility status depends in large part on the earnings of other family members. For all demographic groups except adult males, the presence of an own child age less than six living in the home substantially increases the probability of eligibility for JTPA. Children raise the income cutoff for eligibility by increasing the household size but do not add to the family income. In addition, years of schooling have an important impact on eligibility for all groups.

\footnotetext{
${ }^{7}$ We present mean derivatives and not derivatives evaluated at the mean of the $X$. That is, we calculate the derivative (or finite difference for binary variables) for each observation and report the (weighted) sample mean.
} 
Not surprisingly, the probability of eligibility decreases monotonically with family income for all four demographic groups. The magnitude of the estimated average derivatives is very large for family income categories corresponding to incomes above $\$ 6000$. For adult males, raising family income from less than $\$ 3000$ to between $\$ 9000$ and $\$ 12,000$ produces an average decrease in the probability of JTPA eligibility of 0.268. For male and female youth, the estimated average derivatives are larger still, reflecting the differential importance of family resources in determining eligibility for these groups.

The small set of characteristics included in the specifications reported in Table 2 do well at predicting within-sample eligibility status. For all four groups, over 70 percent of the eligibles and almost 90 percent of the non-eligibles are correctly predicted when we use the overall eligibility rate within each group to define the cutoff for predicting eligibility. Taken together, our results demonstrate that the eligibility rules for JTPA produced substantial group differences in access to subsidized government training.

\section{The Determinants of Awareness of the JTPA Program}

This section investigates the determinants of awareness of the JTPA program using data on the controls and eligible non-participants at four JTPA sites. The concept of program awareness is an elusive but important one. Differential access to information about the program can affect awareness and thereby influence participation. Language barriers are an obvious case in point. However, awareness also depends on the incentives a person has to participate in the program. In some cases the desire to participate may influence awareness rather than awareness independently influencing participation. 
As we lack evidence on individual information-gathering activities, we are unable to determine the extent to which information costs, and therefore program awareness, play a causal role in determining program participation choices. However, the evidence presented in this section indicates that awareness of JTPA among those eligible for it is by no means universal, and that program awareness appears to be related to the likelihood of participation in the program, to education, and to language skills. We also present evidence that a sizeable fraction of persons who are eligible for the program do not believe that they are eligible for it. Taken together, this evidence suggests that barriers to information are an important determinant of program participation.

Each member of the ENP sample was asked whether or not he or she had heard of the JTPA program. In keeping with the decentralized nature of the JTPA program, local training sites often select operating names other than JTPA. To overcome this problem, ENPs were asked about their awareness of JTPA under several different names, including the program's primary name in their locality. Persons who indicated that they were aware of the JTPA program were then asked whether or not they believed themselves to be presently eligible for it. Persons participating in the program are assumed to be aware of it and of their own eligibility for it.

Table 3 presents rates of awareness and self-reported eligibility for eligible nonparticipants in each major demographic group. The first column presents the fraction of the ENPs who have heard of JTPA. These fractions are surprisingly low. For all four groups, the awareness rate is below 50 percent. The rate is higher for youth than for adults, which may indirectly reflect requirements that sites expended 40 percent of their training resources on youth, who constitute well less than 40 percent of the eligible 
population (a similar requirement, reduced to 30 percent, holds for the WIA program). The second column gives the fraction of those persons aware of the program who think that they are eligible for it. Note that all of the ENPs are determined to be eligible at the time of their screening interviews and that nearly all are still eligible at the time the question was asked in the baseline interview. Conditional on awareness, only 36 percent of adult males, 46 percent of adult females and around 55 percent of youth realize that they qualify for JTPA services. Taking the product of these two probabilities yields the unconditional probability of awareness and self-reported eligibility appearing in the third column. Barely 12 percent of adult male eligibles can identify both the program and their own eligibility for it. Even among youth, only about 25 percent of eligibles are both aware of the program and of their own eligibility for it. These figures suggest that there are substantial costs associated with finding out about social programs such as JTPA and about the rules governing access to their services, and that information costs play an important role in producing demographic differentials in program participation.

The results from a logit analysis of the determinants of awareness of the JTPA program appear in Tables $4 \mathrm{a}$ and $4 \mathrm{~b}$. These tables have the same basic structure as Tables $2 \mathrm{a}$ and $2 \mathrm{~b}$. For all four demographic groups, black eligibles are relatively more likely than white eligibles to know about JTPA. Adult Hispanic eligibles are relatively less likely than whites to know about JTPA, with the difference being statistically significant in both cases. The negative and statistically significant coefficient estimates for Hispanic adult eligibles arise even after controlling for facility with the English language and for level of education. ${ }^{8}$ It has often been noted (see, e.g., Tienda and

\footnotetext{
${ }^{8}$ The English language ability variable should be interpreted with caution as it arises from different underlying measures in the ENP and control group samples. For the ENPs, lack of English ability is
} 
Jensen, 1988) that Hispanics participate less in government programs compared to nonHispanics with the same basic economic characteristics. Language skills and educational deficits play a role in explaining this phenomenon but more than just language deficits are involved. If Hispanics are less likely to utilize public services, or if they participate in networks with fewer public service recipients, then they are less likely to be aware of JTPA and of other programs.

Consistent with the standard human capital model (see, e.g., Becker 1964), older adults have statistically significantly lower probabilities of awareness of the program than persons age 22 to 29 . This may reflect the reduced demand for skill enhancement programs with age documented in Leigh (1995). The pattern with respect to education is hump-shaped. Persons with the lowest levels of schooling have lower conditional probabilities of awareness than those who have completed high school. This evidence supports the notion of substantial information processing costs among those with very low levels of schooling. A lower likelihood of participating in JTPA, and hence a lower value to information about the program, accounts for the evidence that the most educated persons are less aware of the program.

Among adults, divorced, widowed or separated eligibles have a higher probability of awareness than do those who are single. The difference is both statistically and substantively significant for adult males. For three of the four groups, living in a family that receives Food Stamps has a positive effect on the probability of being aware of JTPA, while living in a family that receives AFDC has a positive effect only for adult males and for female youth. The estimated effect of living in a family receiving Food

measured by the language in which the respondent chose to complete the baseline survey, while for the controls it is obtained from a question on language preference administered around the time of random assignment. 
Stamps is large, with mean numerical derivatives of 0.164 and 0.133 , and it is statistically significant for both adult males and females. As nearly all of the adult female AFDC recipients also receive Food Stamps, the negative (essentially zero) coefficient on the AFDC variable indicates the additional effect of receiving both AFDC and Food Stamps, rather than just Food Stamps. Interpreted in this way, the absence of any AFDC effect becomes less surprising. The strong effects observed for Food Stamp receipt are consistent with the practice in that program of providing recipients with information about training opportunities.

Unemployed eligibles have a higher probability of program awareness for all four demographic groups. This difference between the unemployed and the employed is statistically significant for both male and female adults. In contrast, eligible individuals who are out of the labor force have lower probabilities of awareness than employed eligibles for all four demographic groups. These results are consistent with the relative value of information about JTPA for the two groups.

While the concept of program awareness is a conceptually problematic one, the evidence presented here indicates that learning about the JTPA program and its eligibility requirements is not costless, and that the likelihood of becoming aware of the program varies in predictable ways. In particular, we find that differences in information costs, in information processing and language skills, and in the expected value of information about the JTPA program, which is itself a function of the probability of participation in the program and its expected benefit, can account for the patterns we observe in the data.

\section{The Determinants of Application and Acceptance into JTPA}


This section presents a logit analysis of the determinants of application and acceptance into the JTPA program conditional on awareness of the program using data on controls and ENPs from the National JTPA Study. We combine the application and acceptance stages here because we lack the data to examine them separately. Combining these two stages in the program participation process means that the patterns we observe reflect the joint influence of individual decisions to apply and to persist through the (sometimes lengthy) application process and of JTPA staff decisions to accept or encourage some applicants while rejecting or discouraging others.

Tables $5 \mathrm{a}$ and $5 \mathrm{~b}$ report estimates of logit models of application and acceptance into the JTPA program as a function of observed characteristics for the four demographic groups. Coefficient estimates and estimated standard errors take account of the choicebased nature of the sample. The training site indicators included in the model have no behavioral interpretation, as the relative numbers of ENPs and controls at each site is an artifact of the study design. The notes to Tables $5 \mathrm{a}$ and $5 \mathrm{~b}$ summarize the within-sample predictive success of the models. Appendix C provides additional details regarding the methods used to obtain the reported results.

The most dramatic result in Tables $5 \mathrm{a}$ and $5 \mathrm{~b}$ is the powerful effect of recent labor force status dynamics on application and acceptance into JTPA. ${ }^{9}$ For both adult males and adult females, all of the labor force status pattern indicators have coefficients statistically different from zero, though many of the coefficients cannot be statistically distinguished from one another. In general, persons entering unemployment either from outside the labor force or from employment are the most likely to enter the JTPA program. For adult men, individuals who recently became unemployed, either by leaving

\footnotetext{
${ }^{9}$ Heckman and Smith (1999) discuss the importance of these variables at greater length.
} 
employment or by reentering the labor force, have higher application and acceptance probabilities than the long term (over six months) unemployed. This difference does not appear for women.

Older adults have a lower conditional probability of application and acceptance, consistent with conventional arguments that the return to training declines with age. The effect of years of completed schooling on acceptance into the program shows a hillshaped pattern for adults, with individuals with less than 10 or more than 15 years of schooling having differentially low estimated application and acceptance probabilities. This pattern reveals that it is more than just low rates of awareness that cause those with less than a high school education to have low rates of participation in JTPA conditional on eligibility. For youth, the probability of application and acceptance increases monotonically in years of schooling.

Relative to single, never married persons, currently married persons have a statistically significantly lower probability of application and acceptance for three of the four demographic groups. Among adult men, but not the other three demographic groups, divorced, widowed and separated persons also have lower probabilities of application and acceptance into JTPA.

The effect of living in a family receiving AFDC is negative for all four groups, and statistically significant for three. In contrast, family Food Stamp receipt has a positive influence in all cases. Interpreting the AFDC coefficient as the marginal effect of family AFDC receipt in addition to Food Stamps, it appears that among aware eligibles, AFDC recipients have much lower probabilities of application and/or acceptance into JTPA than do those receiving only Food Stamps. As the effect of young 
children in the home is being controlled for, this difference does not result from young children acting as a barrier to work or training outside the home.

The effects of family income differ across groups. High levels of family income reduce the probability of application and acceptance among adult males, have little effect for adult females, and raise the probability of participation for both youth groups. The availability of income from other family members to provide support during training appears to encourage youth to apply to JTPA.

Absent from the specifications reported here are measures of the state of the local economy at the four sites during the time that the ENP and control samples were collected. In work not reported in detail here, we estimate models including both countylevel monthly unemployment rates averaged over the counties constituting each of the sites, and interactions between these unemployment rates and the site indicators. Surprisingly, given the strong effects of individual unemployment found here, these variables never attain statistical significance and never have a noticeable impact on the proportion of correct predictions. One reason for this is that the number of ENPs whose month of measured eligibility occurs in a given calendar month depends not only on the size of the eligible population in that month, but also on the administrative schedule of the consulting firm conducting the surveys. A second reason is that the flow into the program, as measured by the number of persons randomly assigned in each calendar month, depends on other factors beyond the local economy, including the academic schedule of the community colleges that provide much of the JTPA training at these sites. In Appendix D, we report estimates of the determinants of application and acceptance into JTPA conditional on eligibility rather than on awareness. In general, the 
main findings are the same in the two analyses. In particular, the labor force status transition variables dominate both sets of results. The differences between the two are consistent with the patterns in the two conditional analyses, so that factors whose main impact is on awareness are statistically significant when we condition on eligibility but are not when we condition on both eligibility and awareness.

Our analysis of application and acceptance into JTPA conditional on eligibility reveals the fundamental importance of labor force status dynamics in determining who applies and is accepted into the program conditional on program awareness. A number of other factors including age, schooling, marital status and family income play important supporting roles.

\section{The Determinants of Enrollment in JTPA}

Formal enrollment constitutes the final stage in the JTPA participation process. In this section we examine the determinants of the transition from acceptance into the program, defined here as reaching random assignment, to formal enrollment. ${ }^{10}$ A key difference between acceptance and enrollment is that only the outcomes of persons formally enrolled in JTPA influenced the rewards (or punishments) that a site received under the JTPA performance standards system. Training centers in JTPA had considerable discretion regarding whether (and when) to enroll persons accepted into the program. The performance standards system provided an incentive for training centers to delay enrollment until accepted applicants provided evidence that they were likely to obtain a

\footnotetext{
${ }^{10}$ Heckman, Smith and Taber (1998) discuss non-enrollment within the experimental treatment group and its implications for the evaluation of JTPA. See also the general discussions of treatment group dropout and control group substitution in Heckman, Hohmann, Smith and Khoo (2000) and Heckman, LaLonde and Smith (1999).
} 
job or to otherwise count favorably toward center performance. In practice, this often meant that individuals receiving job search assistance were not enrolled until they found a job and that persons assigned to receive subsidized on-the-job training at private firms were not enrolled until a firm willing to provide them with such training had been located. For persons assigned to receive classroom training, training centers would often wait until trainees successfully attended class before enrolling them in the program. Thus, we expect that the incentives provided by the performance standards system should result in higher probabilities of enrollment for persons with characteristics associated with employability, such as higher levels of schooling or recent employment experience. Another factor influencing enrollment decisions for persons recommended for classroom training is their ability to maintain themselves during the time they are enrolled in training. Classroom training typically lasts longer than employment-related services such as job search assistance. At the same time, unlike earlier programs such as CETA, JTPA provided no stipends to trainees except in unusual circumstances. Thus, the willingness of a person to pursue classroom training may depend on the availability of a stable income from outside sources. Two important sources of income are transfer programs such as AFDC and family income. Given that persons with limited access to outside income may not take classroom training that is offered, and that enrollment usually does not occur until a person begins attending classes, we would expect AFDC and family income to have positive effects on the probability of enrollment, particularly for adult women and female youth, who are relatively more likely to receive classroom training (see, e.g., Kemple, Doolittle and Wallace, 1993). 
At the same time, the lag between acceptance into the program and enrollment in it may lead to changes in the opportunity costs of participation. Accepted applicants may receive job offers that dominate the training offered by JTPA, or they may experience illness or family problems that make it impossible for them to enroll. Thus, the patterns we observe represent the combined influence of bureaucratic decisions regarding enrollment and of individual decisions to continue in or drop out of the program in response to changes in opportunity costs.

Tables $6 \mathrm{a}$ and $6 \mathrm{~b}$ present the results of logit analyses of enrollment for the four demographic groups. The notes to the tables discuss the within-sample predictive performance of the model, which is quite good. We find that the four training centers have very different overall enrollment rates, even controlling for the observable characteristics of their accepted applicants. For all four demographic groups, accepted applicants at the Fort Wayne and Jersey City centers have enrollment probabilities substantially lower than similar persons at Corpus Christi, which is the omitted training center in our analysis. These differences reflect in part the differing mix of services offered at the various sites. Corpus Christi offered mainly classroom training. This form of service leads to a higher enrollment rate than other JTPA services (see Kemple, Doolittle and Wallace, 1993). In contrast, Fort Wayne and, to a lesser extent, Jersey City, primarily offered on-the-job training and job search assistance. Centers offering these services will have lower enrollment rates among accepted applicants because those who fail to locate a job or for whom no firm is willing to provide on-the-job training often do not ever get enrolled in the program. 
Conditional on acceptance into JTPA, older adults are less likely to enroll than younger adults. This finding is consistent with the lower expected returns to training for older persons, which would make them relatively more likely to drop out of the program in response to a given outside opportunity. Family participation in the Food Stamp program has a negative effect for three of the four demographic groups, with the effect both large and statistically significant for adult females. To the extent that Food Stamp recipients are less likely to find employment than other accepted applicants, this is consistent with creaming induced by the operation of JTPA performance standards. Also consistent with these incentives is our finding that for women and male youth, having no employment experience strongly reduces the probability of enrollment.

Finally, we estimate a large positive effect of family income on the enrollment probability for adults. Family income may allow an accepted applicant to undertake training even in the absence of a stipend. Thus, even though higher family income lowers eligibility it raises the probability of enrollment among accepted applicants.

Taken together, our findings on the determinants of enrollment, particularly the effects of recent employment and participation in a transfer program, provide support for the hypothesis that bureaucrats attempt to maximize the employability of those persons selected for enrollment in the JTPA program from among the accepted applicants.

\section{Decomposing the Process of Selection into JTPA}


In order to determine at what stage - enrollment (en), awareness (aw), acceptance (ac) or eligibility $(e l)$ - and in which direction particular observable characteristics operate to determine participation in the program, we use the chain rule to decompose the probability of participation in the following way:

$$
\begin{aligned}
& \frac{\partial \operatorname{Pr}(e n=1 \mid x)}{\partial x}= \\
& {\left[\frac{\partial \operatorname{Pr}(e n=1 \mid a c=1, a w=1, e l=1, x)}{\partial x}\right] \operatorname{Pr}(a c=1 \mid a w=1, e l=1, x) \operatorname{Pr}(a w=1 \mid e l=1, x) \operatorname{Pr}(e l=1 \mid x)} \\
& +\operatorname{Pr}(e n=1 \mid a c=1, a w=1, e l=1, x)\left[\frac{\partial \operatorname{Pr}(a c=1 \mid a w=1, e l=1, x)}{\partial x}\right] \operatorname{Pr}(a w=1 \mid e l=1, x) \operatorname{Pr}(e l=1 \mid x) \\
& +\operatorname{Pr}(e n=1 \mid a c=1, a w=1, e l=1, x) \operatorname{Pr}(a c=1 \mid a w=1, e l=1, x)\left[\frac{\partial \operatorname{Pr}(a w=1 \mid e l=1, x)}{\partial x}\right] \operatorname{Pr}(e l=1 \mid x) \\
& +\operatorname{Pr}(e n=1 \mid a c=1, a w=1, e l=1, x) \operatorname{Pr}(a c=1 \mid a w=1, e l=1, x) \operatorname{Pr}(a w=1 \mid e l=1, x)\left[\frac{\partial \operatorname{Pr}(e l=1 \mid x)}{\partial x}\right]
\end{aligned}
$$

This equation decomposes the effect of a change in $x$ on the probability of participation in the program into its effect on each constituent probability weighted by the remaining probabilities. In each term, the component in square brackets is the effect of a change in $x$ on one of the conditional probabilities leading to participation in the program. ${ }^{11}$ For dichotomous variables, we replace derivatives with finite changes.

Using (3), we can assess through which channels, if any, variation in $x$ operates to affect the probability of participation in JTPA. In this section, we present results for two different decompositions. The two decompositions differ in terms of the number of steps included, the set of variables included, and the data used to perform the decomposition. These criteria are interrelated because the probability estimates are derived from different

\footnotetext{
${ }^{11}$ These relationships can be expressed more concisely using logarithmic derivatives. We do not use that approach here because logarithmic derivatives are more difficult to interpret.
} 
data sets and not all of the data sets contain all of the variables used to estimate the conditional probabilities discussed in the preceding sections. Reducing the number of stages enables us to estimate the effects of more characteristics. In addition, for certain variables some of the stages in (3) are effectively eliminated. For example, belonging to a family that receives AFDC or Food Stamps makes the probability of eligibility equal to one. It is only informative to examine the effects of AFDC and Food Stamp receipt on the remaining components of the decomposition.

The first decompositions we present appear in Tables $7 \mathrm{a}$ to $7 \mathrm{~d}$. The format of each table corresponds directly to equation (3). The estimates of the probability of eligibility are based on the SIPP data. The estimates for the conditional probabilities of awareness, of application and acceptance, and of enrollment all draw on data from the four sites in the National JTPA Study, with the first two constructed using the ENP and control data and the last obtained from the experimental treatment group. As in the earlier tables, the reported derivatives consist of sample averages of individual derivatives (or finite differences). They are not the derivatives evaluated at the sample means of the characteristics. ${ }^{12}$

The first column in the table presents the overall effect of a change in the indicated characteristic $x$ on the probability of enrollment; this is the term on the left-hand side of (3). These values are expressed in terms of the expected change in the probability of participation resulting from the indicated change in characteristics, multiplied by 100 for ease of presentation. To put the terms in context, note that the unconditional probability of participation is around 0.03 , so that an overall effect of -0.867 , which is the effect for adult males of switching from a family income of $\$ 0-\$ 3,000$ to one over

\footnotetext{
${ }^{12}$ Appendix C contains a detailed discussion of the simulations.
} 
$\$ 15,000$, translates into a change in the probability of -0.00867 , or a reduction of nearly one-third relative to the unconditional probability.

The second, fourth, sixth and eighth columns of the first panel present the four chain rule terms that compose the overall effect. Thus, for the decomposition in Tables $7 \mathrm{a}$ to $7 \mathrm{~d}$, the weighted eligibility term is given by the first term on the right-hand side of (3), the weighted acceptance term by the second term in (3), the weighted awareness term by the third term in (3), and the weighted enrollment term by the fourth term in (3). The third, fifth, seventh and ninth columns present the percentage of the overall effect attributable to each of the four components. Thus, the third column indicates the percentage of the overall effect that results from the effect of the indicated change in $x$ on the conditional probability of eligibility, which is given by the ratio of the weighted eligibility term to the overall effect multiplied by 100 . The second panel of each table presents the unweighted effect of the indicated change in $x$ on each of the conditional probabilities. This unweighted effect is just the average partial derivative (or finite difference) of the probability with respect to the characteristic.

The results for race and ethnicity are especially striking. Blacks consistently have an overall probability of participation higher than that of whites. For three of the four demographic groups, this higher overall probability decomposes into higher conditional probabilities of eligibility and awareness, but lower conditional probabilities of acceptance and enrollment. Decomposing the overall effect in this way makes it clear where blacks fall out of the participation process, and suggests that policy measures designed to increase their participation should focus on application, acceptance and enrollment, rather than on changes in eligibility rules or on outreach efforts to increase 
awareness. This evidence indicates that the concerns expressed in the GAO report discussed in the introduction to this paper regarding minority participation may be relevant. Administrative discretion may have played a role in reducing black participation in JTPA, and may continue to do so under WIA.

A different pattern emerges for the categorical age variables. For adults, older persons nearly always have lower conditional probabilities at every stage in the participation process relative to persons age 22-29. The same is true of youth, where a modest overall negative effect for 19-21 year olds relative to 16-18 year olds is mirrored at each stage in the process except for the application and acceptance stage for male youth and the eligibility and enrollment stages for female youth.

Overall, being married rather than being single decreases the probability of participation in JTPA for all four demographic groups. The dominant factor lowering enrollment among married persons is a strong negative effect of marriage on the conditional probability of application and acceptance. For adult males, this negative term outweighs a positive effect of marriage on the conditional probabilities of eligibility, awareness and enrollment. The probability of participation for divorced, widowed or separated persons exceeds that for single persons in three of the four groups. For adult males, positive effects of having once been married on eligibility, awareness and enrollment dominate the negative acceptance term, while all but the eligibility term are positive for adult females.

For adults, the relationship between the overall probability of participation into JTPA and years of completed schooling is roughly hill-shaped, with its peak occurring at 10-11 years of completed schooling for men and 13-15 years for women. The 
decompositions reveal that the overall relationship results from combining a negative relationship between years of schooling and eligibility, and generally hill-shaped relationships between schooling and awareness, application and acceptance, and enrollment. For youth, the overall relationship between participation and years of completing school peaks at 10-11 years for males and at less than 10 years for females.

For three of the four demographic groups, the overall effect of having an own child under six years of age in the home breaks down into a positive component due to increased conditional probabilities of eligibility and enrollment, and negative components due to decreased probabilities of awareness and acceptance. The overall effect is negative for men and positive for women.

The overall probability of participation in JTPA decreases monotonically in family income for adult males and male and female youth, and peaks in the $\$ 3000-\$ 9000$ category for adult females. The strong negative relationship between family income and the probability of eligibility described in section four dominates the overall effect in almost every case. The exception is the peak for adult females, which results from the influence of a similarly peaked pattern in the relationship between family income and the conditional probabilities of awareness and of application and acceptance for that group.

Tables $8 \mathrm{a}$ to $8 \mathrm{~d}$ present a second set of decompositions. In these tables, we decompose the probability of application and acceptance conditional on eligibility into components due to awareness and due to application and acceptance given awareness. Omitting the stages of eligibility and enrollment allows us to simulate using the same ENP and control data from the National JTPA Study that we use to estimate the conditional probabilities of awareness and of application and acceptance. Omitting the 
enrollment stage allows us to include variables representing recent labor force status transitions, which are not available in the treatment group data we use to estimate the probability of enrollment. Otherwise, the format of the tables and the construction of the individual terms parallels that for the decompositions already discussed.

The basic patterns for those variables, such as age and schooling, included in the earlier decompositions remain essentially the same, so we do not dwell on them here. Of great interest are the decompositions of the overall effects of family receipt of AFDC and Food Stamps on the application and acceptance probabilities. The overall effect of AFDC receipt is negative for all four groups. For both groups of adults, the overall effect decomposes into a small effect due to awareness, combined with a large negative effect of living in a family receiving AFDC on the probability of application and acceptance conditional on awareness. For male youth, living in a family receiving AFDC has negative effects of roughly equal size on awareness and on application and acceptance given awareness, while for female youth positive awareness and negative application and acceptance effects roughly cancel to yield a small overall effect.

All four demographic groups show a positive impact of living in a family receiving Food Stamps on the probability of application and acceptance. For all the groups except female youth, this effect decomposes into roughly equal positive effects of Food Stamp receipt on the probabilities of awareness and of application and acceptance conditional on awareness. For female youth, the contribution of the awareness term is negligible, leaving the impact of living in a family receiving Food Stamps on application and acceptance to dominate the overall effect. Interpreting the estimated effect of family receipt of AFDC as the additional effect of AFDC receipt given that the family receives 
Food Stamps, we find that AFDC provides additional information about JTPA but acts to discourage application and acceptance.

Finally, examination of the decompositions for the variables representing the two most recent labor force statuses at the time of random assignment or eligibility screening shows that in all cases it is the effect of these statuses on the probability of application and acceptance conditional on awareness that accounts for their large positive effects on the unconditional probability of application and acceptance. The estimated effects of labor force transitions on awareness are small and are of mixed sign, with negative estimated effects usually associated with transitions out of the labor force.

These decompositions offer unique insights regarding the effects of characteristics such as race, age, education, program participation, labor force status and family income on the various stages of the process by which individuals select and are selected into the JTPA program. For many characteristics, such as race and ethnicity, the same characteristic has competing effects at different stages of the process. Other characteristics, such as age among adults, operate in the same direction on the conditional probabilities of program eligibility, awareness, application and acceptance, and formal enrollment. Sorting out the effects of particular characteristics at each step enriches our understanding of the overall participation process.

\section{Summary and Conclusions}

In this paper, we develop a framework for studying the determinants of participation in social programs. Our framework decomposes participation into a series of stages: eligibility, awareness, application, acceptance and enrollment. Compared to 
simple comparisons of the characteristics of program eligibles and program participants, our framework allows a deeper examination of issues related to the equity of the distribution of program benefits, to the effects of administrative choices under the influence of administrative performance standards systems, and to the optimal design of non-experimental evaluations of program impacts.

Several major empirical lessons emerge from this study. Although they arise from data on JTPA, the similarity between JTPA and many other programs in the U.S. and elsewhere that we document in Section 3 suggests they likely apply more broadly. First, there is evidence of cream skimming in the program that is consistent with the incentives embodied in the JTPA performance standards system. Among applicants accepted into the program, blacks, persons with less than a high school education, persons from poorer families and those without recent employment experience are less likely to be enrolled than are persons in other racial and ethnic groups, persons with a high school education, persons from richer families and persons with recent employment experience. While these patterns are consistent with cream skimming, our analysis does not reveal the separate influences of self-selection and selection by program staff..$^{13}$

Second, there is strong evidence that informational barriers play a major role in determining differences in program participation rates, but these barriers do not fully account for the differentially low participation rate of Hispanics identified by Gonzales and Romero (1989) and Sandell and Rupp (1988). We have already discussed the role of

\footnotetext{
${ }^{13}$ In other work (Heckman, Smith and Taber, 1996), we use data from a single site in the National JTPA Study to look solely at the transition from application to enrollment, the stage of the participation process over which case workers presumably have the greatest control. We find evidence that caseworkers select the applicants likely to do the worst, rather than the best, in the absence of the program. This suggests that caseworker preferences for serving the most disadvantaged may overcome the incentives provided by the performance standards system in some contexts. However, the findings in Heckman, Smith and Taber (1996) could also result from more employable applicants leaving the program for employment prior to enrolling.
} 
education in improving awareness of the program. Controlling for other factors, persons who are not fluent in English are less likely to be aware of the program. However, differences in educational levels and in language ability are not the sole reason why Hispanics are less likely to participate in the program than other groups. After taking account of these differences, Hispanics were less likely to participate in JTPA.

Third, labor force status dynamics, in particular recent unemployment histories, played an important role in determining who applied and was accepted into JTPA from among the population of eligible persons aware of the program. Eligible persons aware of JTPA who were unemployed at the time they were deciding whether or not to participate in the program, particularly those unemployed persons who had recently lost a job or re-entered the labor force, have relatively high probabilities of application and acceptance into JTPA. In contrast, persons in the midst of a stable employment spell or a stable spell out of the labor force were quite unlikely to apply and be accepted into JTPA. The JTPA program was in part a form of job search for the unemployed, and so attracted persons who were actively seeking work.

This finding indicates the importance of collecting information on detailed labor force status transitions at the monthly level in non-experimental evaluations of employment and training programs. Conditioning on earnings is not enough, as the set of individuals with zero earnings includes individuals who are unemployed and individuals who are out of the labor force, two groups that have very different patterns of program participation and labor market outcomes.

Finally, we demonstrate that changes in eligibility rules will have only a weak effect on the participation of many groups. While the JTPA eligibility rules effectively 
denied access to program services to many groups, such as those with high family incomes, they were powerless to induce particular groups within the eligible population to participate. Put simply, you can lead a horse to water, but you can't make it drink. For example, individuals with low levels of schooling have very high rates of eligibility but relatively low rates of participation conditional on eligibility. Even more striking is the case of AFDC recipients, who were automatically eligible for JTPA but who had a low participation probability relative to other groups within the eligible population. Getting these groups to participate in employment and training programs such as JTPA and WIA requires more than just making them eligible for program services.

Our framework yields substantial insights regarding program equity, the effects of administrative performance management systems, and the design of non-experimental program evaluations. The evidence we present reveals the complex nature of the program participation process, with some variables having conflicting effects on participation at different stages in the process, and others operating in the same direction at every stage. These insights are achieved by decomposing the participation process. our analysis indicates the potential value of collecting the data required to perform similar decompositions for other programs. 


\section{Bibliography}

Amemiya, Takeshi. Advanced Econometrics. Cambridge, MA: Harvard University Press, 1985.

Anderson, Kathryn; Burkhauser, Richard; and Raymond, Jennie. "The Effect of Creaming on Placement Rates Under the Job Training Partnership Act." Industrial and Labor Relations Review, 46 (1993): 613-624.

Anderson, Kathryn; Burkhauser, Richard; Raymond, Jennie; and Russell, Clifford. "Mixed Signals in the Job Training Partnership Act." Growth and Change, 22 (1991): 3248.

Anderson, Patricia, and Meyer, Bruce. 1997. "Unemployment Insurance and the AfterTax Value of Benefits.” Quarterly Journal of Economics 112 (1997): 913-937.

Ashenfelter, Orley. "Determining Participation in Income-Tested Social Programs." Journal of the American Statistical Association 78 (1983): 517-525.

Ashenfelter, Orley, and Card, David. "Using the Longitudinal Structure of Earnings to Estimate the Effect of Training Programs." The Review of Economics and Statistics 47 (1985): 648-660.

Barnow, Burt. "Getting It Right: Thirty Years of Changing Federal, State, and Local Relationships in Employment and Training Programs." Publius: The Journal of Federalism 23 (1993): 75-94.

Becker, Gary. Human Capital: A Theoretical and Empirical Analysis, with Special Reference to Education. New York: Columbia University Press, 1964.

Blank, Rebecca. "What Causes Public Assistance Caseloads to Grow?" Journal of Human Resources 36 (2001): 85-118.

Blank, Rebecca, and Ruggles, Patricia. "When Do Women Use Aid to Families with Dependent Children and Food Stamps? The Dynamics of Eligibility vs. Participation." Journal of Human Resources 24 (1989) 54-87.

Bloom, Howard; Orr, Larry; Bell, Stephen; Cave, George; Doolittle, Fred; Lin, Winston; and Bos, Johannes. "The Benefits and Costs of JTPA Title II-A Programs: Findings from the National Job Training Partnership Act Study." Journal of Human Resources 32 (1997): 549-576.

Card, David, and Sullivan, Daniel. "Measuring the Effect of Subsidized Training Programs on Movements In and Out of Employment." Econometrica 56 (1988): 497-530. 
Devine, Theresa, and Heckman, James. "The Structure and Consequences of Eligibility Rules for a Social Program." In Research in Labor Economics, Volume 15, edited by Solomon Polachek, pp. 111-170. Greenwich, CT: JAI Press. 1996.

Doolittle, Fred, and Traeger, Linda. Implementing the National JTPA Study. New York, NY: Manpower Demonstration Research Corporation, 1990.

Gonzales, J. and Romero F. "Falling Through The Cracks: Hispanic Underrepresentation in The Job Training Partnership Act." Working Paper H46. National Council of La Raza, 1989.

Heckman, James; Hohmann, Neil; Smith, Jeffrey; and Khoo, Michael. "Substitution and Drop Out Bias in Social Experiments: A Study of an Influential Social Experiment." Quarterly Journal of Economics 115 (2000): 651-694.

Heckman, James; Ichimura, Hidehiko; and Todd, Petra. "Matching as an Econometric Evaluation Estimator: Evidence from Evaluating a Job Training Programme." Review of Economic Studies 64 (1997): 605-654.

Heckman, James; Ichimura, Hidehiko; and Todd, Petra. "Matching as an Econometric Evaluation Estimator.” Review of Economic Studies 65 (1998): 261-294.

Heckman, James; Ichimura, Hidehiko; Smith, Jeffrey; and Todd, Petra. "Characterizing Selection Bias Using Experimental Data.” Econometrica 66 (1998): 1017-1098.

Heckman, James; LaLonde, Robert; and Smith, Jeffrey. "The Economics and Econometrics of Active Labor Market Programs." In Handbook of Labor Economics, Volume 3A, pp. 1865-2097. Amsterdam: North-Holland, 1999.

Heckman, James and Salvador Navarro-Lozano. "Using Matching, Instrumental Variables and Control Functions to Estimate Econometric Models." NBER Working Paper No. 9497, February 2003.

Heckman, James, and Robb, Richard. "Alternative Methods for Evaluating the Impact of Interventions." In James Heckman and Burton Singer, eds., Longitudinal Analysis of Labor Market Data, pp. 156-246. New York, NY: Cambridge University Press for Econometric Society Monograph Series, 1985.

Heckman, James, and Smith, Jeffrey. "The Pre-Programme Dip and the Determinants of Participation in a Social Programme: Implications for Simple Programme Evaluation Strategies." Economic Journal 109 (1999): 313-348.

Heckman, James; Smith, Jeffrey; and Taber, Christopher. "Accounting for Dropouts in Evaluations of Social Programs." Review of Economics and Statistics 80 (1998): 1-14. 
Heckman, James; Smith, Jeffrey; and Taber, Christopher. "What Do Bureaucrats Do? The Effects of Performance Standards and Bureaucratic Preferences on Acceptance into the JTPA Program." In Advances in the Study of Entrepreneurship, Innovation and Economic Growth: Reinventing Government and the Problem of Bureaucracy, Volume 7, edited by Gary Libecap, pp. 191-217. Greenwich, CT: JAI Press, 1996.

Jacobson, Louis; LaLonde, Robert; and Sullivan, Daniel. "Measures of Program Performance and the Training Choices of Displaced Workers." In Targeting Employment Services, edited by Randall Eberts, Christopher O'Leary and Stephen Wandner, pp. 187214. Kalamazoo, MI: W.E. Upjohn Institute for Employment Research, 2002.

Kemple, James; Doolittle, Fred; and Wallace, John. The National JTPA Study: Site Characteristics and Participation Patterns. New York, NY: Manpower Demonstration Research Corporation, 1993.

Leigh, Duane. Assisting Workers Displaced by Structural Change. Kalamazoo, MI: W.E. Upjohn Institute for Employment Research, 1995.

McCall, Brian. "The Impact of Unemployment Insurance Benefit Levels on Recipiency." Journal of Business and Economic Statistics 13 (1995): 189-198.

Orr, Larry; Bloom, Howard; Bell, Stephen; Doolittle, Fred; Lin, Winston; and Cave, George. Does Training Work for the Disadvantaged? Evidence from the National JTPA Study. Washington, DC: Urban Institute Press, 1996.

O'Shea, Daniel, and King, Christopher. "The Workforce Investment Act of 1998: Restructuring Workforce Development Initiatives in States and Localities." Report No. 12. Albany, NY: Nelson Rockefeller Institute of Government.

Parsons, Donald. "Self-Screening in Targeted Public Transfer Programs." Journal of Political Economy 99 (1991): 859-876.

Remler, Dahlia; Rachlin, Jason; and Glied, Sherry. "What Can the Take-Up of Other Programs Teach Us About How to Improve Take-Up of Health Insurance Programs?" Working Paper No. 8185. Cambridge, MA: National Bureau of Economic Research, March 2001.

Riphahn, Regina. "Rational Poverty or Poor Rationality? The Take-Up of Social Assistance Benefits." Review of Income and Wealth 47 (2001): 379-398.

Sandell, Steven, and Rupp, Kalman. "Who is Served in JTPA Programs: Patterns of Participation and Intergroup Equity." Research Report RR-88-03. Washington, DC: National Commission for Employment Policy, February 1988.

Smith, Jeffrey. "Sampling Frame for the Eligible Non-Participant Sample. Unpublished manuscript. Chicago, IL: University of Chicago Department of Economics, 1994. 
Storer, Paul; Van Audenrode, Marc. "Unemployment Insurance Take-Up Rates in Canada: Facts, Determinants and Implications." Canadian Journal of Economics 28 (1995): 822-835.

Tienda, Marta, and Jensen, Leif. "Poverty and Minorities: A Quarter-Century Profile of Color and Socioeconomic Disadvantage." In Divided Opportunities: Minorities, Poverty and Social Policy, edited by Gary Sandefur and Marta Tienda, pp. 25-33. New York, NY: Plenum, 1988.

U.S. General Accounting Office. "Job Training Partnership Act: Racial and Gender Disparities in Services.” GAO/HRD-91-148. Washington, DC: U.S. General Accounting Office, 1991.

U.S. Department of Labor. Job Training Quarterly Survey: JTPA Title IIA and III Enrollments and Terminations During Program Year 1991 (July 1991-June 1992). Washington, DC: U.S. Department of Labor, Employment and Training Administration, Office of Strategic Planning and Policy Development, Division of Performance Management and Evaluation, 1993a.

U.S. Department of Labor. Title II Eligibility Documentation. Washington, DC: U.S Department of Labor, Employment and Training Administration, $1993 \mathrm{~b}$.

U.S. Department of Labor. Summary of Workforce Development Provisions of the Workforce Investment Act of 1998 (P.L. 105-220). Washington, DC: U.S. Department of Labor, Employment and Training Administration, 1998.

[http://www.doleta.gov/usworkforce/summarywia.htm]

Witte, Ann Dryden, and Queralt, Magaly. "Take-Up Rates and Trade Offs After the Age of Entitlement: Some Thoughts and Empirical Evidence for Child Care Subsidies." Working Paper No. 8886. Cambridge, MA: National Bureau of Economic Research, April 2002.

Zweimuller, Josef, and Winter-Ebmer, Rudolf. "Manpower Training Programmes and Employment Stability.” Economica 63 (1996): 113-130. 


\section{Table 1 \\ Definitions of Variables}

Site Indicators

Ft. Wayne, Jersey City and Providence indicate the site of residence. Corpus Christi is the omitted site.

Race and Ethnicity

Black, Hispanic and other race/ethnicity indicate race or ethnicity. Whites are the omitted group.

Age

Age categories indicate age at the time of eligibility determination or of the participation decision. The omitted category is $16-18$ years for youth and 22-29 years for adults.

Highest Grade Completed

Schooling categories indicate the highest grade of formal schooling completed. The omitted category is exactly twelve years.

Low English Ability

This variable indicates low ability in English. For the ENPs, this means that the person completed the baseline interview in a language other than English. For the controls, it means that the person indicated a language other than English in response to a survey question on language preference.

Marital Histories

These categories indicate the respondent's marital status history. The omitted category is single, never married. In Table 8, the divorced, widowed and separated category is broken up into two categories, one for persons who were last married from 1-24 months ago and one for persons who were last married more than 24 months ago.

Presence of Young Children

Children less than six indicates an own child less than six years old in the household.

Current AFDC Receipt

This variable indicates that the respondent was receiving benefits under the Aid to Families with Dependent Children program, either as a case head or as part of someone else's case.

Current Food Stamp (FS) Receipt

This variable indicates that the respondent was in a household receiving food stamps.

Current Labor Force Status

These variables indicate whether the respondent was employed, unemployed (not working but looking for work) or out of the labor force (not employed and not looking for work). The omitted category is currently employed.

\section{Labor Force Status Transitions}

These categories in Tables 5 and 8 indicate the two most recent labor force statuses in the seven months up to and including the month of the participation decision. The second status in each pattern indicates the labor force status at the time of the participation decision. The first status indicates the status of the most recent prior spell during the preceding six months. Thus, the pattern "employed $->$ unemployed" indicates someone who was unemployed at the time of the participation decision but whose most recent prior labor force status within the preceding six months was employed. Persons in the same labor force status for all seven months have repeated patterns of the form "OLF - > OLF". The omitted pattern is "employed - > employed", indicating persistent employment. In some cases, the "employed - > OLF" and "unemployed - > OLF" categories are collapsed due to small sample sizes.

Time Since Most Recent Employment

These categories indicate the number of months since the person was last employed. The omitted category is currently employed.

Family Income in the Last Year

These categories indicate total family earnings in the past year. The omitted category is less than $\$ 3000$. For some tables, the original six categories are combined into four due to small sample sizes. 
Table 2a

Determinants of JTPA Eligibility: Adults

\begin{tabular}{|c|c|c|c|c|}
\hline \multirow[b]{2}{*}{ Black } & \multicolumn{2}{|c|}{$\begin{array}{c}\text { Adult Males } \\
\text { Number of observations: } 80598\end{array}$} & \multicolumn{2}{|c|}{$\begin{array}{c}\text { Adult Females } \\
\text { Number of observations: } 89196\end{array}$} \\
\hline & 1.315 & {$[0.060]$} & 2.172 & {$[0.129]$} \\
\hline & $(0.034)$ & 0.000 & $(0.032)$ & 0.000 \\
\hline \multirow[t]{2}{*}{ Hispanic } & 1.070 & {$[0.048]$} & 2.270 & {$[0.136]$} \\
\hline & $(0.036)$ & 0.000 & $(0.030)$ & 0.000 \\
\hline \multirow[t]{2}{*}{ Other race-ethnicity } & 1.352 & {$[0.062]$} & 1.551 & {$[0.090]$} \\
\hline & $(0.087)$ & 0.000 & $(0.051)$ & 0.000 \\
\hline \multirow[t]{2}{*}{ Age 30-39 } & -0.860 & {$[-0.038]$} & 0.018 & {$[0.001]$} \\
\hline & $(0.030)$ & 0.000 & $(0.026)$ & 0.489 \\
\hline \multirow[t]{2}{*}{ Age 40-49 } & -0.939 & {$[-0.042]$} & 0.144 & {$[0.007]$} \\
\hline & $(0.040)$ & 0.000 & $(0.030)$ & 0.000 \\
\hline \multirow[t]{2}{*}{ Age $50-54$} & -1.586 & {$[-0.064]$} & 0.047 & {$[0.002]$} \\
\hline & $(0.049)$ & 0.000 & $(0.035)$ & 0.176 \\
\hline \multirow[t]{2}{*}{ Highest grade $<10$} & 0.737 & {$[0.033]$} & 0.974 & {$[0.060]$} \\
\hline & $(0.034)$ & 0.000 & $(0.029)$ & 0.000 \\
\hline \multirow[t]{2}{*}{ Highest grade 10-11 } & 0.292 & {$[0.012]$} & 0.514 & {$[0.031]$} \\
\hline & $(0.033)$ & 0.000 & $(0.028)$ & 0.000 \\
\hline \multirow[t]{2}{*}{ Highest grade 13-15 } & -0.231 & {$[-0.009]$} & -0.408 & {$[-0.022]$} \\
\hline & $(0.031)$ & 0.000 & $(0.025)$ & 0.000 \\
\hline \multirow[t]{2}{*}{ Highest grade $>15$} & -0.064 & {$[-0.003]$} & -1.652 & {$[-0.075]$} \\
\hline & $(0.036)$ & 0.074 & $(0.032)$ & 0.000 \\
\hline \multirow[t]{2}{*}{ Currently married } & 0.157 & {$[0.006]$} & 1.366 & {$[-0.074]$} \\
\hline & $(0.035)$ & 0.000 & $(0.029)$ & 0.000 \\
\hline \multirow[t]{2}{*}{ Div-Wid-Sep } & 0.177 & {$[0.007]$} & 0.043 & {$[0.003]$} \\
\hline & $(0.042)$ & 0.000 & $(0.031)$ & 0.162 \\
\hline \multirow[t]{2}{*}{ Child age $<6$ years } & -0.205 & {$[-0.008]$} & 0.646 & {$[0.035]$} \\
\hline & $(0.036)$ & 0.000 & $(0.027)$ & 0.000 \\
\hline \multirow[t]{2}{*}{ Family Income $3 \mathrm{~K}-6 \mathrm{~K}$} & 0.113 & {$[0.019]$} & -0.367 & {$[-0.039]$} \\
\hline & $(0.050)$ & 0.024 & $(0.044)$ & 0.000 \\
\hline \multirow[t]{2}{*}{ Family Income 6K-9K } & -1.814 & {$[-0.206]$} & -1.737 & {$[-0.154]$} \\
\hline & $(0.048)$ & 0.000 & $(0.043)$ & 0.000 \\
\hline \multirow[t]{2}{*}{ Family Income 9K-12K } & -3.103 & {$[-0.268]$} & -2.671 & {$[-0.214]$} \\
\hline & $(0.056)$ & 0.000 & $(0.043)$ & 0.000 \\
\hline \multirow[t]{2}{*}{ Family Income $12 \mathrm{~K}-15 \mathrm{~K}$} & -3.857 & {$[-0.295]$} & -3.318 & {$[-0.249]$} \\
\hline & $(0.056)$ & 0.000 & $(0.044)$ & 0.000 \\
\hline \multirow[t]{2}{*}{ Family Income $>15 \mathrm{~K}$} & -4.966 & {$[-0.331]$} & -4.461 & {$[-0.301]$} \\
\hline & $(0.048)$ & 0.000 & $(0.037)$ & 0.000 \\
\hline \multirow[t]{2}{*}{ Constant } & -0.474 & {$[0.000]$} & 4.714 & {$[0.000]$} \\
\hline & $(0.033)$ & 0.000 & $(0.043)$ & 0.000 \\
\hline
\end{tabular}

Source: Authors' calculations using person-month data from 1986 SIPP full panel.

Notes: Omitted categories in the logit are white, age 22-29, highest grade equals 12 , never married, no young children and family income less then $\$ 3,000$. Using the sample proportion eligible as the cutoff value, the within-sample prediction rates for adult males are 72.48 percent for eligibles and 91.10 percent for non-eligibles. The corresponding rates for adult females are 79.82 percent for eligibles and 88.32 percent for non-eligibles. 
Table 2b

Determinants of JTPA Eligibility: Youth

\begin{tabular}{|c|c|c|c|c|}
\hline \multirow{2}{*}{ Black } & \multicolumn{2}{|c|}{$\begin{array}{c}\text { Male Youth } \\
\text { Number of observations: } 10280\end{array}$} & \multicolumn{2}{|c|}{$\begin{array}{c}\text { Female Youth } \\
\text { Number of observations: } 11165\end{array}$} \\
\hline & 1.111 & {$[0.056]$} & 2.446 & {$[0.155]$} \\
\hline & $(0.164)$ & 0.000 & $(0.092)$ & 0.000 \\
\hline \multirow[t]{2}{*}{ Hispanic } & 2.255 & {$[0.121]$} & 1.114 & {$[0.068]$} \\
\hline & $(0.103)$ & 0.000 & $(0.076)$ & 0.000 \\
\hline \multirow[t]{2}{*}{ Other race-ethnicity } & 1.514 & {$[0.078]$} & 2.065 & [0.129] \\
\hline & $(0.195)$ & 0.000 & $(0.408)$ & 0.000 \\
\hline \multirow[t]{2}{*}{ Age 19-21 } & -0.434 & {$[-0.021]$} & 0.124 & {$[0.007]$} \\
\hline & $(0.082)$ & 0.000 & $(0.070)$ & 0.079 \\
\hline \multirow[t]{2}{*}{ Highest grade $<10$} & 1.959 & {$[0.100]$} & 0.915 & {$[0.057]$} \\
\hline & $(0.105)$ & 0.000 & $(0.107)$ & 0.000 \\
\hline \multirow[t]{2}{*}{ Highest grade 10-11 } & 1.469 & {$[0.074]$} & 0.134 & {$[0.008]$} \\
\hline & $(0.109)$ & 0.000 & $(0.086)$ & 0.118 \\
\hline \multirow[t]{2}{*}{ Highest grade $>12$} & -0.150 & {$[-0.007]$} & -0.617 & {$[-0.036]$} \\
\hline & $(0.107)$ & 0.160 & $(0.072)$ & 0.000 \\
\hline \multirow[t]{2}{*}{ Currently married } & -1.657 & {$[-0.068]$} & 0.609 & {$[0.036]$} \\
\hline & $(0.168)$ & 0.000 & $(0.082)$ & 0.000 \\
\hline \multirow[t]{2}{*}{ Div-Wid-Sep } & -3.041 & {$[-0.106]$} & 1.511 & [0.094] \\
\hline & $(0.380)$ & 0.000 & $(0.242)$ & 0.000 \\
\hline \multirow[t]{2}{*}{ Child age $<6$ years } & 1.161 & {$[0.061]$} & 1.468 & [0.090] \\
\hline & $(0.168)$ & 0.000 & $(0.081)$ & 0.000 \\
\hline \multirow[t]{2}{*}{ Family Income $3 \mathrm{~K}-6 \mathrm{~K}$} & -2.582 & {$[-0.387]$} & -1.306 & {$[-0.201]$} \\
\hline & $(0.153)$ & 0.000 & $(0.102)$ & 0.000 \\
\hline \multirow[t]{2}{*}{ Family Income $6 \mathrm{~K}-9 \mathrm{~K}$} & -4.370 & {$[-0.547]$} & -3.008 & {$[-0.436]$} \\
\hline & $(0.165)$ & 0.000 & $(0.126)$ & 0.000 \\
\hline \multirow[t]{2}{*}{ Family Income 9K-12K } & -4.595 & {$[-0.561]$} & -4.237 & {$[-0.552]$} \\
\hline & $(0.157)$ & 0.000 & $(0.144)$ & 0.000 \\
\hline \multirow[t]{2}{*}{ Family Income $12 \mathrm{~K}-15 \mathrm{~K}$} & -5.935 & {$[-0.631]$} & -5.057 & {$[-0.61]$} \\
\hline & $(0.204)$ & 0.000 & $(0.142)$ & 0.000 \\
\hline \multirow[t]{2}{*}{ Family Income $>15 \mathrm{~K}$} & -6.628 & {$[-0.660]$} & -6.585 & {$[-0.695]$} \\
\hline & $(0.153)$ & 0.000 & $(0.103)$ & 0.000 \\
\hline \multirow[t]{2}{*}{ Constant } & 6.246 & {$[0.000]$} & 6.164 & {$[0.000]$} \\
\hline & $(0.170)$ & 0.000 & $(0.117)$ & 0.000 \\
\hline
\end{tabular}

Source: Authors' calculations using person-month data from 1986 SIPP full panel.

Notes: Omitted categories in the logit are white, age 16-18, highest grade equals 12 , never married, no young children and family income less then $\$ 3,000$. Using the sample proportion eligible as the cutoff value, the within-sample prediction rates for male youth are 71.95 percent for eligibles and 90.67 percent for non-eligibles. The corresponding rates for female youth are 72.72 percent for eligibles and 91.32 percent for non-eligibles. 
Table 3

Awareness of and Self-Reported Eligibility for the JTPA Program: JTPA Eligible Non-Participants

\begin{tabular}{lccc}
\hline & $\begin{array}{c}\text { Self-Reported } \\
\text { Awareness of JTPA }\end{array}$ & $\begin{array}{c}\text { Self-Reported } \\
\text { Eligibility for JTPA } \\
\text { Conditional on Awareness }\end{array}$ & $\begin{array}{c}\text { Self-Reported } \\
\text { Eligibility for JTPA } \\
\text { Unconditional on Awareness }\end{array}$ \\
\hline Adult Males & 0.3539 & 0.3598 & 0.1274 \\
Adult Females & $(0.0167)$ & $(0.0311)$ & $(0.0116)$ \\
Male Youth & 0.4165 & 0.4594 & 0.1913 \\
& $(0.0124)$ & $(0.0214)$ & $(0.0099)$ \\
Female Youth & 0.4722 & 0.5672 & 0.2678 \\
& $(0.0373)$ & $(0.0610)$ & $(0.0330)$ \\
& 0.4667 & 0.5410 & 0.2525 \\
& $(0.0289)$ & $(0.0453)$ & $(0.0251)$ \\
\hline
\end{tabular}

Source: Authors' calculations using National JTPA Study data.

Notes: Respondents are coded as aware of JTPA if they report having heard of JTPA by its most common local name. Respondents are coded as self-reported eligibles if they are aware of JTPA and report that they believe themselves to be presently eligible for it. 
Table 4a

Determinants of JTPA Awareness Among JTPA Eligible Non-Participants: Adults

\begin{tabular}{|c|c|c|c|c|}
\hline \multirow{2}{*}{ Ft. Wayne } & \multicolumn{2}{|c|}{$\begin{array}{c}\text { Adult Males } \\
\text { Number of observations: } 1551\end{array}$} & \multicolumn{2}{|c|}{$\begin{array}{c}\text { Adult Females } \\
\text { Number of observations: } 2436\end{array}$} \\
\hline & 0.261 & {$[0.055]$} & -0.187 & {$[-0.039]$} \\
\hline 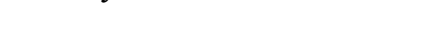 & $(0.233)$ & 0.264 & $(0.203)$ & 0.356 \\
\hline \multirow[t]{2}{*}{ Jersey City } & 0.071 & {$[0.015]$} & -0.174 & {$[-0.036]$} \\
\hline & $(0.210)$ & 0.736 & $(0.191)$ & 0.364 \\
\hline \multirow{2}{*}{ Providence } & -0.268 & {$[-0.054]$} & -0.683 & {$[-0.142]$} \\
\hline & $(0.231)$ & 0.245 & $(0.197)$ & 0.001 \\
\hline \multirow[t]{2}{*}{ Black } & 0.414 & [0.094] & 0.288 & [0.063] \\
\hline & $(0.272)$ & 0.128 & $(0.194)$ & 0.138 \\
\hline \multirow[t]{2}{*}{ Hispanic } & -0.486 & {$[-0.102]$} & -0.360 & {$[-0.077]$} \\
\hline & $(0.210)$ & 0.021 & $(0.185)$ & 0.051 \\
\hline \multirow[t]{2}{*}{ Other race-ethnicity } & -0.290 & {$[-0.063]$} & -0.348 & {$[-0.074]$} \\
\hline & $(0.279)$ & 0.298 & $(0.255)$ & 0.174 \\
\hline \multirow{2}{*}{ Low English ability } & -0.763 & {$[-0.147]$} & -1.334 & {$[-0.254]$} \\
\hline & $(0.180)$ & 0.000 & $(0.144)$ & 0.000 \\
\hline \multirow[t]{2}{*}{ Age $30-39$} & -0.345 & {$[-0.073]$} & -0.114 & {$[-0.024]$} \\
\hline & $(0.165)$ & 0.037 & $(0.137)$ & 0.405 \\
\hline \multirow{2}{*}{ Age $40-49$} & -0.372 & {$[-0.078]$} & -0.235 & {$[-0.050]$} \\
\hline & $(0.201)$ & 0.064 & $(0.174)$ & 0.177 \\
\hline \multirow[t]{2}{*}{ Age $50-54$} & 0.010 & {$[0.002]$} & -0.126 & {$[-0.027]$} \\
\hline & $(0.349)$ & 0.977 & $(0.253)$ & 0.619 \\
\hline \multirow{2}{*}{ Highest grade $<10$} & -0.476 & {$[-0.100]$} & -0.836 & {$[-0.180]$} \\
\hline & $(0.179)$ & 0.008 & $(0.135)$ & 0.000 \\
\hline \multirow[t]{2}{*}{ Highest grade 10-11 } & -0.144 & {$[-0.031]$} & -0.126 & {$[-0.028]$} \\
\hline & $(0.210)$ & 0.494 & $(0.173)$ & 0.468 \\
\hline \multirow{2}{*}{ Highest grade 13-15 } & 0.102 & {$[0.022]$} & -0.263 & {$[-0.058]$} \\
\hline & $(0.239)$ & 0.671 & $(0.201)$ & 0.190 \\
\hline \multirow[t]{2}{*}{ Highest grade $>15$} & -0.387 & {$[-0.082]$} & -0.646 & {$[-0.141]$} \\
\hline & $(0.279)$ & 0.166 & $(0.292)$ & 0.027 \\
\hline \multirow{2}{*}{ Currently married } & 0.019 & {$[0.004]$} & -0.239 & {$[-0.051]$} \\
\hline & $(0.181)$ & 0.918 & $(0.162)$ & 0.142 \\
\hline \multirow[t]{2}{*}{ Div-Wid-Sep } & 0.718 & {$[0.156]$} & 0.112 & [0.024] \\
\hline & $(0.273)$ & 0.009 & $(0.164)$ & 0.494 \\
\hline \multirow[t]{2}{*}{ Child age $<6$ years } & -0.079 & {$[-0.016]$} & -0.062 & {$[-0.013]$} \\
\hline & $(0.161)$ & 0.623 & $(0.130)$ & 0.635 \\
\hline \multirow[t]{2}{*}{ Current AFDC receipt } & 0.088 & [0.019] & -0.086 & {$[-0.018]$} \\
\hline & $(0.499)$ & 0.859 & $(0.218)$ & 0.694 \\
\hline \multirow[t]{2}{*}{ Current Food Stamp receipt } & 0.756 & {$[0.164]$} & 0.625 & [0.133] \\
\hline & $(0.251)$ & 0.003 & $(0.187)$ & 0.001 \\
\hline Currently unemployed & 0.805 & {$[0.176]$} & 0.628 & [0.136] \\
\hline & $(0.289)$ & 0.005 & $(0.250)$ & 0.012 \\
\hline Currently out of the labor force & -0.182 & {$[-0.037]$} & -0.221 & {$[-0.047]$} \\
\hline & $(0.258)$ & 0.481 & $(0.140)$ & 0.115 \\
\hline Family Income 3K-9K & -0.152 & {$[-0.030]$} & 0.604 & [0.129] \\
\hline & $(0.347)$ & 0.662 & $(0.239)$ & 0.012 \\
\hline Family Income $9 \mathrm{~K}-15 \mathrm{~K}$ & -0.070 & {$[-0.014]$} & 0.389 & {$[0.083]$} \\
\hline & $(0.343)$ & 0.838 & $(0.239)$ & 0.104 \\
\hline Family Income $>15 \mathrm{~K}$ & 0.377 & {$[0.080]$} & 0.156 & [0.033] \\
\hline & $(0.340)$ & 0.267 & $(0.215)$ & 0.469 \\
\hline Constant & -0.359 & {$[0.000]$} & 0.238 & {$[0.000]$} \\
\hline & $(0.393)$ & 0.361 & $(0.287)$ & 0.407 \\
\hline
\end{tabular}

Source: Authors' calculations using National JTPA Study data.

Notes: Omitted categories in the logit are Corpus Christi, white, age 22-29, highest grade equals 12, never married, no young children, not currently receiving AFDC, not currently receiving food stamps, currently employed, and family income less than $\$ 3,000$. Using the sample proportion aware of JTPA as the cutoff, the within-sample prediction rates for adult males are 63.29 percent for aware eligibles and 62.95 percent for unaware eligibles. The corresponding rates for adult females are 69.44 percent for aware eligibles and 61.82 percent for unaware eligibles. 
Table 4b

Determinants of JTPA Awareness Among JTPA Eligible Non-Participants: Youth

\begin{tabular}{|c|c|c|c|c|}
\hline \multirow{2}{*}{ Ft. Wayne } & \multicolumn{2}{|c|}{$\begin{array}{c}\text { Male Youth } \\
\text { Number of observations: } 530\end{array}$} & \multicolumn{2}{|c|}{$\begin{array}{c}\text { Female Youth } \\
\text { Number of observations: } 700\end{array}$} \\
\hline & 0.054 & {$[0.011]$} & 0.150 & {$[0.033]$} \\
\hline & $(0.661)$ & 0.935 & $(0.490)$ & 0.759 \\
\hline \multirow[t]{2}{*}{ Jersey City } & -0.147 & {$[-0.031]$} & -0.509 & [-0.111] \\
\hline & $(0.727)$ & 0.839 & $(0.461)$ & 0.270 \\
\hline \multirow[t]{2}{*}{ Providence } & -0.412 & {$[-0.087]$} & -0.686 & {$[-0.153]$} \\
\hline & $(0.666)$ & 0.536 & $(0.438)$ & 0.117 \\
\hline \multirow[t]{2}{*}{ Black } & 1.183 & {$[0.242]$} & 0.902 & {$[0.204]$} \\
\hline & (0.739) & 0.109 & $(0.464)$ & 0.052 \\
\hline \multirow[t]{2}{*}{ Hispanic } & 0.189 & {$[0.040]$} & 0.298 & {$[0.068]$} \\
\hline & $(0.652)$ & 0.772 & $(0.416)$ & 0.475 \\
\hline \multirow[t]{2}{*}{ Other race-ethnicity } & 1.348 & {$[0.277]$} & -0.813 & {$[-0.167]$} \\
\hline & (1.370) & 0.325 & $(0.610)$ & 0.183 \\
\hline \multirow[t]{2}{*}{ Low English ability } & -2.972 & {$[-0.439]$} & -2.373 & {$[-0.393]$} \\
\hline & $(0.751)$ & 0.000 & $(0.664)$ & 0.000 \\
\hline \multirow{2}{*}{ Age 19-21 } & -0.891 & {$[-0.187]$} & -0.212 & {$[-0.048]$} \\
\hline & $(0.528)$ & 0.091 & $(0.300)$ & 0.478 \\
\hline \multirow[t]{2}{*}{ Highest grade $<10$} & -0.025 & {$[-0.005]$} & -0.672 & {$[-0.153]$} \\
\hline & $(0.630)$ & 0.968 & $(0.368)$ & 0.068 \\
\hline \multirow[t]{2}{*}{ Highest grade 10-11 } & 0.280 & [0.059] & -0.077 & {$[-0.018]$} \\
\hline & $(0.592)$ & 0.636 & $(0.405)$ & 0.849 \\
\hline \multirow[t]{2}{*}{ Highest grade $>12$} & -0.254 & {$[-0.053]$} & 0.063 & {$[0.014]$} \\
\hline & (0.729) & 0.728 & $(0.496)$ & 0.898 \\
\hline \multirow{2}{*}{ Currently married } & 1.323 & {$[0.266]$} & 0.136 & {$[0.031]$} \\
\hline & $(0.819)$ & 0.106 & $(0.370)$ & 0.713 \\
\hline \multirow[t]{2}{*}{ Div-Wid-Sep } & -0.584 & [-0.119] & -0.951 & {$[-0.203]$} \\
\hline & $(0.830)$ & 0.482 & $(0.444)$ & 0.032 \\
\hline \multirow[t]{2}{*}{ Child age $<6$ years } & -0.242 & {$[-0.050]$} & -0.164 & {$[-0.037]$} \\
\hline & $(0.758)$ & 0.750 & $(0.323)$ & 0.613 \\
\hline \multirow[t]{2}{*}{ Current AFDC receipt } & -0.838 & {$[-0.170]$} & 0.329 & [0.073] \\
\hline & $(1.087)$ & 0.441 & $(0.420)$ & 0.433 \\
\hline \multirow[t]{2}{*}{ Current Food Stamp receipt } & 0.494 & {$[0.103]$} & -0.026 & {$[-0.006]$} \\
\hline & $(0.813)$ & 0.543 & $(0.410)$ & 0.950 \\
\hline \multirow[t]{2}{*}{ Currently unemployed } & 0.522 & {$[0.110]$} & 0.362 & [0.081] \\
\hline & $(0.575)$ & 0.363 & $(0.471)$ & 0.442 \\
\hline \multirow[t]{2}{*}{ Currently out of the labor force } & -0.990 & {$[-0.203]$} & 0.000 & {$[0.000]$} \\
\hline & $(0.594)$ & 0.095 & $(0.342)$ & 1.000 \\
\hline \multirow[t]{2}{*}{ Family Income 3K-9K } & -0.907 & [-0.188] & 0.040 & [0.009] \\
\hline & $(0.915)$ & 0.321 & $(0.441)$ & 0.928 \\
\hline \multirow[t]{2}{*}{ Family Income 9K-15K } & -0.395 & {$[-0.082]$} & -0.321 & {$[-0.072]$} \\
\hline & $(0.938)$ & 0.673 & $(0.555)$ & 0.563 \\
\hline \multirow[t]{2}{*}{ Family Income $>15 \mathrm{~K}$} & -0.703 & {$[-0.146]$} & -0.410 & {$[-0.092]$} \\
\hline & $(1.031)$ & 0.495 & $(0.534)$ & 0.442 \\
\hline \multirow[t]{2}{*}{ Constant } & 0.613 & {$[0.000]$} & 0.272 & {$[0.000]$} \\
\hline & $(1.019)$ & 0.547 & $(0.633)$ & 0.668 \\
\hline
\end{tabular}

Source: Authors' calculations using National JTPA Study data.

Notes: Omitted categories in the logit are Corpus Christi, white, age 16-18, highest grade equals 12, never married, no young children, not currently receiving AFDC, not currently receiving food stamps, currently employed, and family income less than \$3,000. Using the sample proportion aware of JTPA as the cutoff, the within-sample prediction rates for male youth are 72.31 percent for aware eligibles and 64.86 percent for unaware eligibles. The corresponding rates for female youth are 67.43 percent for aware eligibles and 53.64 percent for unaware eligibles. 
Table 5a

Determinants of Acceptance Into JTPA

Aware ENP and Control Samples: Adults

\begin{tabular}{|c|c|c|c|c|}
\hline \multirow[b]{2}{*}{ Ft. Wayne } & \multicolumn{2}{|c|}{$\begin{array}{c}\text { Adult Males } \\
\text { Number of observations: } 1024\end{array}$} & \multicolumn{2}{|c|}{$\begin{array}{c}\text { Adult Females } \\
\text { Number of observations: } 1520\end{array}$} \\
\hline & 2.334 & {$[0.117]$} & 1.878 & {$[0.118]$} \\
\hline & $(0.450)$ & 0.000 & $(0.256)$ & 0.000 \\
\hline \multirow[t]{2}{*}{ Jersey City } & 1.120 & {$[0.040]$} & 1.228 & {$[0.060]$} \\
\hline & $(0.482)$ & 0.020 & $(0.238)$ & 0.000 \\
\hline \multirow[t]{2}{*}{ Providence } & 1.547 & {$[0.054]$} & 1.720 & [0.084] \\
\hline & $(0.507)$ & 0.002 & $(0.280)$ & 0.000 \\
\hline \multirow[t]{2}{*}{ Black } & 0.159 & {$[0.008]$} & -0.060 & {$[-0.003]$} \\
\hline & $(0.304)$ & 0.600 & (0.199) & 0.763 \\
\hline \multirow[t]{2}{*}{ Hispanic } & -0.170 & {$[-0.007]$} & 0.964 & {$[0.067]$} \\
\hline & $(0.442)$ & 0.701 & $(0.240)$ & 0.000 \\
\hline \multirow[t]{2}{*}{ Other race-ethnicity } & 1.228 & {$[0.079]$} & -0.169 & {$[-0.008]$} \\
\hline & $(0.455)$ & 0.007 & $(0.494)$ & 0.732 \\
\hline \multirow[t]{2}{*}{ Age $30-39$} & -0.564 & {$[-0.028]$} & -0.291 & {$[-0.016]$} \\
\hline & $(0.263)$ & 0.032 & $(0.160)$ & 0.069 \\
\hline \multirow[t]{2}{*}{ Age $40-49$} & -0.836 & {$[-0.038]$} & -0.226 & {$[-0.013]$} \\
\hline & $(0.396)$ & 0.035 & $(0.224)$ & 0.313 \\
\hline \multirow[t]{2}{*}{ Age $50-54$} & -0.766 & {$[-0.036]$} & -0.276 & {$[-0.016]$} \\
\hline & $(0.518)$ & 0.139 & $(0.334)$ & 0.408 \\
\hline \multirow[t]{2}{*}{ Highest grade $<10$} & -0.950 & {$[-0.040]$} & -0.194 & {$[-0.010]$} \\
\hline & $(0.341)$ & 0.005 & $(0.172)$ & 0.258 \\
\hline \multirow[t]{2}{*}{ Highest grade $10-11$} & -0.103 & {$[-0.006]$} & -0.112 & {$[-0.006]$} \\
\hline & $(0.331)$ & 0.755 & $(0.184)$ & 0.543 \\
\hline \multirow[t]{2}{*}{ Highest grade $13-15$} & 0.327 & {$[0.020]$} & 0.413 & {$[0.027]$} \\
\hline & $(0.332)$ & 0.325 & $(0.208)$ & 0.047 \\
\hline \multirow[t]{2}{*}{ Highest grade $>15$} & -1.420 & {$[-0.053]$} & -0.500 & {$[-0.024]$} \\
\hline & $(0.550)$ & 0.010 & $(0.767)$ & 0.515 \\
\hline Currently married & -0.875 & {$[-0.043]$} & -0.909 & {$[-0.042]$} \\
\hline & $(0.314)$ & 0.005 & $(0.214)$ & 0.000 \\
\hline Div-Wid-Sep & -0.571 & {$[-0.031]$} & 0.142 & {$[0.010]$} \\
\hline & $(0.316)$ & 0.071 & $(0.167)$ & 0.398 \\
\hline Child age $<6$ years & -0.166 & {$[-0.007]$} & -0.185 & {$[-0.010]$} \\
\hline & $(0.349)$ & 0.634 & $(0.159)$ & 0.245 \\
\hline Current AFDC receipt & -1.545 & {$[-0.047]$} & -0.975 & {$[-0.050]$} \\
\hline & $(0.691)$ & 0.025 & $(0.232)$ & 0.000 \\
\hline Current Food Stamp receipt & 0.189 & {$[0.009]$} & 0.205 & {$[0.012]$} \\
\hline & $(0.323)$ & 0.558 & $(0.191)$ & 0.282 \\
\hline Unemployed -> Employed & 1.752 & {$[0.068]$} & 1.722 & {$[0.080]$} \\
\hline & $(0.390)$ & 0.000 & $(0.325)$ & 0.000 \\
\hline OLF -> Employed & 2.372 & {$[0.120]$} & 1.122 & {$[0.039]$} \\
\hline & $(0.447)$ & 0.000 & $(0.370)$ & 0.002 \\
\hline Employed -> Unemployed & 3.861 & {$[0.328]$} & 2.782 & {$[0.210]$} \\
\hline & $(0.430)$ & 0.000 & $(0.277)$ & 0.000 \\
\hline Unemployed -> Unemployed & 2.615 & {$[0.146]$} & 2.862 & {$[0.223]$} \\
\hline & $(0.536)$ & 0.000 & $(0.320)$ & 0.000 \\
\hline OLF -> Unemployed & 4.048 & {$[0.360]$} & 2.326 & {$[0.144]$} \\
\hline & $(0.566)$ & 0.000 & $(0.324)$ & 0.000 \\
\hline Employed or Unemployed -> OLF & 5.421 & {$[0.610]$} & & \\
\hline & $(0.937)$ & 0.000 & & \\
\hline Employed -> OLF & & & 1.400 & {$[0.055]$} \\
\hline & & & $(0.314)$ & 0.000 \\
\hline Unemployed -> OLF & & & 2.242 & {$[0.134]$} \\
\hline & & & $(0.452)$ & 0.000 \\
\hline OLF $->$ OLF & 1.550 & {$[0.055]$} & 1.093 & {$[0.037]$} \\
\hline & $(0.556)$ & 0.005 & $(0.260)$ & 0.000 \\
\hline Family Income 3K-9K & -1.196 & {$[-0.075]$} & 0.269 & {$[0.016]$} \\
\hline & $(0.531)$ & 0.024 & $(0.232)$ & 0.246 \\
\hline Family Income 9K-15K & -0.448 & {$[-0.034]$} & -0.023 & {$[-0.001]$} \\
\hline & $(0.480)$ & 0.351 & $(0.339)$ & 0.946 \\
\hline Family Income $>15 \mathrm{~K}$ & -1.895 & {$[-0.098]$} & 0.034 & {$[0.002]$} \\
\hline & $(0.507)$ & 0.000 & $(0.313)$ & 0.914 \\
\hline Constant & -3.385 & {$[0.000]$} & -4.857 & {$[0.000]$} \\
\hline & $(0.564)$ & 0.000 & $(0.385)$ & 0.000 \\
\hline
\end{tabular}

Source: Authors' calculations using National JTPA Study data.

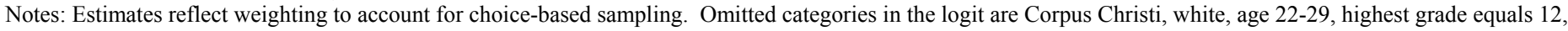

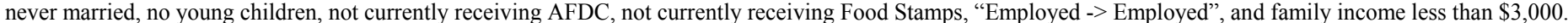

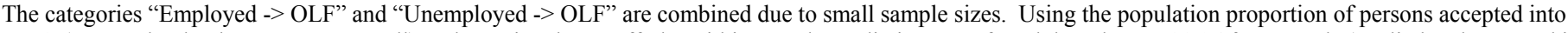

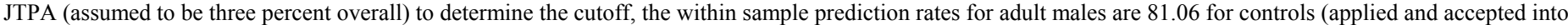
JTPA) and 81.38 for ENPs (did not apply or not accepted into JTPA). The corresponding rates for adult females are 65.94 for controls and 71.43 for ENPs. 
Table 5b

Determinants of Acceptance Into JTPA

Aware ENP and Control Samples: Youth

\begin{tabular}{|c|c|c|c|c|}
\hline \multirow{2}{*}{ Ft. Wayne } & \multicolumn{2}{|c|}{$\begin{array}{c}\text { Male Youth } \\
\text { Number of observations: } 436\end{array}$} & \multicolumn{2}{|c|}{$\begin{array}{c}\text { Female Youth } \\
\text { Number of observations: } 540\end{array}$} \\
\hline & 2.268 & {$[0.127]$} & 0.750 & {$[0.040]$} \\
\hline & $(0.647)$ & 0.000 & $(0.506)$ & 0.139 \\
\hline \multirow[t]{2}{*}{ Jersey City } & 1.445 & {$[0.060]$} & 0.462 & {$[0.022]$} \\
\hline & $(0.649)$ & 0.026 & $(0.545)$ & 0.396 \\
\hline \multirow[t]{2}{*}{ Providence } & 3.627 & {$[0.246]$} & 1.218 & {$[0.067]$} \\
\hline & $(0.632)$ & 0.000 & $(0.471)$ & 0.010 \\
\hline \multirow{2}{*}{ Black } & -0.793 & {$[-0.030]$} & 0.227 & {$[0.011]$} \\
\hline & $(0.515)$ & 0.124 & $(0.434)$ & 0.601 \\
\hline \multirow[t]{2}{*}{ Hispanic } & 0.717 & {$[0.046]$} & 0.097 & {$[0.005]$} \\
\hline & $(0.628)$ & 0.254 & $(0.439)$ & 0.825 \\
\hline \multirow[t]{2}{*}{ Other race-ethnicity } & -4.207 & {$[-0.080]$} & 0.971 & {$[0.064]$} \\
\hline & $(1.252)$ & 0.001 & $(0.798)$ & 0.223 \\
\hline \multirow[t]{2}{*}{ Age 19-21 } & 0.285 & {$[0.013]$} & -0.451 & {$[-0.024]$} \\
\hline & $(0.460)$ & 0.536 & $(0.328)$ & 0.169 \\
\hline \multirow[t]{2}{*}{ Highest grade $<10$} & -0.104 & {$[-0.005]$} & -0.028 & {$[-0.001]$} \\
\hline & $(0.508)$ & 0.838 & $(0.421)$ & 0.947 \\
\hline \multirow[t]{2}{*}{ Highest grade $10-11$} & -0.187 & {$[-0.009]$} & -0.392 & {$[-0.018]$} \\
\hline & $(0.475)$ & 0.693 & $(0.440)$ & 0.373 \\
\hline \multirow[t]{2}{*}{ Highest grade $>12$} & 0.472 & {$[0.028]$} & 0.236 & [0.014] \\
\hline & $(0.845)$ & 0.576 & $(0.441)$ & 0.592 \\
\hline \multirow[t]{2}{*}{ Currently married } & -1.225 & {$[-0.042]$} & -0.527 & {$[-0.022]$} \\
\hline & $(0.637)$ & 0.055 & $(0.436)$ & 0.227 \\
\hline \multirow[t]{2}{*}{ Div-Wid-Sep } & 0.155 & [0.009] & 0.316 & {$[0.018]$} \\
\hline & $(1.226)$ & 0.899 & $(0.662)$ & 0.633 \\
\hline \multirow[t]{2}{*}{ Current AFDC Receipt } & -1.455 & {$[-0.043]$} & -0.934 & {$[-0.007]$} \\
\hline & $(0.980)$ & 0.137 & $(0.399)$ & 0.019 \\
\hline \multirow[t]{2}{*}{ Current Food Stamp receipt } & 0.555 & {$[-0.043]$} & 1.311 & {$[-0.042]$} \\
\hline & $(0.580)$ & 0.339 & $(0.370)$ & 0.000 \\
\hline \multirow[t]{2}{*}{ Child age $<6$ years } & -1.294 & {$[0.030]$} & -0.139 & {$[0.083]$} \\
\hline & $(0.676)$ & 0.056 & $(0.339)$ & 0.681 \\
\hline \multirow[t]{2}{*}{ Unemployed -> Employed } & 2.110 & {$[0.120]$} & 1.776 & {$[0.059]$} \\
\hline & $(0.629)$ & 0.001 & $(0.564)$ & 0.002 \\
\hline OLF -> Employed & -1.331 & {$[-0.021]$} & 2.243 & {$[0.095]$} \\
\hline & $(0.890)$ & 0.135 & $(0.597)$ & 0.000 \\
\hline Employed -> Unemployed & 2.087 & {$[0.118]$} & 3.648 & [0.293] \\
\hline & $(0.537)$ & 0.000 & $(0.664)$ & 0.000 \\
\hline Unemployed -> Unemployed & 2.211 & {$[0.130]$} & 2.638 & {$[0.137]$} \\
\hline & $(0.706)$ & 0.002 & $(0.591)$ & 0.000 \\
\hline OLF -> Unemployed & 1.285 & {$[0.054]$} & 3.292 & {$[0.229]$} \\
\hline & $(0.764)$ & 0.093 & $(0.614)$ & 0.000 \\
\hline Employed or Unemployed -> OLF & 1.959 & {$[0.106]$} & & \\
\hline & $(0.806)$ & 0.015 & & \\
\hline Employed $->$ OLF & & & 1.462 & {$[0.041]$} \\
\hline & & & $(0.498)$ & 0.003 \\
\hline Unemployed -> OLF & & & 0.845 & {$[0.017]$} \\
\hline & & & $(0.886)$ & 0.340 \\
\hline OLF $->$ OLF & 2.387 & {$[0.150]$} & 1.201 & {$[0.030]$} \\
\hline & $(0.699)$ & 0.001 & $(0.549)$ & 0.029 \\
\hline Family Income 3K-9K & 3.867 & [0.309] & -0.386 & {$[-0.015]$} \\
\hline & $(0.748)$ & 0.000 & $(0.536)$ & 0.472 \\
\hline Family Income 9K-15K & 1.552 & {$[0.055]$} & 0.261 & {$[0.013]$} \\
\hline & $(0.746)$ & 0.038 & $(0.691)$ & 0.706 \\
\hline Family Income $>15 \mathrm{~K}$ & 1.011 & {$[0.028]$} & 1.765 & [0.149] \\
\hline & $(0.764)$ & 0.186 & $(0.535)$ & 0.001 \\
\hline Constant & -6.787 & {$[0.000]$} & -4.732 & {$[0.000]$} \\
\hline & $(0.976)$ & 0.000 & $(0.753)$ & 0.000 \\
\hline
\end{tabular}

Source: Authors' calculations using National JTPA Study data.

Notes: Estimates reflect weighting to account for choice-based sampling. Omitted categories in the logit are Corpus Christi, white, age 16-18, highest grade equals 12, never married, no young children, not currently receiving AFDC, not currently receiving Food Stamps, "Employed -> Employed", and family income less than $\$ 3,000$. The categories "Employed -> OLF" and "Unemployed -> OLF" are combined due to small sample sizes. Using the population proportion of persons accepted into JTPA (assumed to be three percent overall) as the cutoff, the within sample prediction rates for male youth are 68.66 for controls (applied and accepted into JTPA) and 76.47 for ENPs (did not apply or not accepted into JTPA). The corresponding rates for female youth are 67.91 for controls and 69.57 for ENPs. 
Table 6a

Determinants of Enrollment into JTPA

Experimental Treatment Group: Adults

\begin{tabular}{|c|c|c|c|c|}
\hline \multirow{2}{*}{ Ft. Wayne } & \multicolumn{2}{|c|}{$\begin{array}{c}\text { Adult Males } \\
\text { Number of Observations: } 1886\end{array}$} & \multicolumn{2}{|c|}{$\begin{array}{c}\text { Adult Females } \\
\text { Number of Observations: } 2012\end{array}$} \\
\hline & -0.692 & {$[-0.163]$} & -1.030 & {$[-0.232]$} \\
\hline & $(0.177)$ & 0.000 & $(0.177)$ & 0.000 \\
\hline \multirow[t]{2}{*}{ Jersey City } & -1.157 & {$[-0.274]$} & -1.280 & {$[-0.292]$} \\
\hline & $(0.204)$ & 0.000 & $(0.195)$ & 0.000 \\
\hline \multirow[t]{2}{*}{ Providence } & 0.447 & {$[0.090]$} & -0.563 & {$[-0.121]$} \\
\hline & $(0.198)$ & 0.024 & $(0.199)$ & 0.005 \\
\hline \multirow[t]{2}{*}{ Black } & -0.180 & {$[-0.041]$} & -0.240 & {$[-0.056]$} \\
\hline & $(0.129)$ & 0.165 & $(0.132)$ & 0.069 \\
\hline \multirow[t]{2}{*}{ Hispanic } & 0.271 & {$[0.060]$} & 0.196 & {$[0.045]$} \\
\hline & $(0.181)$ & 0.135 & $(0.176)$ & 0.265 \\
\hline \multirow[t]{2}{*}{ Other race-ethnicity } & -0.024 & {$[-0.005]$} & 0.637 & {$[0.141]$} \\
\hline & $(0.283)$ & 0.933 & $(0.350)$ & 0.068 \\
\hline \multirow[t]{2}{*}{ Low English ability } & 0.288 & {$[0.065]$} & -0.082 & {$[-0.019]$} \\
\hline & $(0.241)$ & 0.231 & $(0.210)$ & 0.697 \\
\hline \multirow[t]{2}{*}{ Age $30-39$} & -0.105 & {$[-0.023]$} & 0.056 & {$[0.013]$} \\
\hline & $(0.114)$ & 0.358 & $(0.115)$ & 0.629 \\
\hline \multirow[t]{2}{*}{ Age $40-49$} & -0.483 & {$[-0.109]$} & -0.324 & {$[-0.075]$} \\
\hline & $(0.165)$ & 0.003 & $(0.160)$ & 0.042 \\
\hline \multirow[t]{2}{*}{ Age $50-54$} & -0.370 & {$[-0.083]$} & 0.055 & {$[0.013]$} \\
\hline & $(0.285)$ & 0.195 & $(0.305)$ & 0.856 \\
\hline \multirow{2}{*}{ Highest grade $<10$} & -0.129 & {$[-0.029]$} & -0.168 & {$[-0.038]$} \\
\hline & $(0.140)$ & 0.357 & $(0.132)$ & 0.203 \\
\hline \multirow[t]{2}{*}{ Highest grade 10-11 } & -0.210 & {$[-0.047]$} & -0.041 & {$[-0.009]$} \\
\hline & $(0.130)$ & 0.105 & $(0.124)$ & 0.738 \\
\hline \multirow[t]{2}{*}{ Highest grade 13-15 } & 0.001 & {$[0.000]$} & -0.035 & {$[-0.008]$} \\
\hline & $(0.156)$ & 0.993 & $(0.151)$ & 0.817 \\
\hline \multirow[t]{2}{*}{ Highest grade $>15$} & -0.204 & {$[-0.046]$} & -0.216 & {$[-0.049]$} \\
\hline & $(0.260)$ & 0.432 & $(0.302)$ & 0.475 \\
\hline \multirow[t]{2}{*}{ Currently married } & 0.325 & {$[0.073]$} & 0.106 & {$[0.024]$} \\
\hline & $(0.154)$ & 0.034 & $(0.167)$ & 0.525 \\
\hline \multirow{2}{*}{ Div-Wid-Sep } & 0.273 & {$[0.061]$} & 0.203 & {$[0.046]$} \\
\hline & $(0.135)$ & 0.044 & $(0.121)$ & 0.093 \\
\hline \multirow[t]{2}{*}{ Child age $<6$ years } & 0.109 & {$[0.024]$} & 0.336 & {$[0.077]$} \\
\hline & $(0.154)$ & 0.480 & $(0.115)$ & 0.004 \\
\hline Current AFDC Receipt & 0.132 & {$[0.029]$} & 0.158 & {$[0.036]$} \\
\hline & $(0.353)$ & 0.709 & $(0.138)$ & 0.253 \\
\hline Current Food Stamp Receipt & -0.070 & {$[-0.016]$} & -0.237 & {$[-0.054]$} \\
\hline & $(0.132)$ & 0.595 & $(0.117)$ & 0.044 \\
\hline Employed 1-6 months ago & -0.060 & {$[-0.013]$} & 0.308 & {$[0.071]$} \\
\hline & $(0.164)$ & 0.715 & $(0.150)$ & 0.040 \\
\hline Employed 7-12 months ago & -0.058 & {$[-0.013]$} & 0.216 & {$[0.050]$} \\
\hline & $(0.210)$ & 0.781 & $(0.198)$ & 0.276 \\
\hline Employed $>12$ months ago & 0.032 & {$[0.007]$} & 0.287 & {$[0.066]$} \\
\hline & $(0.211)$ & 0.880 & $(0.177)$ & 0.106 \\
\hline Never employed & -0.085 & {$[-0.019]$} & 0.061 & {$[0.014]$} \\
\hline & $(0.227)$ & 0.709 & $(0.192)$ & 0.750 \\
\hline Family Income $3 \mathrm{~K}-9 \mathrm{~K}$ & -0.108 & {$[-0.024]$} & 0.211 & [0.049] \\
\hline & $(0.122)$ & 0.378 & $(0.118)$ & 0.073 \\
\hline Family Income 9K-15K & 0.057 & {$[0.013]$} & 0.441 & {$[0.100]$} \\
\hline & $(0.165)$ & 0.728 & $(0.166)$ & 0.008 \\
\hline Family Income $>15 \mathrm{~K}$ & 0.483 & {$[0.105]$} & 0.599 & {$[0.135]$} \\
\hline & $(0.204)$ & 0.018 & $(0.256)$ & 0.019 \\
\hline Constant & 0.498 & {$[0.000]$} & 0.596 & {$[0.000]$} \\
\hline & $(0.365)$ & 0.172 & $(0.350)$ & 0.088 \\
\hline
\end{tabular}

Source: Authors' calculations using National JTPA Study data.

Notes: Estimation includes observations with imputed covariates due to relative high levels of item non-response. Omitted categories in the logit are Corpus Christi, white, normal English ability, age 22-29, highest grade equals 12, never married, no young children, not currently receiving AFDC, not currently receiving Food Stamps, currently employed, and family income less than $\$ 3,000$. Using the sample proportion of accepted applicants enrolled into JTPA as the cutoff, the within-sample prediction rates for adult males are 62.48 percent for enrollees and 67.94 percent for nonenrollees. The corresponding rates for adult females are 57.64 percent for enrollees and 66.41 percent for non-enrollees. 
Table 6b

Determinants of Enrollment into JTPA

Experimental Treatment Group: Youth

\begin{tabular}{|c|c|c|c|c|}
\hline \multirow{3}{*}{ Ft. Wayne } & \multicolumn{2}{|c|}{$\begin{array}{c}\text { Male Youth } \\
\text { Number of Observations: } 923\end{array}$} & \multicolumn{2}{|c|}{$\begin{array}{c}\text { Female Youth } \\
\text { Number of Observations: } 962\end{array}$} \\
\hline & -1.213 & {$[-0.241]$} & -1.266 & {$[-0.253]$} \\
\hline & $(0.273)$ & 0.000 & $(0.271)$ & 0.000 \\
\hline \multirow[t]{2}{*}{ Jersey City } & -1.350 & {$[-0.274]$} & -1.557 & {$[-0.324]$} \\
\hline & $(0.297)$ & 0.000 & $(0.266)$ & 0.000 \\
\hline \multirow{2}{*}{ Providence } & -0.554 & {$[-0.096]$} & -0.597 & {$[-0.103]$} \\
\hline & $(0.276)$ & 0.045 & $(0.276)$ & 0.031 \\
\hline \multirow[t]{2}{*}{ Black } & -0.291 & {$[-0.061]$} & -0.223 & {$[-0.048]$} \\
\hline & $(0.191)$ & 0.127 & $(0.210)$ & 0.287 \\
\hline \multirow[t]{2}{*}{ Hispanic } & -0.044 & {$[-0.009]$} & 0.212 & {$[0.043]$} \\
\hline & $(0.241)$ & 0.854 & $(0.250)$ & 0.396 \\
\hline \multirow[t]{2}{*}{ Other race-ethnicity } & & & 0.531 & {$[0.102]$} \\
\hline & & & $(0.533)$ & 0.319 \\
\hline \multirow[t]{2}{*}{ Low English ability } & -0.360 & {$[-0.070]$} & 0.113 & {$[0.023]$} \\
\hline & $(0.392)$ & 0.358 & $(0.391)$ & 0.773 \\
\hline \multirow[t]{2}{*}{ Age 19-21 } & -0.429 & {$[-0.087]$} & 0.036 & {$[0.007]$} \\
\hline & $(0.175)$ & 0.014 & $(0.167)$ & 0.830 \\
\hline \multirow[t]{2}{*}{ Highest grade $<10$} & 0.060 & {$[0.012]$} & 0.084 & {$[0.017]$} \\
\hline & $(0.213)$ & 0.779 & $(0.204)$ & 0.680 \\
\hline \multirow{2}{*}{ Highest grade 10-11 } & 0.000 & {$[0.000]$} & 0.131 & {$[0.027]$} \\
\hline & $(0.192)$ & 0.999 & $(0.183)$ & 0.476 \\
\hline \multirow[t]{2}{*}{ Highest grade $>12$} & 0.064 & {$[0.013]$} & -0.111 & {$[-0.023]$} \\
\hline & $(0.405)$ & 0.874 & $(0.355)$ & 0.755 \\
\hline \multirow{2}{*}{ Currently married } & 0.138 & {$[0.028]$} & -0.052 & {$[-0.011]$} \\
\hline & $(0.335)$ & 0.680 & $(0.302)$ & 0.864 \\
\hline \multirow[t]{2}{*}{ Div-Wid-Sep } & 0.338 & {$[0.066]$} & 0.424 & {$[0.083]$} \\
\hline & $(0.729)$ & 0.643 & $(0.381)$ & 0.267 \\
\hline \multirow[t]{2}{*}{ Child age $<6$ years } & 0.279 & {$[0.055]$} & 0.092 & [0.019] \\
\hline & $(0.313)$ & 0.373 & $(0.193)$ & 0.632 \\
\hline \multirow[t]{2}{*}{ Current AFDC Receipt } & -0.699 & {$[-0.151]$} & 0.135 & {$[0.028]$} \\
\hline & $(0.336)$ & 0.038 & $(0.241)$ & 0.576 \\
\hline \multirow{2}{*}{ Current Food Stamp Receipt } & 0.157 & {$[0.032]$} & -0.060 & {$[-0.012]$} \\
\hline & $(0.219)$ & 0.474 & $(0.195)$ & 0.757 \\
\hline \multirow[t]{2}{*}{ Employed 1-6 months ago } & -0.228 & {$[-0.044]$} & -0.220 & {$[-0.044]$} \\
\hline & $(0.254)$ & 0.370 & $(0.239)$ & 0.357 \\
\hline \multirow[t]{2}{*}{ Employed 7-12 months ago } & -0.467 & {$[-0.093]$} & -0.415 & {$[-0.085]$} \\
\hline & $(0.341)$ & 0.170 & $(0.332)$ & 0.211 \\
\hline \multirow[t]{2}{*}{ Employed $>12$ months ago } & -0.413 & {$[-0.082]$} & -0.353 & {$[-0.072]$} \\
\hline & $(0.409)$ & 0.312 & $(0.328)$ & 0.282 \\
\hline \multirow{2}{*}{ Never employed } & -0.657 & {$[-0.134]$} & -0.276 & {$[-0.055]$} \\
\hline & $(0.302)$ & 0.030 & $(0.280)$ & 0.324 \\
\hline Family Income 3K-9K & -0.057 & {$[-0.012]$} & 0.086 & {$[0.018]$} \\
\hline & $(0.185)$ & 0.758 & $(0.176)$ & 0.627 \\
\hline Family Income 9K-15K & -0.463 & {$[-0.099]$} & 0.207 & {$[0.042]$} \\
\hline & $(0.234)$ & 0.048 & $(0.272)$ & 0.446 \\
\hline Family Income $>15 \mathrm{~K}$ & 0.301 & {$[0.058]$} & 0.116 & {$[0.024]$} \\
\hline & $(0.278)$ & 0.279 & $(0.280)$ & 0.680 \\
\hline Constant & 2.505 & {$[0.000]$} & 1.453 & {$[0.000]$} \\
\hline & $(0.586)$ & 0.000 & $(0.557)$ & 0.009 \\
\hline
\end{tabular}

Source: Authors' calculations using National JTPA Study data.

Notes: Estimation includes observations with imputed covariates due to relative high levels of item non-response. Omitted categories in the logit are Corpus Christi, white, normal English ability, age 16-18, highest grade equals 12, never married, no young children, not currently receiving AFDC, not currently receiving Food Stamps, currently employed, and family income less than $\$ 3,000$. Using the sample proportion of accepted applicants enrolled into JTPA as the cutoff, the within-sample prediction rates for male youth are 60.20 percent for enrollees and 65.08 percent for nonenrollees. The corresponding rates for female youth are 57.51 percent for enrollees and 68.75 percent for non-enrollees. 


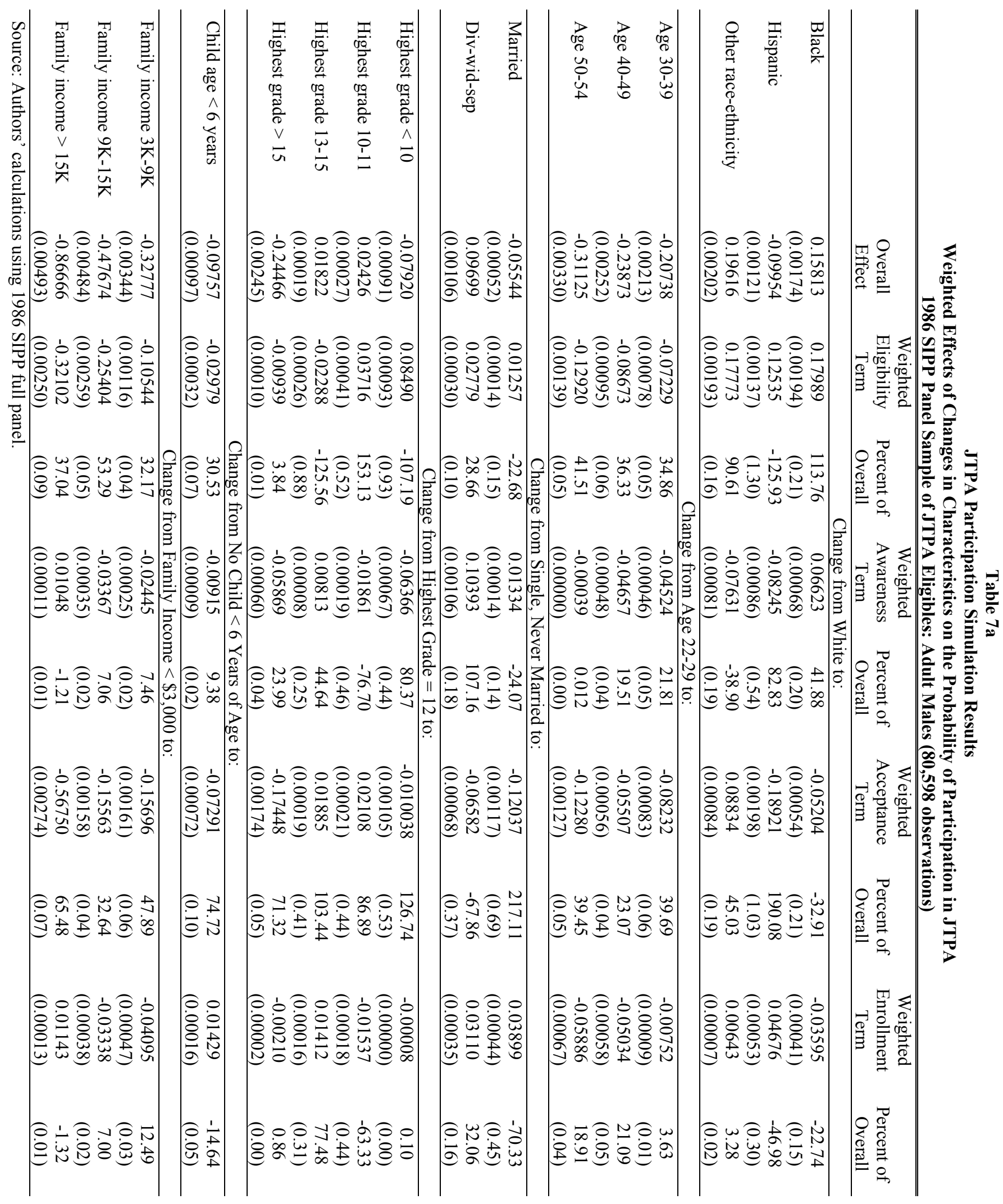


Table 7a (continued)

JTPA Participation Simulation Results

Unweighted Effects of Changes in Characteristics on the Probability of Participation in JTPA 1986 SIPP Panel Sample of JTPA Eligibles: Adult Males (80,598 observations)

\begin{tabular}{|c|c|c|c|c|c|}
\hline & $\begin{array}{l}\text { Overall } \\
\text { Effect }\end{array}$ & $\begin{array}{c}\text { Unweighted } \\
\text { Eligibility Term }\end{array}$ & $\begin{array}{c}\text { Unweighted } \\
\text { Awareness } \\
\text { Term }\end{array}$ & $\begin{array}{c}\text { Unweighted } \\
\text { Acceptance } \\
\text { Term }\end{array}$ & $\begin{array}{c}\text { Unweighted } \\
\text { Enrollment Term }\end{array}$ \\
\hline \multicolumn{6}{|c|}{ Change from White to: } \\
\hline Black & $\begin{array}{c}0.15813 \\
(0.00174)\end{array}$ & $\begin{array}{c}0.06693 \\
(0.00018)\end{array}$ & $\begin{array}{c}0.11697 \\
(0.00005)\end{array}$ & $\begin{array}{l}-0.00968 \\
(0.00005)\end{array}$ & $\begin{array}{l}-0.07041 \\
(0.00005)\end{array}$ \\
\hline Hispanic & $\begin{array}{l}-0.09954 \\
(0.00121)\end{array}$ & $\begin{array}{c}0.04687 \\
(0.00013)\end{array}$ & $\begin{array}{l}-0.14448 \\
(0.00011)\end{array}$ & $\begin{array}{l}-0.03352 \\
(0.00020)\end{array}$ & $\begin{array}{c}0.08792 \\
(0.00000)\end{array}$ \\
\hline \multirow[t]{2}{*}{ Other race-ethnicity } & $\begin{array}{c}0.19616 \\
(0.00202)\end{array}$ & $\begin{array}{c}0.06753 \\
(0.00020)\end{array}$ & $\begin{array}{l}-0.13250 \\
(0.00009)\end{array}$ & $\begin{array}{c}0.01774 \\
(0.00009)\end{array}$ & $\begin{array}{c}0.01230 \\
(0.00000)\end{array}$ \\
\hline & \multicolumn{5}{|c|}{ Change from Age 22-29 to: } \\
\hline Age 30-39 & $\begin{array}{c}-0.20738 \\
(0.00213)\end{array}$ & $\begin{array}{l}-0.02757 \\
(0.00007)\end{array}$ & $\begin{array}{l}-0.08029 \\
(0.00004)\end{array}$ & $\begin{array}{c}-0.01583 \\
(0.00009)\end{array}$ & $\begin{array}{l}-0.01445 \\
(0.00000)\end{array}$ \\
\hline Age 40-49 & $\begin{array}{c}-0.23873 \\
(0.00252)\end{array}$ & $\begin{array}{l}-0.03277 \\
(0.00009)\end{array}$ & $\begin{array}{l}-0.08247 \\
(0.00004)\end{array}$ & $\begin{array}{l}-0.01053 \\
(0.00006)\end{array}$ & $\begin{array}{l}-0.09820 \\
(0.00003)\end{array}$ \\
\hline Age $50-54$ & $\begin{array}{c}-0.31125 \\
(0.00330)\end{array}$ & $\begin{array}{c}-0.04864 \\
(0.00014)\end{array}$ & $\begin{array}{l}-0.00068 \\
(0.00000)\end{array}$ & $\begin{array}{c}-0.02274 \\
(0.00013)\end{array}$ & $\begin{array}{c}-0.11663 \\
(0.00008)\end{array}$ \\
\hline \multicolumn{6}{|c|}{ Change from Single, Never Married to: } \\
\hline Married & $\begin{array}{c}-0.05544 \\
(0.00052)\end{array}$ & $\begin{array}{c}0.00468 \\
(0.00001)\end{array}$ & $\begin{array}{c}0.02359 \\
(0.00001)\end{array}$ & $\begin{array}{l}-0.02424 \\
(0.00012)\end{array}$ & $\begin{array}{c}0.07681 \\
(0.00006)\end{array}$ \\
\hline Div-wid-sep & $\begin{array}{c}0.09699 \\
(0.00106)\end{array}$ & $\begin{array}{c}0.01056 \\
(0.00003)\end{array}$ & $\begin{array}{c}0.18502 \\
(0.00006)\end{array}$ & $\begin{array}{l}-0.01223 \\
(0.00007)\end{array}$ & $\begin{array}{c}0.05862 \\
(0.00002)\end{array}$ \\
\hline \multicolumn{6}{|c|}{ Change from Highest Grade $=12$ to: } \\
\hline Highest grade $<10$ & $\begin{array}{c}-0.07920 \\
(0.00091)\end{array}$ & $\begin{array}{c}0.03184 \\
(0.00008)\end{array}$ & $\begin{array}{l}-0.11108 \\
(0.00007)\end{array}$ & $\begin{array}{c}-0.01834 \\
(0.00010)\end{array}$ & $\begin{array}{l}-0.00016 \\
(0.00000)\end{array}$ \\
\hline Highest grade 10-11 & $\begin{array}{c}0.02426 \\
(0.00027)\end{array}$ & $\begin{array}{c}0.01406 \\
(0.00004)\end{array}$ & $\begin{array}{l}-0.03287 \\
(0.00001)\end{array}$ & $\begin{array}{c}0.00410 \\
(0.00002)\end{array}$ & $\begin{array}{l}-0.02980 \\
(0.00000)\end{array}$ \\
\hline Highest grade $13-15$ & $\begin{array}{c}0.01822 \\
(0.00019)\end{array}$ & $\begin{array}{l}-0.00856 \\
(0.00002)\end{array}$ & $\begin{array}{c}0.01443 \\
(0.00000)\end{array}$ & $\begin{array}{c}0.00364 \\
(0.00002)\end{array}$ & $\begin{array}{c}0.02700 \\
(0.00000)\end{array}$ \\
\hline Highest grade $>15$ & $\begin{array}{c}-0.24466 \\
(0.00245)\end{array}$ & $\begin{array}{l}-0.00355 \\
(0.00001)\end{array}$ & $\begin{array}{l}-0.10503 \\
(0.00003)\end{array}$ & $\begin{array}{l}-0.03325 \\
(0.00017)\end{array}$ & $\begin{array}{l}-0.00404 \\
(0.00000)\end{array}$ \\
\hline \multicolumn{6}{|c|}{ Change from No Child $<6$ Years of Age to: } \\
\hline Child age $<6$ years & $\begin{array}{l}-0.09757 \\
(0.00097)\end{array}$ & $\begin{array}{l}-0.01129 \\
(0.00003)\end{array}$ & $\begin{array}{l}-0.01621 \\
(0.00001)\end{array}$ & $\begin{array}{l}-0.01379 \\
(0.00007)\end{array}$ & $\begin{array}{c}0.02742 \\
(0.00001)\end{array}$ \\
\hline \multicolumn{6}{|c|}{ Change from Family Income $<\$ 3,000$ to: } \\
\hline Family income $3 \mathrm{~K}-9 \mathrm{~K}$ & $\begin{array}{c}-0.32777 \\
(0.00344)\end{array}$ & $\begin{array}{c}-0.03797 \\
(0.00013)\end{array}$ & $\begin{array}{l}-0.04304 \\
(0.00000)\end{array}$ & $\begin{array}{l}-0.02817 \\
(0.00017)\end{array}$ & $\begin{array}{c}-0.08075 \\
(0.00006)\end{array}$ \\
\hline Family income $9 \mathrm{~K}-15 \mathrm{~K}$ & $\begin{array}{c}-0.47674 \\
(0.00484)\end{array}$ & $\begin{array}{l}-0.08709 \\
(0.00035)\end{array}$ & $\begin{array}{l}-0.05927 \\
(0.00000)\end{array}$ & $\begin{array}{l}-0.03101 \\
(0.00019)\end{array}$ & $\begin{array}{l}-0.06552 \\
(0.00000)\end{array}$ \\
\hline Family income $>15 \mathrm{~K}$ & $\begin{array}{l}-0.86666 \\
(0.00493)\end{array}$ & $\begin{array}{l}-0.27189 \\
(0.00040)\end{array}$ & $\begin{array}{c}0.01851 \\
(0.00001)\end{array}$ & $\begin{array}{l}-0.22959 \\
(0.00043)\end{array}$ & $\begin{array}{c}0.02226 \\
(0.00000)\end{array}$ \\
\hline
\end{tabular}

Source: Authors' calculations using 1986 SIPP full panel.

Notes: Bootstrap standard errors appear in parentheses. The standard errors reflect variation due to the sample used to perform the simulations. 


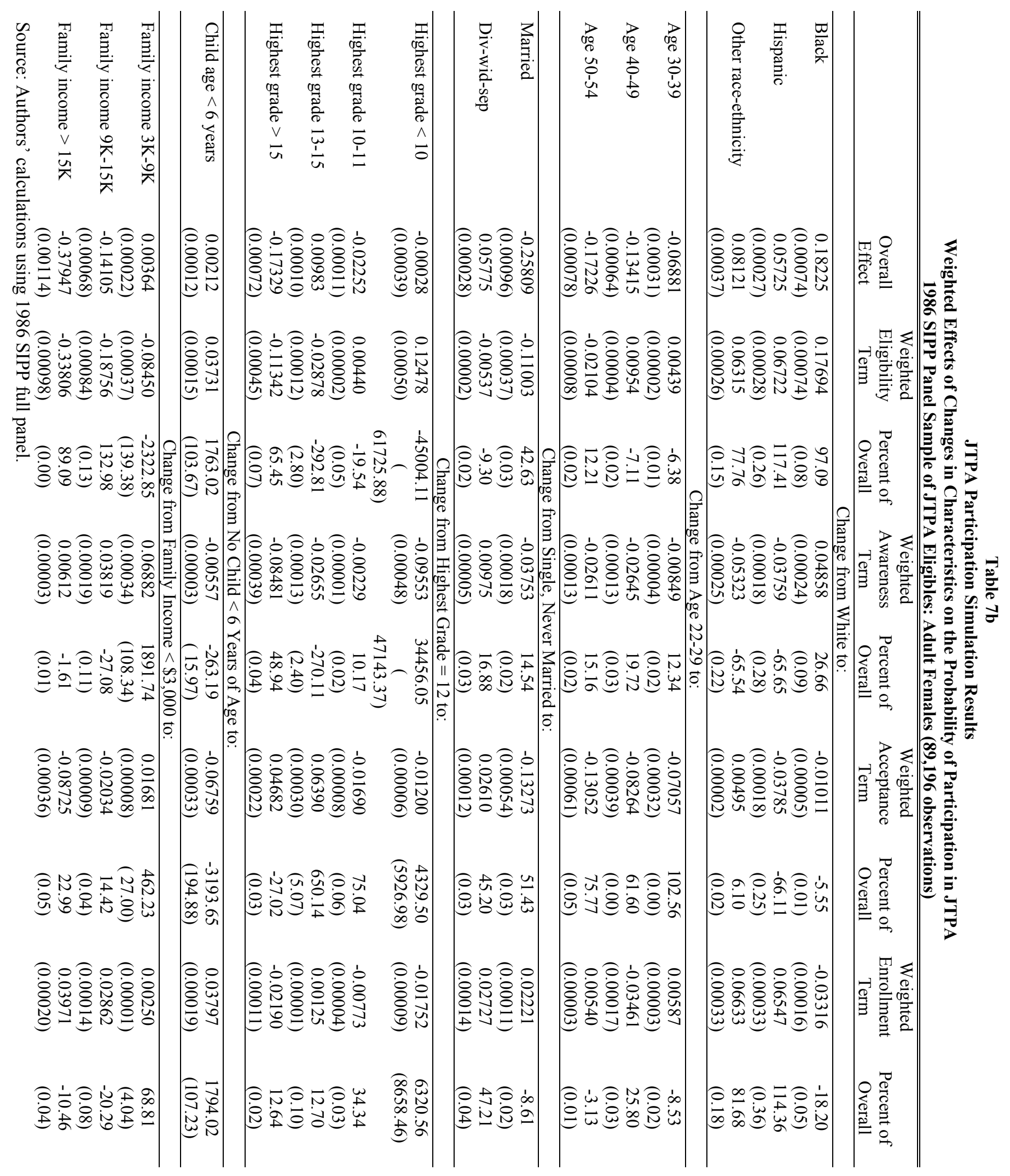


Table $7 b$ (continued)

JTPA Participation Simulation Results

Unweighted Effects of Changes in Characteristics on the Probability of Participation in JTPA 1986 SIPP Panel Sample of JTPA Eligibles: Adult Females (89,196 observations)

\begin{tabular}{|c|c|c|c|c|c|}
\hline & $\begin{array}{c}\text { Overall } \\
\text { Effect }\end{array}$ & $\begin{array}{c}\text { Unweighted } \\
\text { Eligibility Term }\end{array}$ & $\begin{array}{c}\text { Unweighted } \\
\text { Awareness } \\
\text { Term }\end{array}$ & $\begin{array}{c}\text { Unweighted } \\
\text { Acceptance } \\
\text { Term }\end{array}$ & $\begin{array}{c}\text { Unweighted } \\
\text { Enrollment } \\
\text { Term }\end{array}$ \\
\hline \multicolumn{6}{|c|}{ Change from White to: } \\
\hline Black & $\begin{array}{c}0.18225 \\
(0.00074)\end{array}$ & $\begin{array}{c}0.11936 \\
(0.00025)\end{array}$ & $\begin{array}{c}0.10254 \\
(0.00000)\end{array}$ & $\begin{array}{l}-0.00213 \\
(0.00000)\end{array}$ & $\begin{array}{l}-0.07239 \\
(0.00003)\end{array}$ \\
\hline Hispanic & $\begin{array}{c}0.05725 \\
(0.00027)\end{array}$ & $\begin{array}{c}0.04523 \\
(0.00010)\end{array}$ & $\begin{array}{l}-0.07589 \\
(0.00003)\end{array}$ & $\begin{array}{l}-0.00796 \\
(0.00001)\end{array}$ & $\begin{array}{c}0.13711 \\
(0.00006)\end{array}$ \\
\hline Other race-ethnicity & $\begin{array}{c}0.08121 \\
(0.00037) \\
\end{array}$ & $\begin{array}{c}0.04237 \\
(0.00009) \\
\end{array}$ & $\begin{array}{l}-0.10664 \\
(0.00004) \\
\end{array}$ & $\begin{array}{c}0.00105 \\
(0.00000) \\
\end{array}$ & $\begin{array}{c}0.13905 \\
(0.00000)\end{array}$ \\
\hline \multicolumn{6}{|c|}{ Change from Age 22-29 to: } \\
\hline Age 30-39 & $\begin{array}{l}-0.06881 \\
(0.00031)\end{array}$ & $\begin{array}{c}0.00292 \\
(0.00001)\end{array}$ & $\begin{array}{l}-0.01759 \\
(0.00000)\end{array}$ & $\begin{array}{l}-0.01495 \\
(0.00003)\end{array}$ & $\begin{array}{c}0.01270 \\
(0.00000)\end{array}$ \\
\hline Age $40-49$ & $\begin{array}{l}-0.13415 \\
(0.00064)\end{array}$ & $\begin{array}{c}0.00633 \\
(0.00001)\end{array}$ & $\begin{array}{l}-0.05442 \\
(0.00002)\end{array}$ & $\begin{array}{l}-0.01792 \\
(0.00004)\end{array}$ & $\begin{array}{l}-0.07575 \\
(0.00003)\end{array}$ \\
\hline Age $50-54$ & $\begin{array}{l}-0.17226 \\
(0.00078) \\
\end{array}$ & $\begin{array}{l}-0.01395 \\
(0.00004) \\
\end{array}$ & $\begin{array}{l}-0.05343 \\
(0.00003)\end{array}$ & $\begin{array}{l}-0.02759 \\
(0.00004)\end{array}$ & $\begin{array}{c}0.01166 \\
(0.00000) \\
\end{array}$ \\
\hline \multicolumn{6}{|c|}{ Change from Single, Never Married to: } \\
\hline Married & $\begin{array}{l}-0.25809 \\
(0.00096)\end{array}$ & $\begin{array}{l}-0.08046 \\
(0.00017)\end{array}$ & $\begin{array}{c}-0.07888 \\
(0.00004)\end{array}$ & $\begin{array}{l}-0.03365 \\
(0.00004)\end{array}$ & $\begin{array}{c}0.04852 \\
(0.00002)\end{array}$ \\
\hline Div-wid-sep & $\begin{array}{c}0.05775 \\
(0.00028) \\
\end{array}$ & $\begin{array}{l}-0.00355 \\
(0.00001) \\
\end{array}$ & $\begin{array}{c}0.02033 \\
(0.00001) \\
\end{array}$ & $\begin{array}{c}0.00566 \\
(0.00001) \\
\end{array}$ & $\begin{array}{c}0.05814 \\
(0.00000) \\
\end{array}$ \\
\hline \multicolumn{6}{|c|}{ Change from Highest Grade $=12$ to: } \\
\hline Highest grade $<10$ & $\begin{array}{l}-0.00028 \\
(0.00039)\end{array}$ & $\begin{array}{c}0.08384 \\
(0.00017)\end{array}$ & $\begin{array}{l}-0.18277 \\
(0.00014)\end{array}$ & $\begin{array}{l}-0.00254 \\
(0.00001)\end{array}$ & $\begin{array}{l}-0.03823 \\
(0.00001)\end{array}$ \\
\hline Highest grade $10-11$ & $\begin{array}{l}-0.02252 \\
(0.00011)\end{array}$ & $\begin{array}{c}0.00292 \\
(0.00001)\end{array}$ & $\begin{array}{l}-0.00474 \\
(0.00000)\end{array}$ & $\begin{array}{l}-0.00356 \\
(0.00001)\end{array}$ & $\begin{array}{c}-0.01680 \\
(0.00000)\end{array}$ \\
\hline Highest grade $13-15$ & $\begin{array}{c}0.00983 \\
(0.00010)\end{array}$ & $\begin{array}{l}-0.01898 \\
(0.00005)\end{array}$ & $\begin{array}{l}-0.05459 \\
(0.00000)\end{array}$ & $\begin{array}{c}0.01348 \\
(0.00002)\end{array}$ & $\begin{array}{c}0.00270 \\
(0.00000)\end{array}$ \\
\hline Highest grade $>15$ & $\begin{array}{c}-0.17329 \\
(0.00072) \\
\end{array}$ & $\begin{array}{l}-0.07569 \\
(0.00020) \\
\end{array}$ & $\begin{array}{l}-0.17394 \\
(0.00009) \\
\end{array}$ & $\begin{array}{c}0.00970 \\
(0.00002) \\
\end{array}$ & $\begin{array}{l}-0.04777 \\
(0.00002) \\
\end{array}$ \\
\hline \multicolumn{6}{|c|}{ Change from No Child $<6$ Years of Age to: } \\
\hline Child age $<6$ years & $\begin{array}{c}0.00212 \\
(0.00012) \\
\end{array}$ & $\begin{array}{c}0.02473 \\
(0.00006) \\
\end{array}$ & $\begin{array}{l}-0.01154 \\
(0.00001)\end{array}$ & $\begin{array}{l}-0.01397 \\
(0.00003)\end{array}$ & $\begin{array}{c}0.08169 \\
(0.00004) \\
\end{array}$ \\
\hline \multicolumn{6}{|c|}{ Change from Family Income $<\$ 3,000$ to: } \\
\hline Family income $3 \mathrm{~K}-9 \mathrm{~K}$ & $\begin{array}{c}0.00364 \\
(0.00022)\end{array}$ & $\begin{array}{c}-0.05266 \\
(0.00015)\end{array}$ & $\begin{array}{c}0.14643 \\
(0.00006)\end{array}$ & $\begin{array}{c}0.00361 \\
(0.00001)\end{array}$ & $\begin{array}{c}0.00541 \\
(0.00000)\end{array}$ \\
\hline Family income $9 \mathrm{~K}-15 \mathrm{~K}$ & $\begin{array}{l}-0.14105 \\
(0.00068)\end{array}$ & $\begin{array}{l}-0.11255 \\
(0.00035)\end{array}$ & $\begin{array}{c}0.08099 \\
(0.00000)\end{array}$ & $\begin{array}{l}-0.00431 \\
(0.00001)\end{array}$ & $\begin{array}{c}0.06103 \\
(0.00000)\end{array}$ \\
\hline Family income $>15 \mathrm{~K}$ & $\begin{array}{c}-0.37947 \\
(0.00114) \\
\end{array}$ & $\begin{array}{l}-0.26155 \\
(0.00039) \\
\end{array}$ & $\begin{array}{c}0.01266 \\
(0.00001) \\
\end{array}$ & $\begin{array}{l}-0.02135 \\
(0.00003) \\
\end{array}$ & $\begin{array}{c}0.08726 \\
(0.00000)\end{array}$ \\
\hline
\end{tabular}

Source: Authors' calculations using 1986 SIPP full panel.

Notes: Bootstrap standard errors appear in parentheses. The standard errors reflect variation due to the sample used to perform the simulations. 


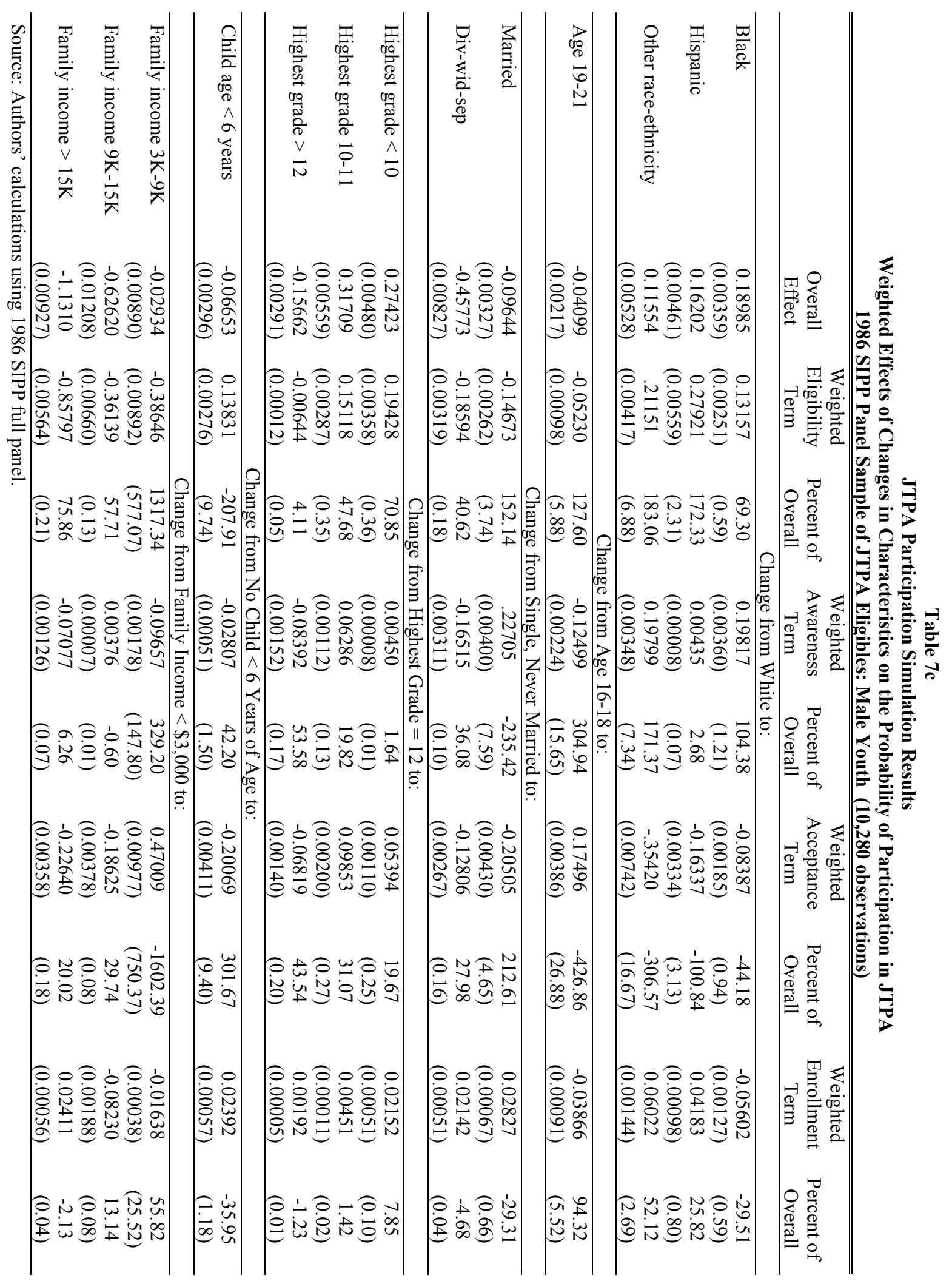


Table 7c (continued)

JTPA Participation Simulation Results

Unweighted Effects of Changes in Characteristics on the Probability of Participation in JTPA 1986 SIPP Panel Sample of JTPA Eligibles: Male Youth (10,280 observations)

\begin{tabular}{|c|c|c|c|c|c|}
\hline & $\begin{array}{l}\text { Overall } \\
\text { Effect }\end{array}$ & $\begin{array}{c}\text { Unweghted } \\
\text { Eligibility } \\
\text { Term }\end{array}$ & $\begin{array}{c}\text { Unweighted } \\
\text { Awareness } \\
\text { Term }\end{array}$ & $\begin{array}{c}\text { Unweighted } \\
\text { Acceptance } \\
\text { Term }\end{array}$ & $\begin{array}{c}\text { Unweighted } \\
\text { Enrollment } \\
\text { Term }\end{array}$ \\
\hline \multicolumn{6}{|c|}{ Change from White to: } \\
\hline Black & $\begin{array}{c}0.18985 \\
(0.00359)\end{array}$ & $\begin{array}{c}0.06224 \\
(0.00033)\end{array}$ & $\begin{array}{c}0.23652 \\
(0.00027)\end{array}$ & $\begin{array}{c}-0.01464 \\
(0.00011)\end{array}$ & $\begin{array}{l}-0.10033 \\
(0.00009)\end{array}$ \\
\hline Hispanic & $\begin{array}{c}0.16202 \\
(0.00461)\end{array}$ & $\begin{array}{c}0.12856 \\
(0.00071)\end{array}$ & $\begin{array}{c}0.00515 \\
(0.00001)\end{array}$ & $\begin{array}{c}-0.02811 \\
(0.00023)\end{array}$ & $\begin{array}{c}0.07099 \\
(0.00011)\end{array}$ \\
\hline Other race-ethnicity & $\begin{array}{c}0.11554 \\
(0.00528)\end{array}$ & $\begin{array}{c}0.09938 \\
(0.00059)\end{array}$ & $\begin{array}{c}0.24597 \\
(0.00029)\end{array}$ & $\begin{array}{c}-0.05971 \\
(0.00051)\end{array}$ & $\begin{array}{c}0.10316 \\
(0.00017)\end{array}$ \\
\hline \multicolumn{6}{|c|}{ Change from Age 16-18 to: } \\
\hline Age $19-21$ & $\begin{array}{c}-0.04099 \\
(0.00217)\end{array}$ & $\begin{array}{l}-0.02447 \\
(0.00013)\end{array}$ & $\begin{array}{c}-0.14922 \\
(0.00014)\end{array}$ & $\begin{array}{c}0.02848 \\
(0.00020)\end{array}$ & $\begin{array}{l}-0.06538 \\
(0.00006)\end{array}$ \\
\hline \multicolumn{6}{|c|}{ Change from Single, Never Married to: } \\
\hline Married & $\begin{array}{c}-0.09644 \\
(0.00327)\end{array}$ & $\begin{array}{l}-0.06715 \\
(0.00043)\end{array}$ & $\begin{array}{c}0.28561 \\
(0.00023)\end{array}$ & $\begin{array}{l}-0.03700 \\
(0.00032)\end{array}$ & $\begin{array}{c}0.04882 \\
(0.00007)\end{array}$ \\
\hline Div-wid-sep & $\begin{array}{c}-0.45773 \\
(0.00827) \\
\end{array}$ & $\begin{array}{c}-0.08370 \\
(0.00060) \\
\end{array}$ & $\begin{array}{c}-0.18808 \\
(0.00048) \\
\end{array}$ & $\begin{array}{c}-0.02320 \\
(0.00018) \\
\end{array}$ & $\begin{array}{c}0.03693 \\
(0.00006) \\
\end{array}$ \\
\hline \multicolumn{6}{|c|}{ Change from Highest Grade $=12$ to: } \\
\hline Highest grade $<10$ & $\begin{array}{c}0.27423 \\
(0.00480)\end{array}$ & $\begin{array}{c}0.09339 \\
(0.00051)\end{array}$ & $\begin{array}{c}0.00533 \\
(0.00001)\end{array}$ & $\begin{array}{c}0.01010 \\
(0.00007)\end{array}$ & $\begin{array}{c}0.03660 \\
(0.00005)\end{array}$ \\
\hline Highest grade 10-11 & $\begin{array}{c}0.31709 \\
(0.00559)\end{array}$ & $\begin{array}{c}0.07254 \\
(0.00039)\end{array}$ & $\begin{array}{c}0.07497 \\
(0.00009)\end{array}$ & $\begin{array}{c}0.01866 \\
(0.00013)\end{array}$ & $\begin{array}{c}0.00780 \\
(0.00001)\end{array}$ \\
\hline Highest grade $>12$ & $\begin{array}{c}-0.15662 \\
(0.00291)\end{array}$ & $\begin{array}{l}-0.00299 \\
(0.00002)\end{array}$ & $\begin{array}{c}-0.09993 \\
(0.00013)\end{array}$ & $\begin{array}{l}-0.01283 \\
(0.00009)\end{array}$ & $\begin{array}{c}0.00333 \\
(0.00000) \\
\end{array}$ \\
\hline \multicolumn{6}{|c|}{ Change from No Child $<6$ Years of Age to: } \\
\hline Child age $<6$ years & $\begin{array}{c}-0.06653 \\
(0.00296) \\
\end{array}$ & $\begin{array}{c}0.06409 \\
(0.00038) \\
\end{array}$ & $\begin{array}{l}-0.03296 \\
(0.00006) \\
\end{array}$ & $\begin{array}{c}-0.03545 \\
(0.00029) \\
\end{array}$ & $\begin{array}{c}0.04130 \\
(0.00006) \\
\end{array}$ \\
\hline \multicolumn{6}{|c|}{ Change from Family Income $<\$ 3,000$ to: } \\
\hline Family income $3 \mathrm{~K}-9 \mathrm{~K}$ & $\begin{array}{c}-0.02934 \\
(0.00890)\end{array}$ & $\begin{array}{l}-0.13607 \\
(0.00150)\end{array}$ & $\begin{array}{c}-0.10801 \\
(0.00018)\end{array}$ & $\begin{array}{c}0.09427 \\
(0.00035)\end{array}$ & $\begin{array}{l}-0.02889 \\
(0.00003)\end{array}$ \\
\hline Family income $9 \mathrm{~K}-15 \mathrm{~K}$ & $\begin{array}{l}-0.62620 \\
(0.01208)\end{array}$ & $\begin{array}{l}-0.17195 \\
(0.00229)\end{array}$ & $\begin{array}{c}0.00445 \\
(0.00001)\end{array}$ & $\begin{array}{l}-0.03412 \\
(0.00027)\end{array}$ & $\begin{array}{l}-0.14599 \\
(0.00013)\end{array}$ \\
\hline Family income $>15 \mathrm{~K}$ & $\begin{array}{l}-1.13101 \\
(0.00927)\end{array}$ & $\begin{array}{l}-0.57966 \\
(0.00228)\end{array}$ & $\begin{array}{l}-0.08677 \\
(0.00010)\end{array}$ & $\begin{array}{l}-0.05300 \\
(0.00026)\end{array}$ & $\begin{array}{c}0.04362 \\
(0.00006)\end{array}$ \\
\hline
\end{tabular}

Source: Authors' calculations using 1986 SIPP full panel.

Notes: Bootstrap standard errors appear in parentheses. The standard errors reflect variation due to the sample used to perform the simulations. 


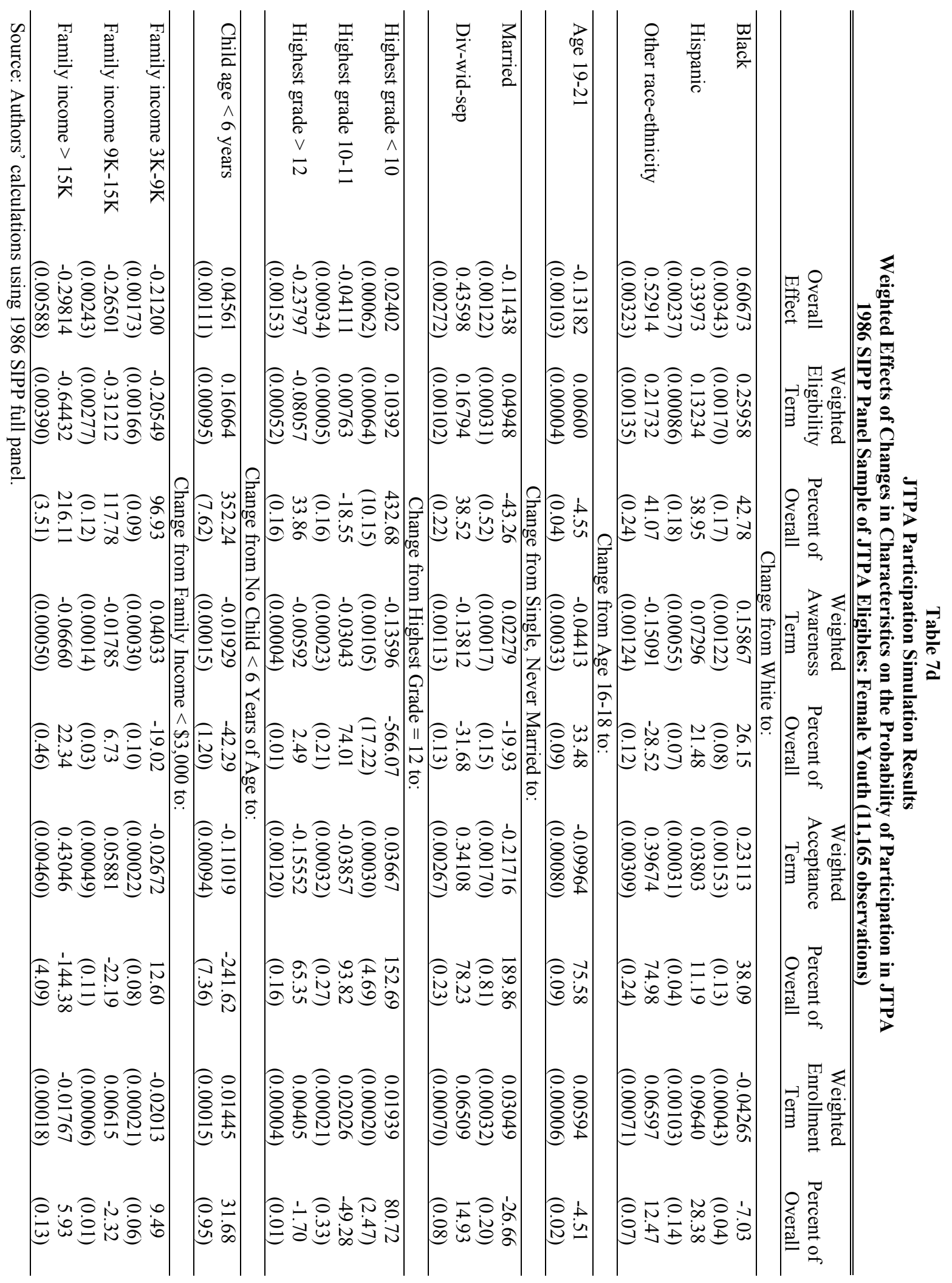


Table 7d (continued)

JTPA Participation Simulation Results

Unweighted Effects of Changes in Characteristics on the Probability of Participation in JTPA 1986 SIPP Panel Sample of JTPA Eligibles: Female Youth (11,165 observations)

\begin{tabular}{|c|c|c|c|c|c|}
\hline & $\begin{array}{l}\text { Overall } \\
\text { Effect }\end{array}$ & $\begin{array}{c}\text { Unweighted } \\
\text { Eligibility } \\
\text { Term }\end{array}$ & $\begin{array}{c}\text { Unweighted } \\
\text { Awareness } \\
\text { Term }\end{array}$ & $\begin{array}{l}\text { Unweighted } \\
\text { Acceptance } \\
\text { Term }\end{array}$ & $\begin{array}{c}\text { Unweighted } \\
\text { Enrollment } \\
\text { Term }\end{array}$ \\
\hline \multicolumn{6}{|c|}{ Change from White to: } \\
\hline Black & $\begin{array}{c}0.60673 \\
(0.00343)\end{array}$ & $\begin{array}{c}0.07514 \\
(0.00020)\end{array}$ & $\begin{array}{c}0.18894 \\
(0.00012)\end{array}$ & $\begin{array}{c}0.08124 \\
(0.00038)\end{array}$ & $\begin{array}{l}-0.06723 \\
(0.00006)\end{array}$ \\
\hline Hispanic & $\begin{array}{c}0.33973 \\
(0.00237)\end{array}$ & $\begin{array}{c}0.03805 \\
(0.00010)\end{array}$ & $\begin{array}{c}0.08826 \\
(0.00004)\end{array}$ & $\begin{array}{c}0.01283 \\
(0.00007)\end{array}$ & $\begin{array}{c}0.14839 \\
(0.00011)\end{array}$ \\
\hline Other race-ethnicity & $\begin{array}{c}0.52914 \\
(0.00323)\end{array}$ & $\begin{array}{c}0.06344 \\
(0.00017)\end{array}$ & $\begin{array}{l}-0.17801 \\
(0.00019)\end{array}$ & $\begin{array}{c}0.13083 \\
(0.00058) \\
\end{array}$ & $\begin{array}{c}0.10252 \\
(0.00011)\end{array}$ \\
\hline \multicolumn{6}{|c|}{ Change from Age 16-18 to: } \\
\hline Age 19-21 & $\begin{array}{l}-0.13182 \\
(0.00103)\end{array}$ & $\begin{array}{c}0.00172 \\
(0.00000)\end{array}$ & $\begin{array}{l}-0.05334 \\
(0.00000)\end{array}$ & $\begin{array}{l}-0.03352 \\
(0.00016)\end{array}$ & $\begin{array}{c}0.00931 \\
(0.00001)\end{array}$ \\
\hline \multicolumn{6}{|c|}{ Change from Single, Never Married to: } \\
\hline Married & $\begin{array}{l}-0.11438 \\
(0.00122)\end{array}$ & $\begin{array}{c}0.01431 \\
(0.00004)\end{array}$ & $\begin{array}{c}0.02747 \\
(0.00002)\end{array}$ & $\begin{array}{l}-0.07153 \\
(0.00036)\end{array}$ & $\begin{array}{c}0.04781 \\
(0.00003)\end{array}$ \\
\hline Div-wid-sep & $\begin{array}{c}0.43598 \\
(0.00272) \\
\end{array}$ & $\begin{array}{c}0.04896 \\
(0.00013) \\
\end{array}$ & $\begin{array}{c}-0.16342 \\
(0.00015) \\
\end{array}$ & $\begin{array}{c}0.11298 \\
(0.00052) \\
\end{array}$ & $\begin{array}{c}0.10116 \\
(0.00011) \\
\end{array}$ \\
\hline \multicolumn{6}{|c|}{ Change from Highest Grade $=12$ to: } \\
\hline Highest grade $<10$ & $\begin{array}{c}0.02402 \\
(0.00062)\end{array}$ & $\begin{array}{c}0.03018 \\
(0.00008)\end{array}$ & $\begin{array}{l}-0.16072 \\
(0.00015)\end{array}$ & $\begin{array}{c}0.01233 \\
(0.00006)\end{array}$ & $\begin{array}{c}0.03028 \\
(0.00003)\end{array}$ \\
\hline Highest grade 10-11 & $\begin{array}{l}-0.04111 \\
(0.00034)\end{array}$ & $\begin{array}{c}0.00219 \\
(0.00001)\end{array}$ & $\begin{array}{l}-0.03662 \\
(0.00002)\end{array}$ & $\begin{array}{l}-0.01290 \\
(0.00007)\end{array}$ & $\begin{array}{c}0.03163 \\
(0.00003)\end{array}$ \\
\hline Highest grade $>12$ & $\begin{array}{c}-0.23797 \\
(0.00153) \\
\end{array}$ & $\begin{array}{c}-0.02355 \\
(0.00005) \\
\end{array}$ & $\begin{array}{l}-0.00714 \\
(0.00000) \\
\end{array}$ & $\begin{array}{c}-0.05464 \\
(0.00028) \\
\end{array}$ & $\begin{array}{c}0.00635 \\
(0.00001) \\
\end{array}$ \\
\hline \multicolumn{6}{|c|}{ Change from No Child $<6$ Years of Age to: } \\
\hline Child age $<6$ years & $\begin{array}{c}0.04561 \\
(0.00111) \\
\end{array}$ & $\begin{array}{c}0.04769 \\
(0.00012) \\
\end{array}$ & $\begin{array}{c}-0.02320 \\
(0.00002) \\
\end{array}$ & $\begin{array}{c}-0.03586 \\
(0.00019) \\
\end{array}$ & $\begin{array}{c}0.02259 \\
(0.00002) \\
\end{array}$ \\
\hline \multicolumn{6}{|c|}{ Change from Family Income $<\$ 3,000$ to: } \\
\hline Family income $3 \mathrm{~K}-9 \mathrm{~K}$ & $\begin{array}{c}-0.21200 \\
(0.00173)\end{array}$ & $\begin{array}{l}-0.05959 \\
(0.00019)\end{array}$ & $\begin{array}{c}0.04868 \\
(0.00002)\end{array}$ & $\begin{array}{c}-0.00894 \\
(0.00005)\end{array}$ & $\begin{array}{l}-0.03154 \\
(0.00002)\end{array}$ \\
\hline Family income $9 \mathrm{~K}-15 \mathrm{~K}$ & $\begin{array}{c}-0.26501 \\
(0.00243)\end{array}$ & $\begin{array}{c}-0.09455 \\
(0.00035)\end{array}$ & $\begin{array}{c}-0.02149 \\
(0.00001)\end{array}$ & $\begin{array}{c}0.01981 \\
(0.00010)\end{array}$ & $\begin{array}{c}0.00962 \\
(0.00001)\end{array}$ \\
\hline Family income $>15 \mathrm{~K}$ & $\begin{array}{c}-0.29814 \\
(0.00588) \\
\end{array}$ & $\begin{array}{c}-0.19203 \\
(0.00017)\end{array}$ & $\begin{array}{c}-0.08038 \\
(0.00002)\end{array}$ & $\begin{array}{c}0.11196 \\
(0.00045)\end{array}$ & $\begin{array}{l}-0.02763 \\
(0.00002)\end{array}$ \\
\hline
\end{tabular}

Source: Authors' calculations using 1986 SIPP full panel.

Notes: Bootstrap standard errors appear in parentheses. The standard errors reflect variation due to the sample used to perform the simulations. 
Table 8a

JTPA Simulation Results - Two Step Decomposition

Weighted Effects of Changes in Characteristics on the Probability of Acceptance into JTPA

National JTPA Study Eligible Non-Participant Sample: Adult Males (1552 observations)

\begin{tabular}{|c|c|c|c|c|c|c|c|c|c|c|}
\hline & $\begin{array}{c}\text { Overall } \\
\text { Effect }\end{array}$ & & $\begin{array}{c}\text { Weighted } \\
\text { Awareness } \\
\text { Term }\end{array}$ & & $\begin{array}{c}\begin{array}{c}\text { Percent } \\
\text { of } \\
\text { Overall }\end{array} \\
\end{array}$ & & $\begin{array}{c}\text { Weighted } \\
\text { Acceptance } \\
\text { Term }\end{array}$ & & $\begin{array}{c}\begin{array}{c}\text { Percent } \\
\text { of } \\
\text { Overall }\end{array} \\
\end{array}$ & \\
\hline \multicolumn{11}{|c|}{ Change from White to: } \\
\hline Black & 2.5149 & $(0.0675)$ & 1.5521 & $(0.0495)$ & 61.72 & $(0.66)$ & .9628 & $(0.0257)$ & 38.28 & $(0.66)$ \\
\hline Hispanic & -2.9536 & $(0.0902)$ & -2.6335 & $(0.0844)$ & 89.16 & $(0.25)$ & -0.3201 & $(0.0087)$ & 10.84 & $(0.25)$ \\
\hline Other race-ethnicity & 5.8446 & $(0.1485)$ & -1.4193 & $(0.0457)$ & -24.28 & $(0.85)$ & 7.2639 & $(0.1668)$ & 124.28 & $(0.85)$ \\
\hline \multicolumn{11}{|c|}{ Change from Age 22-29 to: } \\
\hline Age $30-39$ & -3.7082 & $(0.0993)$ & -1.3499 & $(0.0433)$ & 36.40 & $(0.62)$ & -2.3583 & $(0.0664)$ & 63.60 & $(0.62)$ \\
\hline Age $40-49$ & -4.2680 & $(0.1146)$ & -1.2858 & $(0.0412)$ & 30.13 & $(0.55)$ & -2.9822 & $(0.0838)$ & 69.87 & $(0.55)$ \\
\hline Age $50-54$ & -2.5991 & $(0.0765)$ & .1994 & $(0.0064)$ & -7.67 & $(0.22)$ & -2.7985 & $(0.0803)$ & 107.67 & $(0.22)$ \\
\hline \multicolumn{11}{|c|}{ Change from Highest Grade 12 to: } \\
\hline Highest grade $<10$ & -6.5763 & $(0.1825)$ & -2.1992 & $(0.0693)$ & 33.44 & $(0.54)$ & -4.3771 & $(0.1279)$ & 66.56 & $(0.54)$ \\
\hline Highest grade 10-11 & -1.4067 & $(0.0380)$ & -0.7153 & $(0.0233)$ & 50.85 & $(0.70)$ & -0.6914 & $(0.0193)$ & 49.15 & $(0.70)$ \\
\hline Highest grade $13-15$ & 2.1957 & $(0.0557)$ & .5977 & $(0.0192)$ & 27.22 & $(0.57)$ & 1.5980 & $(0.0430)$ & 72.78 & $(0.58)$ \\
\hline Highest grade $>15$ & -7.3700 & $(0.2089)$ & -1.6050 & $(0.0516)$ & 21.78 & $(0.40)$ & -5.7650 & $(0.1688)$ & 78.22 & $(0.40)$ \\
\hline \multicolumn{11}{|c|}{ Change from not receiving AFDC to: } \\
\hline Current AFDC receipt & -5.5477 & $(0.1714)$ & .4306 & $(0.0138)$ & -7.76 & $(0.22)$ & -5.9783 & $(0.1800)$ & 107.76 & $(0.23)$ \\
\hline \multicolumn{11}{|c|}{ Change from not receiving Food Stamps to: } \\
\hline Current Food Stamp receipt & 4.4612 & $(0.1165)$ & 2.8726 & $(0.0897)$ & 64.39 & $(0.68)$ & 1.5886 & $(0.0424)$ & 35.61 & $(0.68)$ \\
\hline \multicolumn{11}{|c|}{ Change Two Most Recent Labor Force Statuses from Employed -> Employed to: } \\
\hline Unemployed -> Employed & 11.1319 & $(0.2484)$ & 2.8784 & $(0.0920)$ & 25.86 & $(0.60)$ & 8.2535 & $(0.1969)$ & 74.14 & $(0.60)$ \\
\hline OLF -> Employed & 15.2249 & $(0.3061)$ & 2.6670 & $(0.0845)$ & 17.52 & $(0.45)$ & 12.5578 & $(0.2646)$ & 82.48 & $(0.44)$ \\
\hline Employed -> Unemployed & 23.9905 & $(0.4532)$ & 2.8125 & $(0.0946)$ & 11.72 & $(0.31)$ & 21.1780 & $(0.3998)$ & 88.28 & $(0.31)$ \\
\hline Unemployed -> & 15.9797 & $(0.3196)$ & 3.6041 & $(0.1122)$ & 22.55 & $(0.55)$ & 12.3756 & $(0.2652)$ & 77.45 & $(0.55)$ \\
\hline Unemployed & & & & & & & & & & \\
\hline OLF $->$ Unemployed & 28.6514 & $(0.4525)$ & 6.4026 & $(0.2087)$ & 22.35 & $(0.59)$ & 22.2488 & $(0.3654)$ & 77.65 & $(0.59)$ \\
\hline Employed $->$ OLF & 25.9317 & $(0.3865)$ & -1.6591 & $(0.0530)$ & -6.40 & $(0.22)$ & 27.5908 & $(0.3904)$ & 106.40 & $(0.22)$ \\
\hline Unemployed $->$ OLF & 30.8787 & $(0.4021)$ & -4.9403 & $(0.1627)$ & -16.00 & $(0.67)$ & 35.8191 & $(0.3365)$ & 116.00 & $(0.67)$ \\
\hline OLF $->$ OLF & 6.8828 & $(0.1859)$ & -0.0298 & $(0.0009)$ & -0.43 & $(0.01)$ & 6.9126 & $(0.1864)$ & 100.43 & $(0.03)$ \\
\hline \multicolumn{11}{|c|}{ Change from No Child $<6$ Years of Age to: } \\
\hline Child age $<6$ years & -0.9468 & $(0.0270)$ & -0.5962 & $(0.0190)$ & 62.97 & $(0.71)$ & -0.3506 & $(0.0114)$ & 37.03 & $(0.71)$ \\
\hline \multicolumn{11}{|c|}{ Change from Family Income $<\$ 3000$ to: } \\
\hline Family income $3 \mathrm{~K}-9 \mathrm{~K}$ & -5.2227 & $(0.1744)$ & -0.1078 & $(0.0034)$ & 2.06 & $(0.06)$ & -5.1149 & $(0.1725)$ & 97.94 & $(0.04)$ \\
\hline Family income $9 \mathrm{~K}-15 \mathrm{~K}$ & -2.4054 & $(0.0750)$ & -0.1520 & $(0.0048)$ & 6.32 & $(0.18)$ & -2.2535 & $(0.0722)$ & 93.68 & $(0.19)$ \\
\hline Family income $>15 \mathrm{~K}$ & -6.8375 & $(0.2571)$ & 1.6230 & $(0.0511)$ & -23.74 & $(0.94)$ & -8.4605 & $(0.2804)$ & 123.74 & $(0.94)$ \\
\hline \multicolumn{11}{|c|}{ Change from Corpus Christi site indicator to: } \\
\hline Fort Wayne site & 12.6473 & $(0.3162)$ & 1.0828 & $(0.0346)$ & 8.56 & $(0.22)$ & 11.5644 & $(0.2958)$ & 91.44 & $(0.23)$ \\
\hline Jersey City site & 6.3780 & $(0.1534)$ & .3288 & $(0.0105)$ & 5.16 & $(0.15)$ & 6.0492 & $(0.1490)$ & 94.84 & $(0.16)$ \\
\hline Providence site & 6.4292 & $(0.1691)$ & -1.5965 & $(0.0509)$ & -24.83 & $(0.95)$ & 8.0257 & $(0.1824)$ & 124.83 & $(0.95)$ \\
\hline \multicolumn{11}{|c|}{ Change from Never Married to: } \\
\hline Currently married & -4.9098 & $(0.1401)$ & .4562 & $(0.0145)$ & -9.29 & $(0.31)$ & -5.3660 & $(0.1467)$ & 109.29 & $(0.31)$ \\
\hline Married 1-24 months & 4.3002 & $(0.1261)$ & 4.2079 & $(0.1252)$ & 97.85 & $(0.04)$ & .0923 & $(0.0025)$ & 2.15 & $(0.07)$ \\
\hline Married $>24$ months & 5.3340 & $(0.1391)$ & 3.6192 & $(0.1166)$ & 67.85 & $(0.73)$ & 1.7147 & $(0.0441)$ & 32.15 & $(0.73)$ \\
\hline
\end{tabular}

Source: Authors' calculations using National JTPA Study data.

Notes: Bootstrap standard errors appear in parentheses. These standard errors reflect variation in the samples used to do the simulations. 
Table 8b

JTPA Simulation Results - Two Step Decomposition

Weighted Effects of Changes in Characteristics on the Probability of Acceptance into JTPA

National JTPA Study Eligible Non-Participant Sample: Adult Females (2438 observations)

\begin{tabular}{|c|c|c|c|c|c|c|c|c|c|c|}
\hline & $\begin{array}{c}\text { Overall } \\
\text { Effect }\end{array}$ & & $\begin{array}{c}\text { Weighted } \\
\text { Awareness } \\
\text { Term } \\
\end{array}$ & & $\begin{array}{l}\text { Percent } \\
\text { of } \\
\text { Overall }\end{array}$ & & $\begin{array}{c}\text { Weighted } \\
\text { Acceptance } \\
\text { Term } \\
\end{array}$ & & $\begin{array}{c}\text { Percent } \\
\text { of } \\
\text { Overall }\end{array}$ & \\
\hline \multicolumn{11}{|c|}{ Change from White to: } \\
\hline Black & 0.3406 & $(0.0082)$ & .5807 & $(0.0110)$ & 170.49 & $(1.57)$ & -0.2401 & $(0.0044)$ & -70.49 & $(1.57)$ \\
\hline Hispanic & 2.5843 & $(0.0514)$ & -1.5509 & $(0.0312)$ & -60.01 & $(1.29)$ & 4.1352 & $(0.0709)$ & 160.01 & $(1.29)$ \\
\hline Other race-ethnicity & -0.5642 & $(0.0140)$ & -0.9772 & $(0.0192)$ & 173.22 & $(1.55)$ & 0.4130 & $(0.0074)$ & -73.22 & $(1.55)$ \\
\hline \multicolumn{11}{|c|}{ Change from Age 22-29 to: } \\
\hline Age 30-39 & -1.5293 & $(0.0272)$ & -0.2304 & $(0.0044)$ & 15.07 & $(0.18)$ & -1.2989 & $(0.0238)$ & 84.93 & $(0.17)$ \\
\hline Age $40-49$ & -1.0421 & $(0.0184)$ & -0.3973 & $(0.0075)$ & 38.12 & $(0.30)$ & -0.6449 & $(0.0120)$ & 61.88 & $(0.30)$ \\
\hline Age $50-54$ & -0.9142 & $(0.0163)$ & -0.3667 & $(0.0071)$ & 40.12 & $(0.30)$ & -0.5474 & $(0.0102)$ & 59.88 & $(0.30)$ \\
\hline \multicolumn{11}{|c|}{ Change from Highest Grade 12 to: } \\
\hline Highest grade $<10$ & -2.6424 & $(0.0495)$ & -2.0099 & $(0.0393)$ & 76.06 & $(0.21)$ & -0.6325 & $(0.0119)$ & 23.94 & $(0.21)$ \\
\hline Highest grade $10-11$ & -0.8521 & $(0.0151)$ & -0.2605 & $(0.0050)$ & 30.57 & $(0.27)$ & -0.5916 & $(0.0109)$ & 69.43 & $(0.27)$ \\
\hline Highest grade $13-15$ & 1.4035 & $(0.0265)$ & -0.5493 & $(0.0103)$ & -39.14 & $(0.72)$ & 1.9527 & $(0.0332)$ & 139.14 & $(0.72)$ \\
\hline Highest grade $>15$ & -3.5102 & $(0.0668)$ & -1.4343 & $(0.0283)$ & 40.86 & $(0.26)$ & -2.0760 & $(0.0410)$ & 59.14 & $(0.26)$ \\
\hline \multicolumn{11}{|c|}{ Change from not receiving AFDC to: } \\
\hline Current AFDC receipt & -3.9558 & $(0.0809)$ & -0.0051 & $(0.0001)$ & .13 & $(0.00)$ & -3.9507 & $(0.0808)$ & 99.87 & $(0.00)$ \\
\hline \multicolumn{11}{|c|}{ Change from not receiving food stamps to: } \\
\hline $\begin{array}{l}\text { Current Food Stamp } \\
\text { receipt }\end{array}$ & 2.4674 & $(0.0416)$ & 1.3765 & $(0.0242)$ & 55.79 & $(0.30)$ & 1.0908 & $(0.0201)$ & 44.21 & $(0.30)$ \\
\hline \multicolumn{11}{|c|}{ Change Two Most Recent Labor Force Statuses from Employed -> Employed to: } \\
\hline $\begin{array}{l}\text { Unemployed -> } \\
\text { Employed }\end{array}$ & 10.1978 & $(0.1374)$ & .2336 & $(0.0044)$ & 2.29 & $(0.04)$ & 9.9642 & $(0.1353)$ & 97.71 & $(0.00)$ \\
\hline OLF -> Employed & 6.0237 & $(0.0963)$ & -0.6424 & $(0.0123)$ & -10.66 & $(0.17)$ & 6.6660 & $(0.1040)$ & 110.66 & $(0.18)$ \\
\hline Employed -> & 20.0536 & $(0.2370)$ & 1.9825 & $(0.0363)$ & 9.89 & $(0.15)$ & 18.0711 & $(0.2195)$ & 90.11 & $(0.15)$ \\
\hline Unemployed & & & & & & & & & & \\
\hline $\begin{array}{l}\text { Unemployed -> } \\
\text { Unemployed }\end{array}$ & 19.1886 & $(0.2369)$ & 1.1889 & $(0.0234)$ & 6.20 & $(0.12)$ & 17.9997 & $(0.2287)$ & 93.80 & $(0.11)$ \\
\hline OLF -> Unemployed & 13.1690 & $(0.1825)$ & .8147 & $(0.0151)$ & 6.19 & $(0.09)$ & 12.3543 & $(0.1737)$ & 93.81 & $(0.09)$ \\
\hline Employed -> OLF & 7.3442 & $(0.1160)$ & .2988 & $(0.0056)$ & 4.07 & $(0.06)$ & 7.0454 & $(0.1125)$ & 95.93 & $(0.04)$ \\
\hline Unemployed -> OLF & 13.9890 & $(0.1926)$ & -0.6109 & $(0.0118)$ & -4.37 & $(0.08)$ & 14.5999 & $(0.1989)$ & 104.37 & $(0.05)$ \\
\hline OLF $->$ OLF & 4.2671 & $(0.0845)$ & -0.9764 & $(0.0188)$ & -22.88 & $(0.45)$ & 5.2435 & $(0.0952)$ & 122.88 & $(0.46)$ \\
\hline \multicolumn{11}{|c|}{ Change from No Child $<6$ Years of Age to: } \\
\hline Child age $<6$ years & -0.8987 & $(0.0173)$ & -0.1516 & $(0.0029)$ & 16.87 & $(0.21)$ & -0.7471 & $(0.0151)$ & 83.13 & $(0.20)$ \\
\hline \multicolumn{11}{|c|}{ Change from Family Income $<\$ 3000$ to: } \\
\hline Family income $3 \mathrm{~K}-9 \mathrm{~K}$ & 2.1865 & $(0.0390)$ & 1.1198 & $(0.0208)$ & 51.22 & $(0.38)$ & 1.0667 & $(0.0215)$ & 48.78 & $(0.38)$ \\
\hline Family income $9 \mathrm{~K}-15 \mathrm{~K}$ & 1.0367 & $(0.0183)$ & .6227 & $(0.0117)$ & 60.07 & $(0.38)$ & 0.4140 & $(0.0083)$ & 39.93 & $(0.37)$ \\
\hline Family income $>15 \mathrm{~K}$ & 0.5172 & $(0.0107)$ & -0.0683 & $(0.0013)$ & -13.20 & $(0.22)$ & 0.5855 & $(0.0116)$ & 113.20 & $(0.23)$ \\
\hline \multicolumn{11}{|c|}{ Change from Corpus Christi site indicator to: } \\
\hline Fort Wayne site & 7.6811 & $(0.1556)$ & -0.6637 & $(0.0124)$ & -8.64 & $(0.19)$ & 8.3448 & $(0.1608)$ & 108.64 & $(0.18)$ \\
\hline Jersey City site & 5.4065 & $(0.0990)$ & -0.7513 & $(0.0147)$ & -13.90 & $(0.24)$ & 6.1578 & $(0.1084)$ & 113.90 & $(0.23)$ \\
\hline Providence site & 7.3382 & $(0.1506)$ & -2.0068 & $(0.0412)$ & -27.35 & $(0.62)$ & 9.3450 & $(0.1711)$ & 127.35 & $(0.62)$ \\
\hline \multicolumn{11}{|c|}{ Change from Never Married to: } \\
\hline Currently married & -3.7900 & $(0.0758)$ & -0.3984 & $(0.0077)$ & 10.51 & $(0.13)$ & -3.3915 & $(0.0697)$ & 89.49 & $(0.12)$ \\
\hline Married 1-24 months & 3.1004 & $(0.0569)$ & -0.0496 & $(0.0009)$ & -1.60 & $(0.02)$ & 3.1499 & $(0.0576)$ & 101.60 & $(0.00)$ \\
\hline Married $>24$ months & 6.3540 & $(0.1107)$ & .5205 & $(0.0100)$ & 8.19 & $(0.11)$ & 5.8335 & $(0.1038)$ & 91.81 & $(0.12)$ \\
\hline
\end{tabular}

Source: Authors' calculations using National JTPA Study data.

Notes: Bootstrap standard errors appear in parentheses. These standard errors reflect variation in the samples used to do the simulations. 
Table 8c

JTPA Simulation Results - Two Step Decomposition

Weighted Effects of Changes in Characteristics on the Probability of Acceptance into JTPA National JTPA Study Eligible Non-Participant Sample: Male Youth (530 observations)

\begin{tabular}{|c|c|c|c|c|c|c|c|c|c|c|}
\hline & $\begin{array}{l}\text { Overall } \\
\text { Effect }\end{array}$ & & $\begin{array}{c}\text { Weighted } \\
\text { Awareness } \\
\text { Term } \\
\end{array}$ & & $\begin{array}{c}\text { Percent } \\
\text { of } \\
\text { Overall }\end{array}$ & & $\begin{array}{c}\text { Weighted } \\
\text { Acceptance } \\
\text { Term }\end{array}$ & & $\begin{array}{c}\text { Percent } \\
\text { of } \\
\text { Overall }\end{array}$ & \\
\hline \multicolumn{11}{|c|}{ Change from White to: } \\
\hline Black & 4.8041 & $(0.2699)$ & 6.6041 & $(0.2893)$ & 137.47 & $(2.52)$ & -1.7999 & $(0.0720)$ & -37.47 & $(2.52)$ \\
\hline Hispanic & 5.9390 & $(0.2145)$ & .2688 & $(0.0123)$ & 4.53 & $(0.22)$ & 5.6701 & $(0.2112)$ & 95.47 & $(0.22)$ \\
\hline Other race-ethnicity & -3.1888 & $(0.3835)$ & 6.6837 & $(0.3157)$ & -209.60 & $(28.11)$ & -9.8724 & $(0.4783)$ & 309.60 & $(28.11)$ \\
\hline \multicolumn{11}{|c|}{ Change from Age 16-18 to: } \\
\hline Age 19-21 & -1.1238 & $(0.2264)$ & -5.3078 & $(0.2366)$ & 472.32 & $(109.67)$ & 4.1840 & $(0.1576)$ & -372.32 & $(109.67)$ \\
\hline \multicolumn{11}{|c|}{ Change from Never Married to: } \\
\hline Currently married & 2.1384 & $(0.3343)$ & 7.4097 & $(0.3489)$ & 346.50 & $(54.91)$ & -5.2712 & $(0.2273)$ & -246.50 & $(54.91)$ \\
\hline Div-wid-sep & -3.4641 & $(0.1330)$ & -2.0780 & $(0.0950)$ & 59.99 & $(1.04)$ & -1.3862 & $(0.0561)$ & 40.01 & $(1.04)$ \\
\hline \multicolumn{11}{|c|}{ Change from Highest Grade 12 to: } \\
\hline Highest grade $<10$ & -0.3731 & $(0.0267)$ & -0.6401 & $(0.0292)$ & 171.56 & $(6.06)$ & 0.2670 & $(0.0103)$ & -71.56 & $(6.06)$ \\
\hline Highest grade $10-11$ & 1.9636 & $(0.0810)$ & 1.6799 & $(0.0760)$ & 85.55 & $(0.59)$ & 0.2837 & $(0.0110)$ & 14.45 & $(0.59)$ \\
\hline Highest grade $>12$ & -1.8382 & $(0.0667)$ & -0.6697 & $(0.0305)$ & 36.43 & $(1.04)$ & -1.1685 & $(0.0468)$ & 63.57 & $(1.04)$ \\
\hline \multicolumn{11}{|c|}{ Change from not receiving AFDC to: } \\
\hline Current AFDC receipt & -11.1117 & $(0.4965)$ & -4.2387 & $(0.1942)$ & 38.15 & $(0.74)$ & -6.8730 & $(0.3298)$ & 61.85 & $(0.74)$ \\
\hline \multicolumn{11}{|c|}{ Change from not receiving Food Stamps to: } \\
\hline $\begin{array}{l}\text { Current Food Stamp } \\
\text { receipt }\end{array}$ & 3.7423 & $(0.1253)$ & 1.8386 & $(0.0835)$ & 49.13 & $(1.20)$ & 1.9037 & $(0.0692)$ & 50.87 & $(1.20)$ \\
\hline \multicolumn{11}{|c|}{ Change Two Most Recent Labor Force Statuses from Employed -> Employed to: } \\
\hline $\begin{array}{l}\text { Unemployed -> } \\
\text { Employed }\end{array}$ & 14.4300 & $(0.3934)$ & 1.1809 & $(0.0536)$ & 8.18 & $(0.40)$ & 13.2491 & $(0.3886)$ & 91.82 & $(0.40)$ \\
\hline OLF -> Employed & -4.5935 & $(0.2030)$ & .5569 & $(0.0255)$ & -12.12 & $(0.57)$ & -5.1505 & $(0.2159)$ & 112.12 & $(0.57)$ \\
\hline Employed -> & 16.6120 & $(0.4569)$ & 3.5322 & $(0.1670)$ & 21.26 & $(0.93)$ & 13.0798 & $(0.4174)$ & 78.74 & $(0.93)$ \\
\hline Unemployed & & & & & & & & & & \\
\hline Unemployed -> & 10.3782 & $(0.2823)$ & 3.2308 & $(0.1478)$ & 31.13 & $(1.11)$ & 7.1474 & $(0.2211)$ & 68.87 & (1.11) \\
\hline Unemployed & & & & & & & & & & \\
\hline OLF -> Unemployed & 0.3517 & $(0.0666)$ & -1.2450 & $(0.0573)$ & -354.01 & $(72.52)$ & 1.5967 & $(0.0634)$ & 454.01 & $(72.52)$ \\
\hline Employed -> OLF & 26.9129 & (1.1099) & -8.8298 & $(0.4202)$ & -32.81 & $(2.70)$ & 35.7427 & $(0.8344)$ & 132.81 & $(2.70)$ \\
\hline Unemployed -> OLF & 5.5548 & $(0.3447)$ & 7.5616 & $(0.3597)$ & 136.13 & (2.89) & -2.0068 & $(0.0916)$ & -36.13 & (2.89) \\
\hline OLF $\rightarrow$ OLF & 6.9113 & $(0.5004)$ & -6.8417 & $(0.3147)$ & -98.99 & $(10.08)$ & 13.7529 & $(0.4157)$ & 198.99 & (10.08) \\
\hline \multicolumn{11}{|c|}{ Change from No Child $<6$ Years of Age to: } \\
\hline Child age $<6$ years & -9.2754 & $(0.4498)$ & -1.9897 & $(0.0911)$ & 21.45 & $(0.67)$ & -7.2856 & $(0.3823)$ & 78.55 & $(0.67)$ \\
\hline \multicolumn{11}{|c|}{ Change from Family Income $<\$ 3000$ to: } \\
\hline Family income $3 \mathrm{~K}-9 \mathrm{~K}$ & 9.3512 & $(0.4811)$ & -4.6211 & $(0.2073)$ & -49.42 & $(3.64)$ & 13.9722 & $(0.4734)$ & 149.42 & $(3.64)$ \\
\hline Family income $9 \mathrm{~K}-15 \mathrm{~K}$ & -2.6233 & $(0.1288)$ & -3.1610 & $(0.1402)$ & 120.50 & $(1.17)$ & 0.5377 & $(0.0256)$ & -20.50 & $(1.17)$ \\
\hline Family income $>15 \mathrm{~K}$ & -4.7303 & $(0.1979)$ & -3.8578 & $(0.1714)$ & 81.56 & $(0.69)$ & -0.8725 & $(0.0425)$ & 18.44 & $(0.69)$ \\
\hline \multicolumn{11}{|c|}{ Change from Corpus Christi site indicator to: } \\
\hline Fort Wayne site & 10.3470 & $(0.3620)$ & .3657 & $(0.0169)$ & 3.53 & $(0.17)$ & 9.9813 & $(0.3578)$ & 96.47 & $(0.17)$ \\
\hline Jersey City site & 3.0515 & $(0.1968)$ & -1.4890 & $(0.0675)$ & -48.80 & $(3.80)$ & 4.5406 & $(0.2061)$ & 148.80 & $(3.80)$ \\
\hline Providence site & 18.4090 & $(0.6361)$ & -2.3738 & $(0.1081)$ & -12.89 & $(0.76)$ & 20.7827 & $(0.6359)$ & 112.89 & $(0.75)$ \\
\hline
\end{tabular}

Source: Authors' calculations using National JTPA Study data.

Notes: Bootstrap standard errors appear in parentheses. These standard errors reflect variation in the samples used to do the simulations. 


\section{Table 8d}

JTPA Simulation Results - Two Step Decomposition

Weighted Effects of Changes in Characteristics on the Probability of Acceptance into JTPA

National JTPA Study Eligible Non-Participant Sample: Female Youth (701 observations)

\begin{tabular}{|c|c|c|c|c|c|c|c|c|c|c|}
\hline & $\begin{array}{c}\text { Overall } \\
\text { Effect }\end{array}$ & & $\begin{array}{c}\text { Weighted } \\
\text { Awareness } \\
\text { Term }\end{array}$ & & $\begin{array}{c}\text { Percent } \\
\text { of } \\
\text { Overall }\end{array}$ & & $\begin{array}{c}\text { Weighted } \\
\text { Acceptance } \\
\text { Term }\end{array}$ & & $\begin{array}{c}\text { Percent } \\
\text { of } \\
\text { Overall }\end{array}$ & \\
\hline \multicolumn{11}{|c|}{ Change from White to: } \\
\hline Black & 3.9275 & $(0.1724)$ & 3.0290 & $(0.1451)$ & 77.12 & $(0.49)$ & 0.8985 & $(0.0322)$ & 22.88 & $(0.49)$ \\
\hline Hispanic & 1.0273 & $(0.0415)$ & .5037 & $(0.0249)$ & 49.03 & $(0.75)$ & 0.5236 & $(0.0189)$ & 50.97 & $(0.75)$ \\
\hline Other race-ethnicity & 2.8539 & $(0.1085)$ & -2.4043 & $(0.1197)$ & -84.25 & $(5.34)$ & 5.2582 & $(0.1592)$ & 184.25 & $(5.34)$ \\
\hline \multicolumn{11}{|c|}{ Change from Age 16-18 to: } \\
\hline Age 19-21 & -2.3024 & $(0.0867)$ & -0.5579 & $(0.0272)$ & 24.23 & $(0.54)$ & -1.7445 & $(0.0634)$ & 75.77 & $(0.54)$ \\
\hline \multicolumn{11}{|c|}{ Change from Never Married to: } \\
\hline Currently married & -1.5024 & $(0.0587)$ & .6539 & $(0.0321)$ & -43.52 & $(1.63)$ & -2.1563 & $(0.0833)$ & 143.52 & $(1.63)$ \\
\hline Div-wid-sep & -1.1802 & $(0.0922)$ & -2.5635 & $(0.1267)$ & 217.21 & $(7.55)$ & 1.3833 & $(0.0481)$ & -117.21 & $(7.55)$ \\
\hline \multicolumn{11}{|c|}{ Change from Highest Grade 12 to: } \\
\hline Highest grade $<10$ & -2.0172 & $(0.0973)$ & -2.0554 & $(0.0984)$ & 101.89 & $(0.00)$ & 0.0381 & $(0.0014)$ & -1.89 & $(0.05)$ \\
\hline Highest grade $10-11$ & -1.7373 & $(0.0661)$ & -0.4037 & $(0.0200)$ & 23.24 & $(0.50)$ & -1.3336 & $(0.0487)$ & 76.76 & $(0.51)$ \\
\hline Highest grade $>12$ & 1.0272 & $(0.0355)$ & -0.0518 & $(0.0025)$ & -5.04 & $(0.16)$ & 1.0790 & $(0.0375)$ & 105.04 & $(0.15)$ \\
\hline \multicolumn{11}{|c|}{ Change from not receiving AFDC to: } \\
\hline Current AFDC receipt & -2.3463 & $(0.0926)$ & 1.2829 & $(0.0633)$ & -54.68 & $(2.33)$ & -3.6292 & $(0.1378)$ & 154.68 & $(2.33)$ \\
\hline \multicolumn{11}{|c|}{ Change from not receiving food stamps to: } \\
\hline $\begin{array}{l}\text { Current Food Stamp } \\
\text { receipt }\end{array}$ & 6.5595 & $(0.2010)$ & .1105 & $(0.0054)$ & 1.68 & $(0.06)$ & 6.4490 & $(0.1971)$ & 98.32 & $(0.07)$ \\
\hline \multicolumn{11}{|c|}{ Change Two Most Recent Labor Force Statuses from Employed -> Employed to: } \\
\hline $\begin{array}{l}\text { Unemployed -> } \\
\text { Employed }\end{array}$ & 9.5744 & $(0.2550)$ & -0.4118 & $(0.0203)$ & -4.30 & $(0.18)$ & 9.9862 & $(0.2662)$ & 104.30 & $(0.18)$ \\
\hline OLF -> Employed & 11.3506 & $(0.2832)$ & -1.8182 & $(0.0898)$ & -16.02 & $(0.81)$ & 13.1688 & $(0.3136)$ & 116.02 & $(0.81)$ \\
\hline Employed -> & 24.0502 & $(0.4336)$ & -1.4540 & $(0.0712)$ & -6.05 & $(0.31)$ & 25.5041 & $(0.4422)$ & 106.05 & $(0.32)$ \\
\hline Unemployed & & & & & & & & & & \\
\hline $\begin{array}{l}\text { Unemployed -> } \\
\text { Unemployed }\end{array}$ & 17.0906 & $(0.4181)$ & 1.2007 & $(0.0580)$ & 7.03 & $(0.29)$ & 15.8899 & $(0.3908)$ & 92.97 & $(0.29)$ \\
\hline OLF -> Unemployed & 21.6456 & $(0.4132)$ & .3991 & $(0.0197)$ & 1.84 & $(0.09)$ & 21.2465 & $(0.4105)$ & 98.16 & $(0.08)$ \\
\hline Employed -> OLF & 8.6803 & $(0.2773)$ & 1.4078 & $(0.0686)$ & 16.22 & $(0.52)$ & 7.2725 & $(0.2306)$ & 83.78 & $(0.53)$ \\
\hline Unemployed -> OLF & 7.1564 & $(0.2625)$ & 3.3152 & $(0.1614)$ & 46.32 & $(0.97)$ & 3.8412 & $(0.1313)$ & 53.68 & $(0.97)$ \\
\hline OLF $->$ OLF & 4.6998 & $(0.1774)$ & -1.0262 & $(0.0503)$ & -21.84 & $(0.98)$ & 5.7260 & $(0.2065)$ & 121.84 & $(0.99)$ \\
\hline \multicolumn{11}{|c|}{ Change from No Child $<6$ Years of Age to: } \\
\hline Child age $<6$ years & -1.3768 & $(0.0594)$ & -0.8447 & $(0.0417)$ & 61.36 & $(0.74)$ & -0.5320 & $(0.0210)$ & 38.64 & $(0.74)$ \\
\hline \multicolumn{11}{|c|}{ Change from Family Income $<\$ 3000$ to: } \\
\hline Family Income $3 \mathrm{~K}-9 \mathrm{~K}$ & -0.8170 & $(0.0328)$ & .1014 & $(0.0050)$ & -12.41 & $(0.43)$ & -0.9184 & $(0.0366)$ & 112.41 & $(0.43)$ \\
\hline Family Income 9K-15K & -0.7310 & $(0.0416)$ & -0.9901 & $(0.0490)$ & 135.45 & $(1.50)$ & 0.2591 & $(0.0101)$ & -35.45 & $(1.50)$ \\
\hline Family Income $>15 \mathrm{~K}$ & 8.3821 & $(0.2512)$ & -1.1948 & $(0.0593)$ & -14.25 & $(0.59)$ & 9.5768 & $(0.2877)$ & 114.25 & $(0.59)$ \\
\hline \multicolumn{11}{|c|}{ Change from Corpus Christi site indicator to: } \\
\hline Fort Wayne site & 3.5282 & $(0.1269)$ & .3522 & $(0.0173)$ & 9.98 & $(0.30)$ & 3.1761 & $(0.1138)$ & 90.02 & $(0.30)$ \\
\hline Jersey City site & 0.3881 & $(0.0532)$ & -1.5274 & $(0.0769)$ & -393.62 & $(69.52)$ & 1.9155 & $(0.0728)$ & 493.62 & $(69.53)$ \\
\hline Providence site & 3.5378 & $(0.1675)$ & -2.1585 & $(0.1040)$ & -61.01 & $(3.86)$ & 5.6963 & $(0.2075)$ & 161.01 & $(3.86)$ \\
\hline
\end{tabular}

Source: Authors' calculations using National JTPA Study data.

Notes: Bootstrap standard errors appear in parentheses. These standard errors reflect variation in the samples used to do the simulations. 
Figure 1

The JTPA Selection Process

Eligibility for JTPA

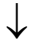

Awareness of JTPA

$\downarrow$

Application to JTPA

$\downarrow$

Acceptance into JTPA

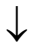

Enrollment into JTPA 


\section{Appendix A: Data from the National JTPA Study}

\section{A. Eligible Non-Participant (ENP) Sample}

The ENP sample is based on a sample of dwelling units drawn from the areas served by the Corpus Christ, Texas, Fort Wayne, Indiana, Jersey City, New Jersey and Providence, Rhode Island JTPA training centers. The sampling frame excluded low poverty areas containing up to, but not more than, five percent of those in each site with incomes at or below 125 percent of the poverty level in 1980. In the remaining areas around each center, each dwelling unit had an equal probability of selection for the initial screener interviews. These interviews gathered information sufficient to determine the eligibility status of each person in the surveyed household. The initial screening interviews were conducted from January 1988 to December 1989, and had an overall response rate at the four sites of 90 percent. See Smith (1994) for a detailed description of the ENP sampling frame.

Attempts were made to administer the Full Baseline Survey (FBS) to all of the JTPA-eligible persons identified on the screeners at each site who were (1) eligible for JTPA via economic disadvantage; (2) 16 to 54 years of age; (3) not in junior high or high school; and (4) not permanently disabled. Persons over age 54 were known in advance to have a low participation rate in JTPA and so were excluded in order to focus the available resources on groups more likely to participate in the program. Youth in junior high or high school were excluded in order to match a similar exclusion in the experimental evaluation. The FBS interviews were completed between June 1988 and December 1989, with a quarter of the completed interviews occurring five or more months after the initial 
screening. The overall response rate of potential ENPs to the FBS was 78 percent, yielding a sample of 3004 ENPs at the four sites. ${ }^{1}$

Following their inclusion in the ENP sample, roughly three percent (104) of the ENPs were later randomly assigned as part of the experimental component of the National JTPA Study. As a result, a small number of respondents appear in both the experimental and ENP samples analyzed in this paper. Because of their small number, we do not omit these persons from either group.

All ENPs with valid values for the relevant variables were used to construct the rates shown in Table 3, to estimate the awareness logits presented in Table 4, to estimate the acceptance logits reported in Table 5 and in Appendix D, to estimate the awareness and acceptance logits underlying the decompositions in Tables 7 and 8, and to construct the decompositions presented in Table 8.

\section{B. Experimental Control Group Sample}

The control group sample consists of persons randomly assigned to the experimental control group at four of the sixteen JTPA training centers taking part in the experimental evaluation component of the National JTPA Study. Control group members were not allowed to receive any JTPA services in the 18 months after random assignment. At the Corpus Christi and Fort Wayne centers, random assignment began in December 1987 and concluded in January 1989, while in Jersey City and Providence it ran from November

\footnotetext{
${ }^{1}$ The ENP sample was originally intended to match the control sample in size at each of the four centers. The final sample sizes have Corpus Christi with 1060 ENPs and 489 controls, Ft. Wayne with 529 ENPs and 1191 controls, Jersey City with 892 ENPs and 530 controls, and Providence with 523 ENPs and 507 controls.
} 
1987 to September 1989. During these periods, a total of 2717 persons were assigned to the control group at the four centers.

All controls with valid values for the relevant variables were used to estimate the awareness logits presented in Table 4, to estimate the acceptance logits presented in Table 5 and in Appendix D, and to estimate the awareness and acceptance logits underlying the decompositions presented in Tables 7 and 8.

\section{Experimental Treatment Group Sample}

The treatment group sample consists of persons randomly assigned to the experimental treatment group at the same four sites in the National JTPA Study at which the control and ENP samples were drawn. Treatment group members were allowed to (but often did not) receive JTPA services in the 18 months after random assignment. A total of 5914 persons were randomly assigned to the experimental treatment group at the four sites. Enrollment information is based on data collected from site administrative records by MDRC. All treatment group members with valid values for the relevant variables were used to estimate the enrollment logits presented in Table 6 and underlying the decompositions presented in Table 7.

\section{Imputations}

Missing values due to item non-response were imputed for the ENPs and controls for variables used in the awareness and acceptance logits. Missing values of dichotomous variables, such as the presence of an own child less than six years of age in the household, were replaced with the predicted probabilities estimated in a logit equation. 
Missing values of indicator variables corresponding to particular values of categorical variables with more than two categories, such as the five indicators for the categories of the highest grade completed variable, were replaced by the predicted probabilities obtained from a multinomial logit model with the categorical variable as the dependent variable.

In all cases, the estimating equations used to produce the imputations included the following: (1) indicators for race/ethnicity, (2) indicators for age categories, (3) indicators for receipt of a high school diploma or a GED, (4) site indicators and (5) interactions between control status and all of these variables. These variables were chosen because they had no (or very few) missing values in the sample. Imputed values were constructed separately for each of the four demographic target groups. A similar imputation procedure was followed for the experimental treatment group for values of variables used in estimating the enrollment equations missing due to item non-response. A sensitivity analysis comparing the results generated using the imputed values to results obtained through listwise deletion of observations with missing values and through the inclusion of missing value indicators shows the reported results to be robust to the method used to handle item non-response. 


\section{Appendix B: SIPP Sample of JTPA Eligibles}

The national sample that we use to estimate the determinants of JTPA eligibility is drawn from the 1986 Panel of the Survey of Income and Program Participation (SIPP). The SIPP is a continuing longitudinal self-weighting survey of the non-institutional population of the United States with a focus on current income and participation in social programs. A new panel is introduced every year with each panel followed for about 2.5 years. Respondents are divided into four rotation groups with a different group interviewed in each calendar month. In the 1986 SIPP Panel used here, three of the rotation groups are interviewed seven times, and one is interviewed six times. At least one rotation group is represented from October 1985 to March 1988. The calendar dates in which all four of the rotation groups are represented are January 1986 to December 1987. This period is immediately prior to the period during which the ENP and experimental control and treatment group samples from the National JTPA Study were determined eligible for JTPA. The reference period for each SIPP interview is the four calendar months preceding the interview month. Devine and Heckman (1996) show that attrition from the SIPP panel has little effect on substantive results regarding JTPA eligibility.

Establishing the JTPA eligibility status of respondents in the SIPP requires operational definitions of families and of family income. A person's family members include all other SIPP respondents who were living with the person and related by blood, marriage, or adoption. A person's family could be comprised of different people in each month. A person is eligible via participation in a cash welfare program in a given month if anyone in the person's current family receives AFDC payments, general assistance, or 
other cash welfare in that month. A person is eligible via participation in the food stamp program in a given month if anyone in the person's current family receives food stamps in that month. A person is eligible by virtue of low family income if the sum of family income in the previous six months is less than the higher of the poverty income guideline or the BLS lower living standard income level applicable to the month of eligibility determination and to the respondent's geographic location and family size. Family income in the previous six months is defined as the sum of the income in each month of all of the people who were in the person's family in that month. ${ }^{2}$

Family income need not be the same for two people who are currently in the same family because they may have been in different families during the six months prior to eligibility determination. The definition of eligibility used here corresponds to Definition B in Devine and Heckman (1996) and captures only eligibility via economic disadvantage.

Note that in the SIPP data we are not able to accurately measure foster child status, disability or homelessness on a monthly basis, and so we are unable to implement the special eligibility rules applicable to these groups in selecting our sample of eligibles. However, these groups represent only a very small fraction of the eligible population, and many of those eligible under the special provisions will also be identified as eligible using the basic family income and program participation criteria that apply to all individuals.

We established the eligibility status of each sample member in each month after the seventh month of the panel for which data were available. Eligibility cannot be

\footnotetext{
${ }^{2}$ See Devine and Heckman (1996) for a list of the types of income that do and do not count in determining JTPA eligibility.
} 
established with certainty for all sample members during the first six months of the panel because the requisite six months of prior data on family income are not available. To match the ENP sample, we exclude persons outside the 16 to 54 age range along with persons enrolled in junior high or high school. All persons with valid values for the relevant variables were used to estimate the eligibility logits presented in Table 2 and those underlying the decompositions presented in Table 7. The same sample was used to construct the decompositions displayed in Table 7. 


\section{Appendix C: Construction of the Reported Results}

\section{A. Logit Estimates}

The logit estimates of the determinants of eligibility presented in Table 2 are obtained using the SIPP sample. As we use the SIPP in person-month form, dependence may exist between person-month observations corresponding to the same person. We estimate logit equations allowing for semi-parametric heterogeneity to take account of this potential dependence.

The logit estimates of awareness of JTPA presented in Table 4, the logit estimates of acceptance presented in Table 5 and in Appendix D, and the logit estimates of awareness and of application and acceptance into JTPA conditional on awareness underlying the decompositions in Table 7 and Table 8 are based on weighted logit equations, with estimated standard errors adjusted to take account of choice based sampling as in Amemiya (1985). The choice-based sampling in this case results from the over-representation of the controls relative to their proportion of the eligible population. Weights are derived from the assumption that controls represent three percent of the eligible population, from the sample proportions of ENPs who indicate awareness of the program, and from the assumption that all controls are aware of JTPA.

The logit estimates of the determinants of enrollment presented in Table 6 are obtained from ordinary unweighted logit equations. For all of the logit estimates we present, the numerical derivatives are based on finite differences averaged over the sample, not on derivatives at the sample mean. 


\section{B. Decompositions}

The decompositions presented in Tables 7 and 8 are based on estimates of the conditional probabilities of JTPA eligibility, awareness, acceptance and enrollment obtained as described above. To construct the values shown in Table 7, each term in equation (3) was calculated for each person-month observation in the SIPP sample. The values reported in Table 7 are the sample average for each term or combination of terms. The values in Table 8 were constructed in the same manner, but using the ENP sample rather than the SIPP sample. In both tables, derivatives are approximated using finite differences. 


\section{Appendix D: Determinants of Application and Acceptance Conditional on Eligibility}

In this appendix, we present the results of a logit analysis of the determinants of

application and acceptance into JTPA conditional on eligibility. The estimates appear in

Tables D1a and D1b. These results complement the estimates of the determinants of application and acceptance conditional on awareness presented in Table 5 in the main text. 
Table D1a

Determinants of JTPA Participation

Weighted ENP and Control Samples: Adults

\begin{tabular}{|c|c|c|c|c|}
\hline \multirow{2}{*}{ Ft. Wayne } & \multicolumn{2}{|c|}{$\begin{array}{c}\text { Adult Males } \\
\text { Number of observations: } 1552\end{array}$} & \multicolumn{2}{|c|}{$\begin{array}{c}\text { Adult Females } \\
\text { Number of observations: } 2438\end{array}$} \\
\hline & 1.938 & {$[0.054]$} & 1.238 & {$[0.037]$} \\
\hline & $(0.313)$ & 0.000 & $(0.203)$ & 0.000 \\
\hline \multirow[t]{2}{*}{ Jersey City } & 1.063 & {$[0.021]$} & 0.725 & {$[0.017]$} \\
\hline & $(0.307)$ & 0.001 & $(0.182)$ & 0.000 \\
\hline \multirow[t]{2}{*}{ Providence } & 1.102 & {$[0.019]$} & 0.635 & {$[0.013]$} \\
\hline & $(0.344)$ & 0.001 & $(0.213)$ & 0.003 \\
\hline \multirow{2}{*}{ Black } & 0.107 & {$[0.003]$} & 0.177 & {$[0.005]$} \\
\hline & $(0.270)$ & 0.690 & $(0.173)$ & 0.307 \\
\hline \multirow{2}{*}{ Hispanic } & -0.364 & {$[-0.008]$} & 0.424 & {$[0.012]$} \\
\hline & $(0.304)$ & 0.232 & $(0.187)$ & 0.023 \\
\hline \multirow[t]{2}{*}{ Other race-ethnicity } & 0.340 & {$[0.010]$} & 0.009 & {$[0.000]$} \\
\hline & $(0.410)$ & 0.406 & $(0.449)$ & 0.985 \\
\hline \multirow{2}{*}{ Age 30-39 } & -0.417 & {$[-0.011]$} & -0.319 & {$[-0.009]$} \\
\hline & $(0.235)$ & 0.076 & $(0.136)$ & 0.019 \\
\hline \multirow[t]{2}{*}{ Age $40-49$} & -0.970 & {$[-0.022]$} & -0.316 & {$[-0.009]$} \\
\hline & $(0.307)$ & 0.002 & $(0.175)$ & 0.071 \\
\hline \multirow[t]{2}{*}{ Age $50-54$} & -0.380 & {$[-0.010]$} & -0.395 & {$[-0.011]$} \\
\hline & $(0.388)$ & 0.327 & $(0.271)$ & 0.145 \\
\hline \multirow[t]{2}{*}{ Highest grade $<10$} & -0.601 & {$[-0.013]$} & -0.556 & {$[-0.014]$} \\
\hline & $(0.268)$ & 0.025 & $(0.147)$ & 0.000 \\
\hline \multirow[t]{2}{*}{ Highest grade $10-11$} & 0.297 & {$[0.009]$} & -0.115 & {$[-0.003]$} \\
\hline & $(0.254)$ & 0.243 & $(0.162)$ & 0.479 \\
\hline \multirow{2}{*}{ Highest grade 13-15 } & 0.608 & {$[0.020]$} & 0.182 & {$[0.006]$} \\
\hline & $(0.304)$ & 0.045 & $(0.189)$ & 0.336 \\
\hline \multirow[t]{2}{*}{ Highest grade $>15$} & -1.479 & {$[-0.024]$} & -0.446 & {$[-0.012]$} \\
\hline & $(0.418)$ & 0.000 & $(0.417)$ & 0.285 \\
\hline \multirow{2}{*}{ Currently married } & -0.411 & {$[-0.010]$} & -0.883 & {$[-0.019]$} \\
\hline & $(0.258)$ & 0.112 & $(0.176)$ & 0.000 \\
\hline Div-Wid-Sep & 0.043 & {$[0.001]$} & 0.209 & {$[0.007]$} \\
\hline & $(0.288)$ & 0.881 & $(0.147)$ & 0.154 \\
\hline Child age $<6$ years & -0.182 & {$[-0.004]$} & -0.233 & {$[-0.006]$} \\
\hline & $(0.258)$ & 0.480 & $(0.133)$ & 0.078 \\
\hline Current AFDC receipt & -1.254 & {$[-0.020]$} & -0.736 & {$[-0.018]$} \\
\hline & $(0.527)$ & 0.017 & $(0.199)$ & 0.000 \\
\hline Current Food Stamp receipt & 0.482 & {$[0.013]$} & 0.392 & {$[0.011]$} \\
\hline & $(0.246)$ & 0.051 & $(0.167)$ & 0.019 \\
\hline Unemployed -> Employed & 1.952 & {$[0.039]$} & 1.582 & {$[0.036]$} \\
\hline & $(0.319)$ & 0.000 & $(0.264)$ & 0.000 \\
\hline OLF -> Employed & 2.102 & {$[0.046]$} & 0.954 & {$[0.015]$} \\
\hline & $(0.398)$ & 0.000 & $(0.309)$ & 0.002 \\
\hline Employed -> Unemployed & 3.320 & {$[0.134]$} & 2.749 & {$[0.117]$} \\
\hline & $(0.334)$ & 0.000 & $(0.245)$ & 0.000 \\
\hline Unemployed -> Unemployed & 2.884 & {$[0.094]$} & 2.667 & {$[0.109]$} \\
\hline & $(0.391)$ & 0.000 & $(0.249)$ & 0.000 \\
\hline OLF -> Unemployed & 3.802 & {$[0.189]$} & 2.220 & {$[0.071]$} \\
\hline & $(0.475)$ & 0.000 & $(0.267)$ & 0.000 \\
\hline Employed -> OLF & 2.819 & {$[0.089]$} & 1.252 & {$[0.024]$} \\
\hline & $(0.635)$ & 0.000 & $(0.259)$ & 0.000 \\
\hline Unemployed -> OLF & 3.637 & [0.169] & 1.924 & {$[0.052]$} \\
\hline & $(0.720)$ & 0.000 & $(0.334)$ & 0.000 \\
\hline OLF $->$ OLF & 1.279 & {$[0.018]$} & 0.773 & {$[0.011]$} \\
\hline & $(0.409)$ & 0.002 & $(0.213)$ & 0.000 \\
\hline Family Income 3K-9K & -0.320 & {$[-0.010]$} & 0.463 & {$[0.014]$} \\
\hline & $(0.383)$ & 0.403 & $(0.196)$ & 0.018 \\
\hline Family Income 9K-15K & 0.039 & {$[0.001]$} & 0.142 & {$[0.004]$} \\
\hline & $(0.394)$ & 0.921 & $(0.279)$ & 0.612 \\
\hline Family Income $>15 \mathrm{~K}$ & -1.521 & {$[-0.032]$} & 0.014 & {$[0.000]$} \\
\hline & $(0.483)$ & 0.002 & $(0.268)$ & 0.959 \\
\hline Constant & -4.828 & {$[0.000]$} & -4.963 & {$[0.000]$} \\
\hline & $(0.516)$ & 0.000 & $(0.298)$ & 0.000 \\
\hline
\end{tabular}

Source: Authors' calculations using National JTPA Study data.

Notes: Dependent variable is control status. The sample includes all ENPs and controls (not just those aware of JTPA) and is weighted to account for choice-based sampling. Omitted categories in the logit are Corpus Christi, white, age 22-29, highest grade equals 12, never married, no young children, not currently receiving AFDC, not currently receiving Food Stamps, "Employed -> Employed", and family income less than $\$ 3,000$. Using the population proportion of JTPA participants (controls), which we assume to be three percent, as the cutoff value, the within-sample prediction rates for adult males are 84.20 for non-participants (ENPs) and 82.89 for participants (controls). The corresponding rates for adult females are 75.72 for non-participants and 69.62 for participants. 
Table D1b

Determinants of JTPA Participation

Weighted ENP and Control Samples: Youth

\begin{tabular}{|c|c|c|c|c|}
\hline \multirow{3}{*}{ Ft. Wayne } & \multicolumn{2}{|c|}{$\begin{array}{c}\text { Male Youth } \\
\text { Number of observations: } 530\end{array}$} & \multicolumn{2}{|c|}{$\begin{array}{c}\text { Female Youth } \\
\text { Number of observations: } 701\end{array}$} \\
\hline & 0.951 & {$[0.029]$} & 1.047 & {$[0.034]$} \\
\hline & $(0.429)$ & 0.027 & $(0.392)$ & 0.008 \\
\hline \multirow[t]{2}{*}{ Jersey City } & 0.386 & {$[0.009]$} & 0.515 & {$[0.013]$} \\
\hline & $(0.485)$ & 0.426 & $(0.375)$ & 0.169 \\
\hline \multirow[t]{2}{*}{ Providence } & 1.474 & {$[0.045]$} & 1.032 & {$[0.028]$} \\
\hline & $(0.494)$ & 0.003 & $(0.407)$ & 0.011 \\
\hline \multirow[t]{2}{*}{ Black } & 0.410 & {$[0.014]$} & 0.742 & {$[0.021]$} \\
\hline & $(0.384)$ & 0.285 & $(0.303)$ & 0.014 \\
\hline \multirow[t]{2}{*}{ Hispanic } & -0.494 & {$[-0.011]$} & 0.457 & {$[0.011]$} \\
\hline & $(0.492)$ & 0.315 & $(0.351)$ & 0.193 \\
\hline \multirow[t]{2}{*}{ Other race-ethnicity } & -1.846 & {$[-0.028]$} & -1.058 & {$[-0.014]$} \\
\hline & $(0.899)$ & 0.040 & $(0.650)$ & 0.103 \\
\hline \multirow[t]{2}{*}{ Age 19-21 } & 0.153 & {$[0.004]$} & -0.535 & {$[-0.016]$} \\
\hline & $(0.347)$ & 0.660 & $(0.265)$ & 0.044 \\
\hline \multirow[t]{2}{*}{ Highest grade $<10$} & 0.589 & {$[0.015]$} & -0.394 & {$[-0.011]$} \\
\hline & $(0.441)$ & 0.182 & $(0.324)$ & 0.224 \\
\hline \multirow[t]{2}{*}{ Highest grade $10-11$} & 0.673 & {$[0.018]$} & -0.235 & {$[-0.007]$} \\
\hline & $(0.385)$ & 0.081 & $(0.351)$ & 0.504 \\
\hline \multirow[t]{2}{*}{ Highest grade $>12$} & -0.164 & {$[-0.003]$} & 0.084 & {$[0.003]$} \\
\hline & $(0.598)$ & 0.784 & $(0.365)$ & 0.818 \\
\hline \multirow[t]{2}{*}{ Currently married } & 0.298 & [0.009] & -0.563 & {$[-0.013]$} \\
\hline & $(0.461)$ & 0.518 & $(0.346)$ & 0.104 \\
\hline \multirow[t]{2}{*}{ Div-Wid-Sep } & -0.439 & {$[-0.010]$} & 0.241 & {$[0.008]$} \\
\hline & $(0.817)$ & 0.591 & $(0.403)$ & 0.550 \\
\hline \multirow[t]{2}{*}{ Child age $<6$ years } & -1.059 & {$[-0.021]$} & -0.241 & {$[-0.007]$} \\
\hline & $(0.498)$ & 0.033 & $(0.260)$ & 0.354 \\
\hline \multirow[t]{2}{*}{ Current AFDC receipt } & -0.721 & {$[-0.015]$} & -0.988 & {$[-0.025]$} \\
\hline & $(0.730)$ & 0.323 & $(0.363)$ & 0.006 \\
\hline \multirow[t]{2}{*}{ Current Food Stamp receipt } & -0.046 & {$[-0.001]$} & 1.363 & {$[0.052]$} \\
\hline & $(0.441)$ & 0.917 & $(0.337)$ & 0.000 \\
\hline \multirow[t]{2}{*}{ Unemployed -> Employed } & 2.125 & [0.089] & 1.599 & {$[0.030]$} \\
\hline & $(0.482)$ & 0.000 & $(0.466)$ & 0.001 \\
\hline \multirow{2}{*}{ OLF -> Employed } & -0.166 & {$[-0.002]$} & 1.394 & {$[0.023]$} \\
\hline & $(0.511)$ & 0.745 & $(0.449)$ & 0.002 \\
\hline Employed -> Unemployed & 1.593 & {$[0.051]$} & 3.218 & {$[0.149]$} \\
\hline & $(0.442)$ & 0.000 & $(0.472)$ & 0.000 \\
\hline Unemployed -> Unemployed & 1.162 & {$[0.030]$} & 2.379 & {$[0.070]$} \\
\hline & $(0.579)$ & 0.045 & $(0.473)$ & 0.000 \\
\hline OLF -> Unemployed & 1.000 & {$[0.024]$} & 3.018 & {$[0.126]$} \\
\hline & $(0.597)$ & 0.094 & $(0.509)$ & 0.000 \\
\hline Employed -> OLF & 2.016 & {$[0.080]$} & 1.554 & {$[0.028]$} \\
\hline & $(0.633)$ & 0.001 & $(0.421)$ & 0.000 \\
\hline Unemployed -> OLF & 0.993 & {$[0.023]$} & 1.106 & {$[0.016]$} \\
\hline & $(0.774)$ & 0.199 & $(0.725)$ & 0.127 \\
\hline OLF $->$ OLF & 0.191 & {$[0.003]$} & 0.709 & {$[0.008]$} \\
\hline & $(0.567)$ & 0.737 & $(0.414)$ & 0.087 \\
\hline Family Income 3K-9K & 1.450 & {$[0.058]$} & -0.466 & {$[-0.010]$} \\
\hline & $(0.574)$ & 0.012 & $(0.452)$ & 0.302 \\
\hline Family Income 9K-15K & 0.110 & {$[0.002]$} & 0.031 & {$[0.001]$} \\
\hline & $(0.602)$ & 0.855 & $(0.528)$ & 0.953 \\
\hline Family Income $>15 \mathrm{~K}$ & 0.048 & {$[0.001]$} & 1.423 & {$[0.068]$} \\
\hline & $(0.642)$ & 0.940 & $(0.441)$ & 0.001 \\
\hline Constant & -5.681 & {$[0.000]$} & -5.297 & {$[0.000]$} \\
\hline & $(0.725)$ & 0.000 & $(0.610)$ & 0.000 \\
\hline
\end{tabular}

Source: Authors' calculations using National JTPA Study data.

Notes: Dependent variable is control status. The sample includes all ENPs and controls (not just those aware of JTPA) and is weighted to account for choice-based sampling. Omitted categories in the logit are Corpus Christi, white, age 16-18, highest grade equals 12, never married, no young children, not currently receiving AFDC, not currently receiving Food Stamps, "Employed -> Employed", and family income less than $\$ 3,000$. Using the population proportion of JTPA participants (controls), which we assume to be three percent, as the cutoff value, the within-sample prediction rates for male youth are 69.27 for non-participants (ENPs) and 66.10 for participants (controls). The corresponding rates for adult females are 73.58 for non-participants and 67.16 for participants. 